ANDERSON TAKEHIRO OSHIRO

TÉCNICAS DE CONTROLE PARA POSICIONAMENTO DE MÚLTIPLOS NAVIOS EM OPERAÇÕES DE LANÇAMENTO DE ESTRUTURAS SUBMARINAS 


\title{
TÉCNICAS DE CONTROLE PARA POSICIONAMENTO DE MÚLTIPLOS NAVIOS EM OPERAÇÕES DE LANÇAMENTO DE ESTRUTURAS SUBMARINAS
}

\author{
Dissertação apresentada à Escola \\ Politécnica da Universidade de São Paulo \\ para a obtenção do Título de Mestre em \\ Engenharia. \\ Área de Concentração: \\ Engenharia de Controle e Automação \\ Mecânica
}

Orientador:

Prof. Dr. Eduardo Aoun Tannuri 
Este exemplar foi revisado e alterado em relação à versão original, sob responsabilidade única do autor e com a anuência de seu orientador.

São Paulo, 31 de agosto de 2012.

Assinatura do autor

Assinatura do orientador

\section{FICHA CATALOGRÁFICA}

\section{Oshiro, Anderson Takehiro}

Técnicas de controle para posicionamento de múltiplos navios em operações de lançamento de estruturas submarinas / A.T. Oshiro. - ed.rev. - São Paulo, 2012. $104 \mathrm{p}$.

Dissertação (Mestrado) - Escola Politécnica da Universidade de São Paulo. Departamento de Engenharia Mecatrônica e de Sistemas Mecânicos.

1. Sistemas de posicionamento dinâmico 2. Controle cooperativo I. Universidade de São Paulo. Escola Politécnica. Departamento de Engenharia Mecatrônica e de Sistemas Mecânicos II. t. 
À minha mãe, Rosa,

à minha esposa, Érica,

\author{
e à minha filha, Sara.
}




\section{AGRADECIMENTOS}

Ao meu orientador, Prof. Dr. Eduardo Aoun Tannuri com quem trabalho desde 2007 me proporcionando a oportunidade de participar em diversos projetos de pesquisa. Pela paciência de me acompanhar, parágrafo por parágrafo, no desenvolvimento desta dissertação que não teria sido concluída se não fosse por esse empenho.

À Subsin pela motivação inicial do estudo de caso. Em especial, aos seus diretores Dr. Melquisedec Francisco dos Santos e Msc. Cassiano R. Neves pelo apoio técnico.

À FINEP pelo financiamento do projeto para realizar os ensaios e parte das análises numéricas.

Aos colegas do TPN que participaram nos ensaios experimentais e nas análises numéricas deste trabalho: Dr. Carlos Hakio Fucatu, Dr. Pedro Cardoso de Mello e Msc. Felipe Rateiro.

Aos professores do Departamento de Engenharia Naval e Oceânica da EPUSP: Prof. Dr. Hélio Mitio Morishita, Prof. Dr. Kazuo Nishimoto e Prof. Dr. Alexandre Nicolaos Simos

Aos meus amigos da Poli que me acompanham nestes anos todos na graduação, na pós-graduação e nos trabalhos em projetos de pesquisa: Carlos Eduardo Silva de Souza, Douglas Gustavo Takashi Yuba, Lázaro Moratelli Jr.e Pedro Gomes da Costa, Michel Rejani Miyasaki e Asdrubal N. Queiroz Filho.

Ao TPN pela infraestrutura de trabalho e aos meus colegas de sala pela convivência diária: Daniel Prata Vieira, Victor Tonacio, Rodrigo Mota Amarante, Guilherme Feitosa Rosetti, Rodrigo Lavieri, Rafael Watai, Felipe Ruggeri e Marcelo Nogueira.

Ao CNPQ pela bolsa de mestrado concedida. 


\section{RESUMO}

Este trabalho apresenta o desenvolvimento de uma técnica de controle cooperativo aplicado para embarcações dotadas de sistema de posicionamento dinâmico (sistema DP). Um caso ilustrativo é estudado: o lançamento de um equipamento submarino utilizando duas embarcações DP. Neste exemplo, o sistema cooperativo controla a distância relativa das duas embarcações DP. As vantagens deste método se da no aumento da janela operacional, na tensão no cabo de lançamento que pode ser reduzida pela metade, entre outras.

Um mapeamento dinâmico foi obtido utilizando um simulador 2D simplificado previamente validado por comparação com testes experimentais e o simulador no domínio do tempo TPN - Tanque de Provas Numérico. Nestes mapas, duas regiões foram definidas, de ocorrência e não ocorrência de afrouxamento nos cabos em função da distancia entre as embarcações, profundidade do equipamento submarino e período da onda. Este mapa definiu as posições desejadas das embarcações para cada profundidade do equipamento.

Foi proposto um controle da posição relativa das embarcações tentando manter os movimentos do ponto de conexão em oposição de fase. Isto evita a ocorrência de afrouxamentos no cabo de lançamento. Para isso, um algoritmo baseado em estimação de fase (Transformada de Hilbert) associado a um controlador PD foi implementado. Os resultados mostraram que o controle para ondas regulares é efetivo. Adicionalmente, o controle de pagamento de linha recebe as medidas do movimento vertical do ponto de conexão, e compensa esse movimento, mantendo constante seu comprimento. $O$ controle foi implementado considerando erros de $10 \%$ e atrasos de até $1,5 \mathrm{~s}$ nas medidas. Os resultados confirmaram que o controle pode eliminar os picos de tensão e a ocorrência de afrouxamento no cabo de lançamento.

A conclusão deste trabalho sugere que a estratégia apropriada do controle, considerando ondas regulares, é combinar o controle de posição e o controle de pagamento de linha. $O$ controle de posição, acoplado ao mapeamento dinâmico, define um "caminho ótimo" a ser seguido durante o içamento do equipamento, tentando manter as embarcações próximas da região de não ocorrência de afrouxamentos.

Palavras-chave: Instalação de estruturas submarinas. Sistema de posicionamento dinâmico. Controle cooperativo. 


\begin{abstract}
This work presents the development of cooperative control technique applied to vessels equipped with dynamic positioning (DP) system. An illustrative case study is suggested: the launching of subsea equipment using two DP vessels. In this example, the cooperative system controls the relative distance between the DP vessels. One of the advantages of this method is the increase of operation's safety and operational window, since, among other factors, the tension in the launching cable is reduced by half. Initially, it was proposed the control of vessels relative positions, trying to keep the connection point movements in counter-phase. This avoids the slackening of the launching cable. For this, an algorithm based on phase estimator (Hilbert transform) associated with a PD control was implemented. The results showed that for regular waves this strategy was effective.

A dynamic mapping was then obtained using simplified 2D simulator, previously validated by comparison with experimental tests. In these maps, two regions are defined - occurrence or non-occurrence of cable slackening - as a function of the distance of the vessels and the depth of the subsea equipment. This map defines the proper set-point for the DP systems for each depth of the subsea equipment. This map is used to define the best relative position for the vessels. In addition, the hoisting control receives the measurements of the vertical motion of the connection point, and compensates its motion, trying to maintain a constant lowering velocity. This control was implemented considering errors of $10 \%$ and delay of $0.5 \mathrm{~s}$ in the measurements. The results confirmed that the control is able to eliminate the tension peaks and the occurrence of slackening in the launching cable.

The conclusion is that the appropriate control strategy, considering regular waves, is to combine the control of both position of the vessels and hoisting of the cable. Therefore the position control, coupled with dynamic mapping, defines the "optimal path" to be followed during the line hoisting, trying to keep the vessels as close as possible to the "no slackening" region.
\end{abstract}

Keywords: Installation of subsea structure. Dynamic positioning system. Cooperative control. 


\section{LISTA DE ILUSTRAÇÕES}

Figura 1: Campo de gás de Ormen Lange (Holden, 2006)

Figura 2: Etapas para serem analisadas na instalação de uma estrutura submarina Etapas 1, 2 e 3 (esq), 4, 5 e 6 (dir) (Solutions (2012)) .................. 21

Figura 3: Método $Y$ 22

Figura 4: Instalação utilizando AHTS com A-FRAME (Ribeiro, 2008), (acima) e BGL-1 (abaixo)

Figura 5: Instalação utilizando o Riser de Perfuração de plataformas semi

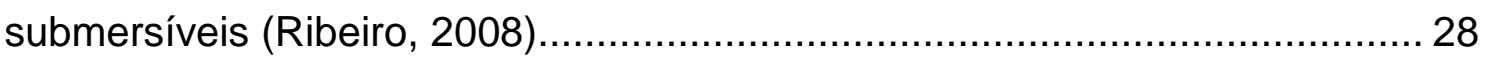

Figura 6: Instalação pelo método da Roldana (Ribeiro, 2008) ......................... 29

Figura 7: Utilização de sistemas compensadores de Heave (adaptado de

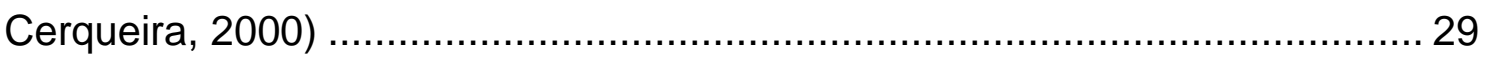

Figura 8: Método Instalação Pendular (Ribeiro, 2008) .................................. 30

Figura 9: Método $Y$ de Lançamento de manifold (Santos et. al., 2009) ............ 31

Figura 10: Instalação de propulsores auxiliares no manifold ............................. 32

Figura 11: Foto Normand Neptun (Mello, et al., 2011) ................................. 35

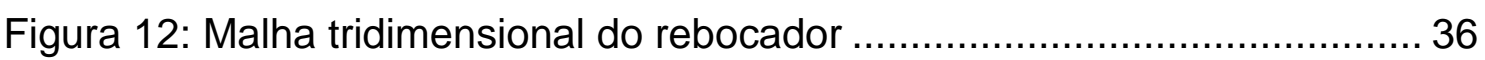

Figura 13: Definições dos movimentos de uma embarcação (SNAME, 1950) . 36

Figura 14: Referência de Incidência de Onda ............................................. 37

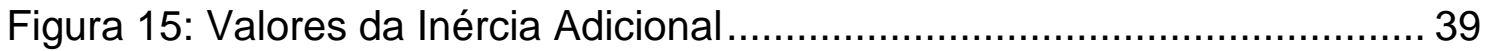

Figura 16: Valores de Amortecimento Potencial ........................................ 40

Figura 17: Comparação valores de amortecimento potencial e externo ........... 41

Figura 18: Forças de Excitação em Ondas ................................................... 42

Figura 19: Eixos de coordenadas considerados para o manifold ...................... 43

Figura 20: Hipótese Navios Alinhados - vista de topo ................................... 43

Figura 21: Definições dos parâmetros geométricos da dinâmica do manifold (esq.) Definições das forças atuantes na dinâmica do manifold (dir.) ........ 44

Figura 22: Modelo da Dinâmica Acoplada.................................................... 46

Figura 23: Incidência de $0^{\circ}$ (Popa) .......................................................... 49

Figura 24: Incidência de $90^{\circ}$ (Través) ….................................................. 50

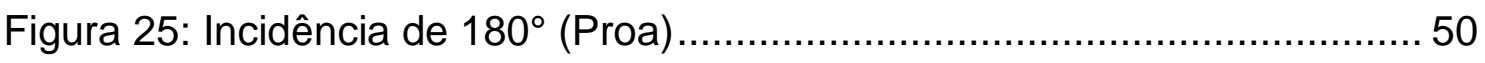

Figura 26: Configuração do ensaio: (esq.) Método Convencional; (dir.) Método Y 
Figura 27: Montagem experimental dos ensaios: (esq.) Lançamento convencional; (dir.) Método Y ..................................................................... 51

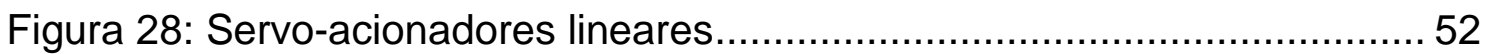

Figura 29: Microprocessador gerador de pulsos de controle ......................... 52

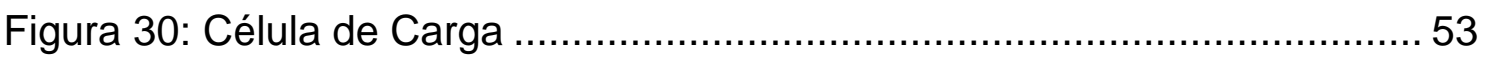

Figura 31: Erro percentual ponderado para cada um dos valores do amortecimento linear e quadrático ......................................................... 56

Figura 32: Estimação coeficiente de amortecimento linear ............................. 57

Figura 33: Lançamento Convencional - comparação Ensaios e Simulações ... 57

Figura 34: Simulações Método Convencional 100m (esquerda) 800m (direita)58

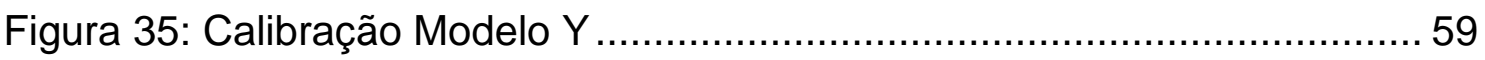

Figura 36: Simulações Método Y: Comparação das trações do ensaio e do

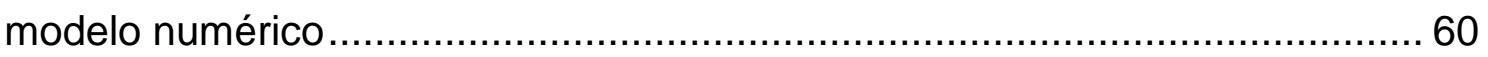

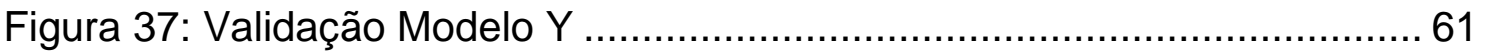

Figura 38: Séries Temporais Validação Modelo Y ......................................... 62

Figura 39: Fenômeno Afrouxamento no Cabo …………………………....... 63

Figura 40: Consideração das simulações do Método Y .................................. 63

Figura 41: Incidências de onda consideradas nas simulações........................... 64

Figura 42: Simulação distância de $120 \mathrm{~m}$ entre as os pontos de conexão:

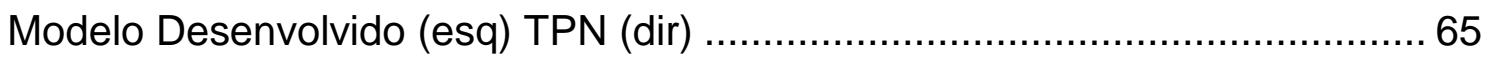

Figura 43: Simulação distância de 160m entre os pontos de conexão: Modelo

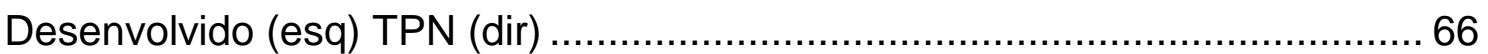

Figura 44: Mapeamento Dinâmico: Distância por período …………………... 68

Figura 45: Mapas Dinâmicos - Imposição de Movimentos Verticais................. 69

Figura 46: Mapas Dinâmicos - Dinâmica dos Navios ....................................... 69

Figura 47: Mapas Dinâmicos - Dinâmica dos Navios - Incidência 30 Proa..... 69

Figura 48: Aumento da Tração Estática com aumento da distância entre as

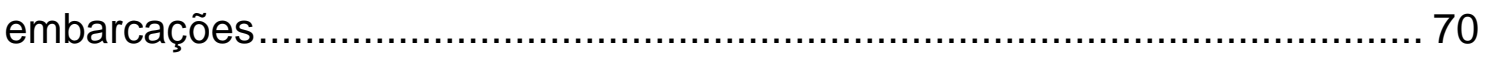

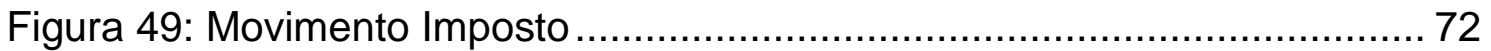

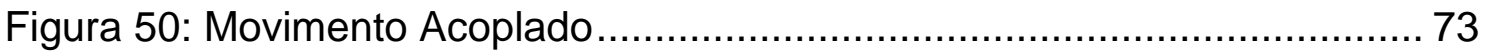

Figura 51 Mapeamento Dinâmico: Distância por profundidade......................... 71

Figura 52 Mapeamento Dinâmico: Distância por Profundidade - período de onda de $6 \mathrm{~s}$ 
Figura 53 Possível configuração para lançamento com período de onda de $6 \mathrm{~s}$

Figura 54 Mapeamento Dinâmico: Distância por Profundidade - período de

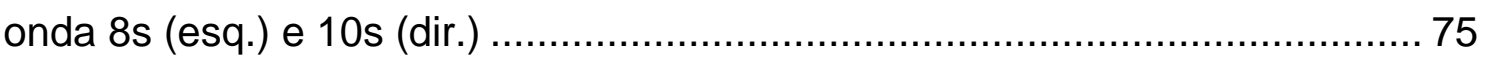

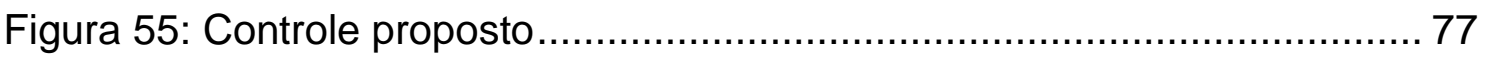

Figura 56: Representação em sinal analítico da transformada de Hilbert: Projeção (1), sinal real (2), sinal analítico (3) e o fasor no plano complexo (4), (Feldman, 2011) 78

Figura 57: Sinal Analítico no plano complexo (Feldman, 2011) ...................... 79

Figura 58: Estimação da diferença de fase utilizando a transformada de Hilbert 80

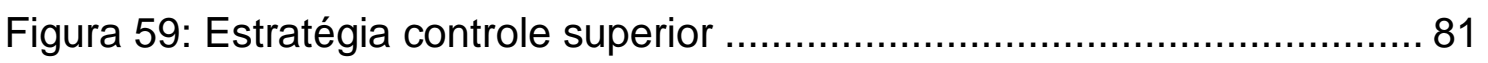

Figura 60: Diagrama de blocos do Controle Superior ................................... 81

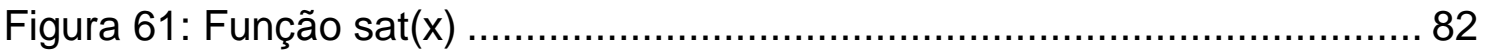

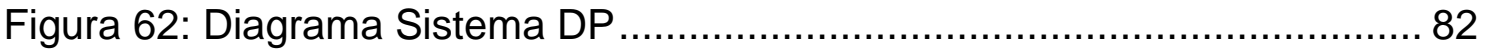

Figura 63: Filtro de Kalman: Período de onda 7s (acima, esq.), 8s (acima, dir.) e

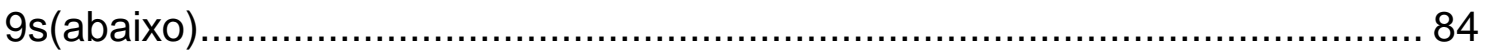

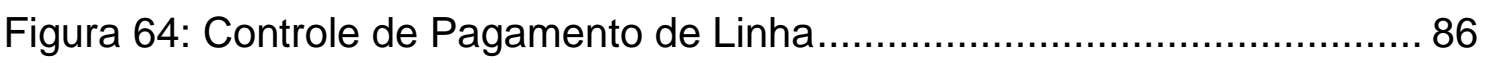

Figura 65: Mapa dinâmico: Simulações do Controle ........................................ 87

Figura 66: Simulação 1: Caso período de onda de 7s $-0^{\circ}$ Incidência .............. 88

Figura 67: Simulação 2: Caso período de onda de 7s - 15\% Incidência............. 89

Figura 68: Simulação 3: Caso período de onda de 7s - 30 Incidência.............. 89

Figura 69: Simulação 4: Caso período de onda de $8 s-0^{\circ}$ Incidência .............. 90

Figura 70: Simulação 5: Caso período de onda de 8s - $15^{\circ}$ Incidência.............. 91

Figura 71: Simulação 6: Caso período de onda de 8s - 30 Incidência............. 91

Figura 72: Simulação 7: Caso período de onda de $9 s-0^{\circ}$ Incidência.............. 92

Figura 73: Simulação 8: Caso período de onda de 9s - 15 Incidência ............ 92

Figura 74: Simulação 9: Caso período de onda de 9s - 30 Incidência ............ 93

Figura 75: Pagamento de linha - Onda $(\mathrm{T}=8 \mathrm{~s}, \mathrm{H}=2 \mathrm{~m})$ - Ponto de Conexão em

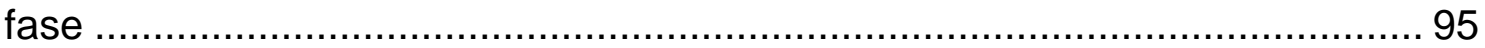

Figura 76: Pagamento de Linha - Onda $(T=8 s, H=2 m)$ - Ponto de Conexão em

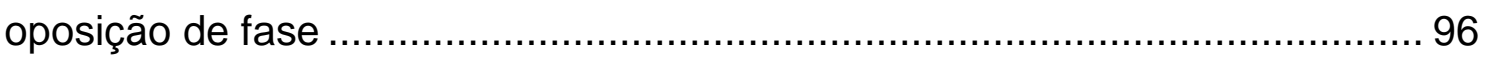

Figura 77: Incidência das ondas da simulação com swell................................ 97

Figura 78: Distância percorrida simulação com swell........................................ 97 
Figura 79: Movimentos do ponto de conexão para simulação com swell......... 98

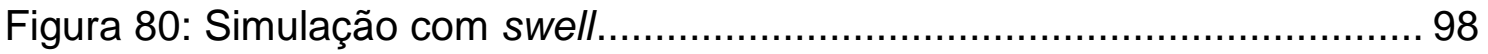




\section{LISTA DE TABELAS}

Tabela 1: Características do rebocador Normand Neptun ........................... 35

Tabela 2: Valores da Matriz de Inércia ................................................. 38

Tabela 3: Valores de amortecimento externo considerados ......................... 40

Tabela 4: Dimensões Principais do manifold........................................... 43

Tabela 5: Ensaios Convencionais - Escala Real .................................... 53

Tabela 6: Ensaios Convencionais - Escala Ensaio ..................................... 53

Tabela 7: Ensaios Método Y - Escala Real .......................................... 54

Tabela 8: Ensaios Método Y - Escala Ensaio.......................................... 54

Tabela 9: Ganhos do Sistema DP ..................................................... 85

Tabela 10: Simulações controle de posição ......................................... 87 


\section{LISTA DE ABREVIATURAS}

$\begin{array}{ll}\text { AHTS } & \text { Anchor Handling Tug Supply } \\ \text { BGL-1 } & \text { Balsa Guindaste de Lançamento 1 } \\ \text { CG } & \text { Centro de Gravidade } \\ \text { DISH } & \text { Deepwater Installation of Subsea Hardware } \\ \text { DP } & \text { Dynamic Positioning } \\ \text { FINEP } & \text { Financiadora de Estudos e Projetos } \\ \text { iVOF } & \text { Improved Volume of Fluid } \\ \text { JIP } & \text { Joint Industry Project } \\ \text { PD } & \text { Proporcional Derivativo } \\ \text { PID } & \text { Proporcional Integral Derivativo } \\ \text { RAO } & \text { Response Amplitude Operator } \\ \text { TPN } & \text { Tanque de Provas Numérico } \\ \text { USP } & \text { Universidade de São Paulo } \\ \text { WAMIT } & \text { Wave Analysis Massachussetts Institute Of Technology }\end{array}$




\section{LISTA DE SÍMBOLOS}

\section{Alfabeto Romano}

\begin{tabular}{|c|c|}
\hline$a$ & Ocorrência de afrouxamento no cabo 1 \\
\hline$b$ & Ocorrência de afrouxamento no cabo 2 \\
\hline$c_{33}$ & Restauração em heave \\
\hline$c_{35}$ & $\begin{array}{l}\text { Parcela de acoplamento do movimento de heave e pitch devido à } \\
\text { assimetria do casco }\end{array}$ \\
\hline$c_{44}$ & Restauração em roll \\
\hline$c_{46}$ & $\begin{array}{l}\text { Parcela de acoplamento do movimento de roll e yaw devido à } \\
\text { assimetria do casco }\end{array}$ \\
\hline$c_{55}$ & Restauração em pitch \\
\hline $\mathrm{C}_{\mathrm{x}}$ & Coeficiente de amortecimento linear horizontal do manifold \\
\hline$C_{1 z}$ & Coeficiente de amortecimento linear vertical do manifold \\
\hline$C_{2 z}$ & Coeficiente de amortecimento vertical quadrático do manifold \\
\hline$C_{D}$ & Coeficiente de arrasto quadrático do manifold \\
\hline$C_{M}$ & Comprimento do manifold \\
\hline$D_{E X T}{ }_{33}$ & Amortecimento externo em heave \\
\hline$D_{E X T_{44}}$ & Amortecimento externo em roll \\
\hline$D_{E X T_{55}}$ & Amortecimento externo em pitch \\
\hline$D_{E X T}$ & Matriz de amortecimento externo \\
\hline$E_{i}$ & Erro percentual ponderado do ensaio i. \\
\hline Erro $_{i}$ & Erro de posição do sistema DP \\
\hline$E$ & Empuxo do manifold \\
\hline$E_{G}$ & Erro percentual ponderado global \\
\hline$H_{\text {aframe }}$ & $\begin{array}{l}\text { Distância horizontal do centro de gravidade da embarcação e o } \\
\text { ponto de conexão }\end{array}$ \\
\hline $\mathrm{Ix}$ & Inércia em roll \\
\hline ly & Inércia em pitch \\
\hline Iz & Inércia em yaw \\
\hline$h_{1}$ & Metade da distância entre as duas embarcações \\
\hline$h_{2}$ & Metade da distância entre as duas embarcações \\
\hline$K_{D}$ & Ganho derivativo do controlador superior \\
\hline$K_{D i}$ & Ganho proporcional do sistema DP da embarcação \\
\hline$K_{I i}$ & Ganho proporcional do sistema DP da embarcação \\
\hline
\end{tabular}




\begin{tabular}{|c|c|}
\hline$K_{P}$ & Ganho proporcional do controlador superior \\
\hline$K_{P i}$ & Ganho proporcional do sistema DP da embarcação \\
\hline $\boldsymbol{K}$ & Matriz de restauração \\
\hline$\overline{L_{l}}$ & Comprimento de cabo controlador \\
\hline$L_{1}$ & Comprimento do cabo 1 \\
\hline$L_{2}$ & Comprimento do cabo 2 \\
\hline$L_{M}$ & Largura do manifold \\
\hline $\mathrm{m}$ & Massa da embarcação \\
\hline$M_{i}$ & Momento resultante devido à tração nos cabos \\
\hline$M_{m}$ & Massa do manifold \\
\hline$M_{x}$ & Massa adicional em horizontal do manifold \\
\hline$M_{z}$ & Massa adicional em bertical do manifold \\
\hline$M_{A}$ & Matriz de inércia adicional \\
\hline$M_{E}$ & Matriz de inércia \\
\hline$n$ & Número de amplitudes de onda consideradas no ensaio. \\
\hline$P$ & Peso do manifold \\
\hline$S P_{i}$ & Setpoint da embarcação \\
\hline$T_{1,2 h}$ & Projeção Horizontal da Tração no Cabo 1 ou 2 \\
\hline$T_{1,2 v}$ & Projeção Vertical da Tração no Cabo 1 ou 2 \\
\hline$v$ & Profundidade considerada \\
\hline Vaframe & $\begin{array}{l}\text { Distância vertical do centro de gravidade da embarcação e o } \\
\text { ponto de conexão }\end{array}$ \\
\hline$x$ & Posição horizontal absoluta do manifold \\
\hline $\bar{X} e n s_{i}^{j}$ & Valor médio da tração no cabo de içamento do ensaio. \\
\hline$X_{e n s}^{j}{ }_{i, \text { Max }}$ & $\begin{array}{l}\text { Valor máximo e mínimo das trações para cada amplitude de onda } \\
\text { j do ensaio i }\end{array}$ \\
\hline$X e n s_{i, \text { Min }}^{j}$ & $\begin{array}{l}\text { Valor máximo e mínimo das trações para cada amplitude de onda } \\
\text { j do ensaio i }\end{array}$ \\
\hline$X \operatorname{sim}_{i, \text { Max }}^{j}$ & $\begin{array}{l}\text { Valor máximo e mínimo das trações para cada amplitude de onda } \\
\text { j da simulação numérica do ensaio i. }\end{array}$ \\
\hline$X \operatorname{sim}_{i, \text { Min }}^{j}$ & $\begin{array}{l}\text { Valor máximo e mínimo das trações para cada amplitude de onda } \\
\text { j da simulação numérica do ensaio i. }\end{array}$ \\
\hline$y_{1}$ & Posição vertical do ponto de conexão. \\
\hline$y_{2}$ & Posição vertical do ponto de conexão. \\
\hline$z$ & Posição vertical absoluta do manifold \\
\hline
\end{tabular}




\section{Alfabeto Grego}

$\Delta S P_{1}^{2}$

$\widetilde{\Delta \psi}$

$\delta_{1} \quad$ Elongações dos cabos

$\delta_{2} \quad$ Elongações dos cabos

$\eta_{1} \quad$ Movimento em surge

$\eta_{2} \quad$ Movimento em sway

$\eta_{3} \quad$ Movimento em heave

$\eta_{4} \quad$ Rotação em roll

$\eta_{5} \quad$ Rotação em pitch

$\eta_{6} \quad$ Rotação em yaw

$\tau_{C}$

$\psi_{d}$

$\tau_{T}$

$\tau_{w}$

$\Delta \psi$

$\rho$

$\boldsymbol{\eta}$
Vetor de forças dos propulsores instalados na embarcação

Diferença de fase desejada $\left(180^{\circ}\right)$.

Forças e momentos resultantes devido à tração nos cabos

Vetor de força e momento devido a ondas

Diferença de fase do movimento vertical do ponto de içamento

Densidade da água

Vetor dos movimentos de translação e rotação da embarcação 


\section{SUMÁRIO}

\section{LISTA DE ILUSTRAÇÕES}

\section{LISTA DE TABELAS}

\section{LISTA DE ABREVIATURAS}

\section{LISTA DE SÍMBOLOS}

1 Introdução.......................................................................... 19

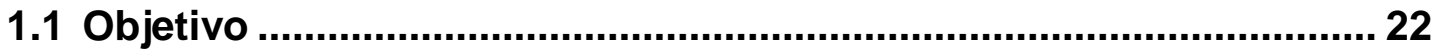

1.2 Justificativa

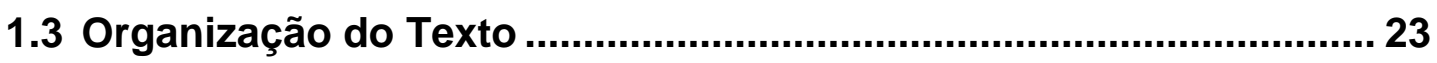

2 Revisão Bibliográfica ..................................................... 25

2.1 Análise e Operação de Lançamento Submarino ............................. 25

2.1.1 Métodos convencionais de instalação................................... 26

2.1.2 Propostas de métodos de instalação....................................... 30

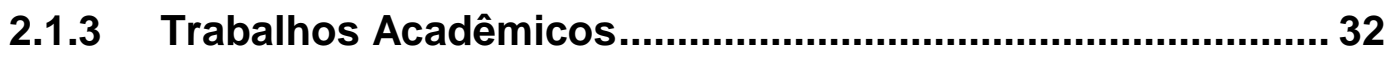

2.1.3.1 Método Y.......................................................................... 32

2.1.3.2 Instalação de propulsores nos equipamentos

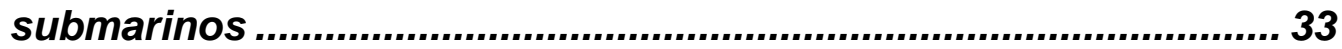

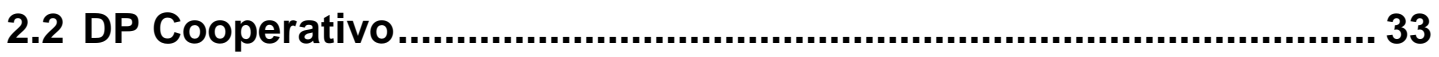

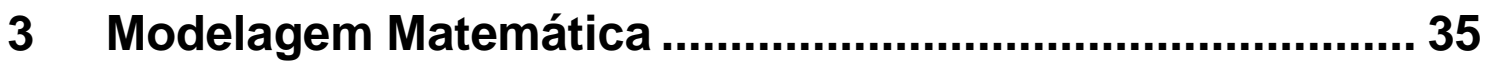

3.1 Modelo da Dinâmica da Embarcação................................................ 35

3.1.1 Definição dos referenciais utilizados ..................................... 36

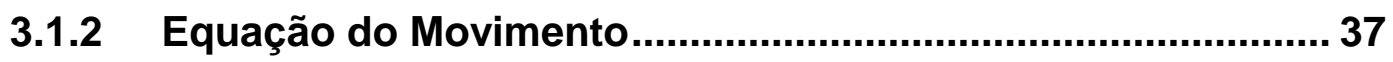

3.2 Modelo da dinâmica do manifold suspenso por cabos .................. 42

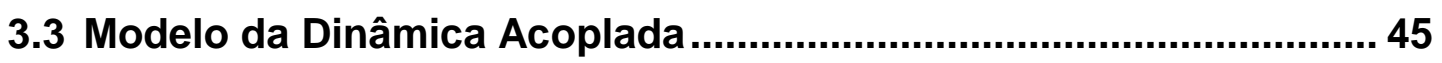

4 Validação do Modelo Matemático ...................................... 48

4.1 Validação da Dinâmica da Embarcação ............................................48

4.2 Validação do Modelo do manifold..................................................5 50

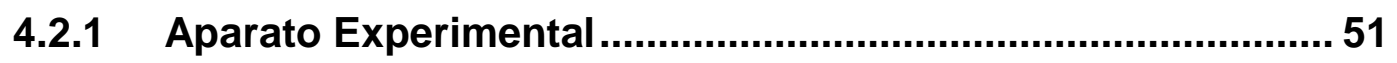

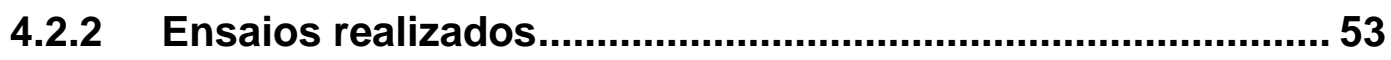


4.2.3 Estimação dos valores de amortecimento linear e quadrático 54

4.2.4 Resultado da Calibração ..................................................... 57

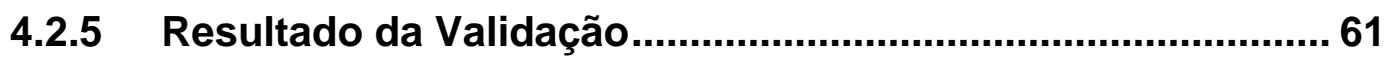

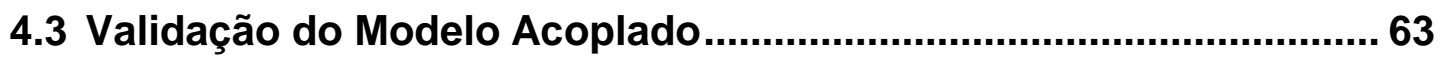

5 Análise Dinâmica............................................................... 67

5.1 Período da onda pela distância entre as embarcações .................... 67

5.2 Distância entre as embarcações pela profundidade do manifold ... 71

6 Controle ....................................................................... 76

6.1 Transformada de Hilbert ................................................................... 77

6.1.1 Definição da Transformada de Hilbert ................................... 77

6.1.2 Representação da Transformada de Hilbert na forma de sinal

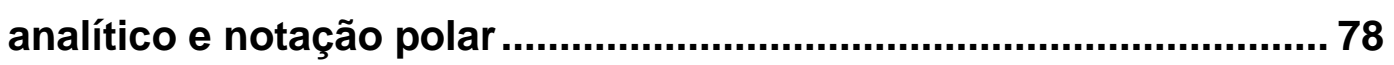

6.1.3 Diferença de fase relativa instantânea................................... 79

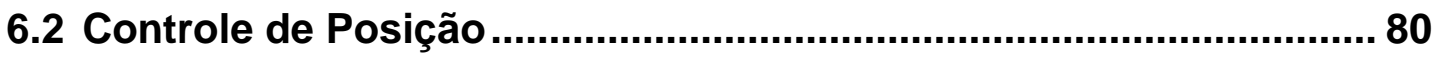

6.2.1 Controle superior - definição da posição desejada (set-point) 80

6.2.2 Controle da embarcação - Sistema DP .................................. 82

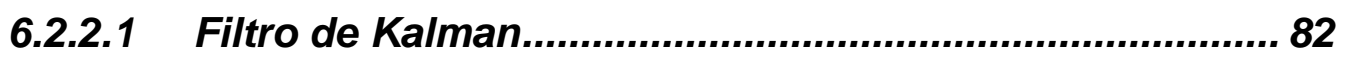

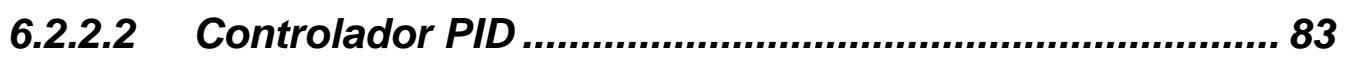

6.3 Controle de Pagamento da linha de içamento ................................ 85

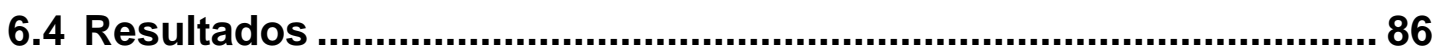

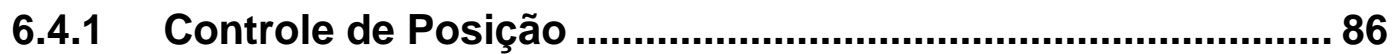

6.4.2 Controle de pagamento de linha .......................................... 93

6.4.3 Controle de Posição com swell ............................................ 97

7 Considerações Finais ...................................................... 99

8 REFERÊNCIAS............................................................. 101 


\section{Introdução}

A exploração de petróleo em águas profundas apresenta inúmeros desafios, dentre eles, a instalação de equipamentos submarinos. Em campos com grandes profundidades, tais como os recém-descobertos campos do Pré-Sal brasileiro, a contribuição das atividades de instalação de equipamentos submarinos ao custo do projeto é significativa. Devido às condições ambientais mais severas e à maior distância da costa, os riscos associados a essas operações também são maiores, o que torna as condições ambientais e operacionais fatores chave para a instalação de estruturas submarinas.

Além disso, com o avanço da exploração em águas profundas, a alternativa de se utilizarem estruturas de produção e processamento submersas tem se tornado mais atrativa e algumas vezes viável. O desenvolvimento de novos equipamentos de processamento submarino também motiva esta alternativa. Isso demanda operações complexas de lançamento e instalação. Um exemplo de um campo de exploração de gás offshore totalmente operado com equipamentos submarinos é o campo de Omern Langem na Noruega (Figura 1). Este campo, já em operação, não possui plataformas, e o fluxo de gás é controlado e bombeado diretamente por equipamentos instalados na cabeça dos poços.

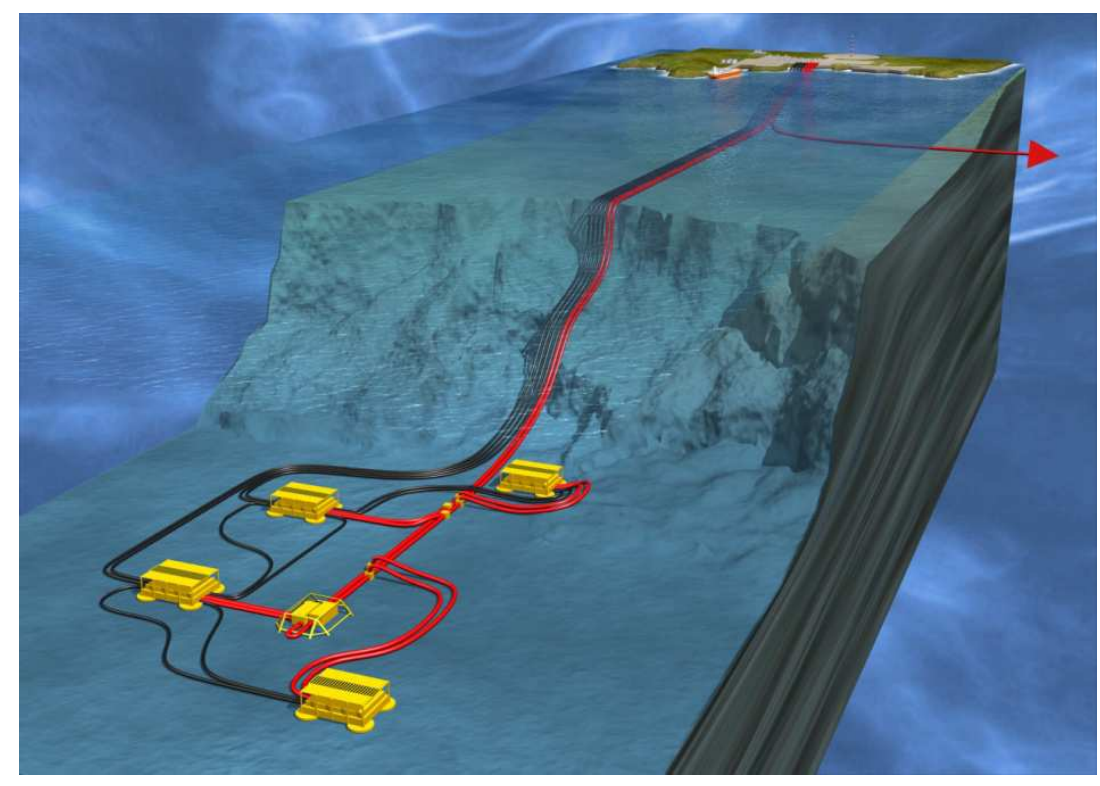

Figura 1: Campo de gás de Ormen Lange (Holden, 2006) 
Estes dois fatores motivam cada vez mais o estudo de novas tecnologias para a realização de operações de lançamento, com maior segurança operacional, menos restrições ambientais e que permitam o lançamento de estruturas e equipamentos cada vez maiores.

O procedimento de instalação das estruturas submarinas é definido pela norma da DNV - Marine Operations (2010).

1. Início do processo de içamento na embarcação e a manobra de retirada do objeto da embarcação à água.

2. Içamento do equipamento através da superfície ("zona de onda")

3. Processo de içamento com a descida até o leito submarino

4. Posicionamento e assentamento

Uma ilustração desse procedimento é apresentada na Figura 2.

Todas estas fases devem ser analisadas em operações de lançamento de equipamentos submarinos. Neste trabalho será analisada a terceira fase que corresponde ao içamento com a descida até o leito submarino. Esta análise inclui os máximos estados de mar permitidos, movimentos dos equipamentos e a tração esperada dos cabos durante a instalação. Geralmente são feitas análises para um intervalo de alturas de onda e de períodos de onda associado à dinâmica da embarcação de instalação.

Um dos equipamentos que necessitam ser instalados são os manifolds. Estes dispositivos são projetados para combinar, distribuir, controlar e monitorar o escoamento do fluido. Desta forma simplificam os sistemas submarinos, diminuindo o número de risers e otimizando o escoamento da produção do sistema. Os manifolds submarinos são instalados no leito submarino como um agregador de poços para coletar a produção ou para injetar água ou gás nos poços. Com o aumento da profundidade, estes equipamentos estão ficando cada vez maiores e mais pesados dificultando sua instalação.

Diversos métodos são utilizados para a instalação do manifold. Estes métodos serão detalhados na seção 2.1. Os métodos convencionais possuem limitações do tamanho da carga e da profundidade que serão instalados. Para realizar a instalação de um equipamento de grande porte em águas profundas são 
necessárias embarcações especiais dotadas de compensadores de movimento ou plataformas de perfuração. O problema no uso destas embarcações é sua pouca disponibilidade e seu alto custo.
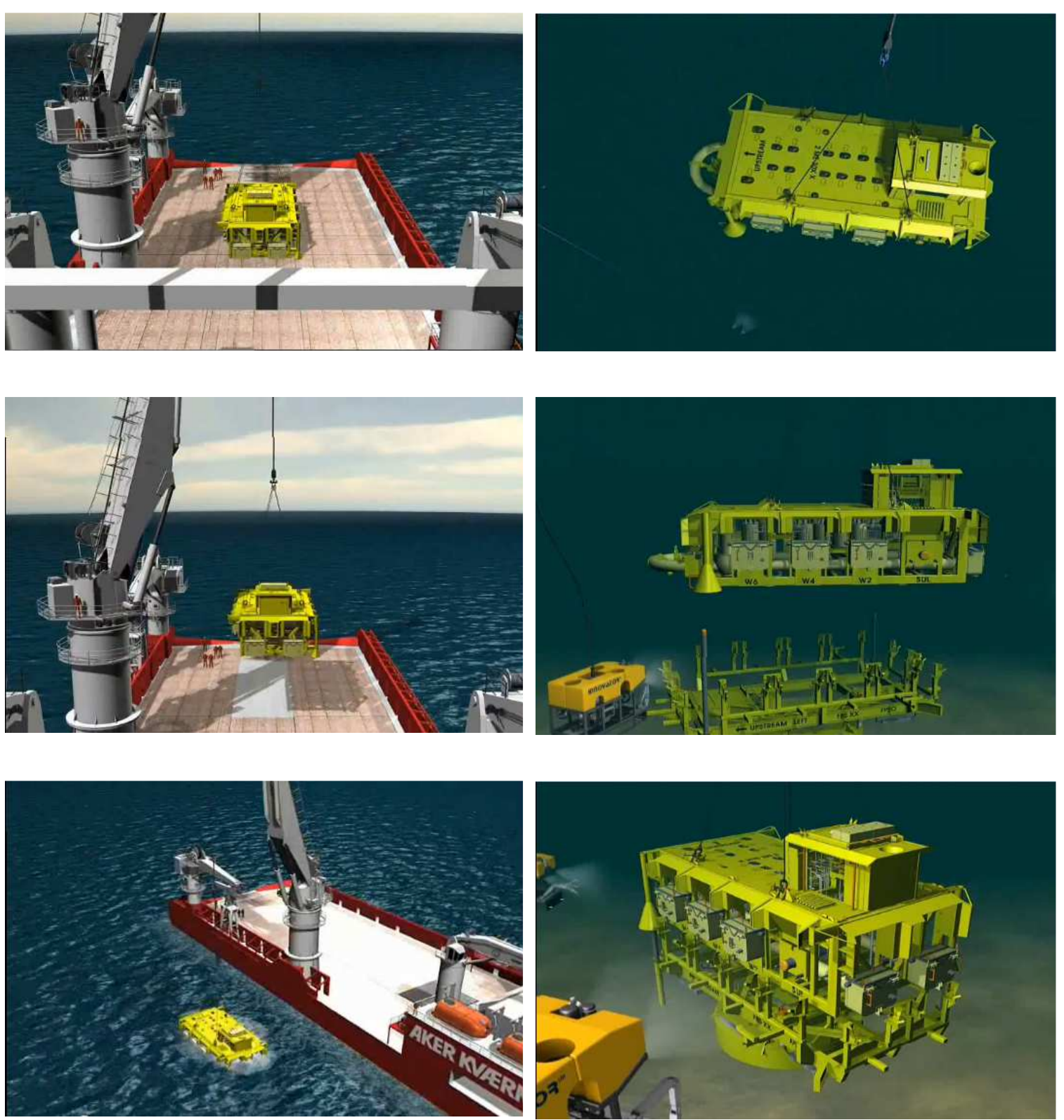

Figura 2: Etapas para serem analisadas na instalação de uma estrutura submarina (Solutions (2012)).

Devido a este cenário, estão sendo realizadas pesquisas em busca de novos métodos inovadores de instalação. Estes métodos buscam reduzir os problemas de ressonância que podem ocorrer em determinadas profundidade e reduzir os custos de instalação evitando-se utilizar embarcações muitos sofisticadas $O$ primeiro método desenvolvido é o método pendular que utiliza 
duas embarcações na qual uma delas é utilizada como o pivô do movimento pendular que o equipamento realiza ao ser lançado em queda livre.

Neste trabalho é apresentado um novo método, que compreende a utilização de duas embarcações e uma configuração de linhas de içamento em formato Y. O trabalho enfoca o projeto de um controle cooperativo para as duas embarcações para lançar o manifold no leito submarino (Figura 3), evitando o afrouxamento no cabo e picos de tensão. O método também provê uma etapa de posicionamento e assentamento do equipamento. Nesta etapa para-se o lançamento do equipamento e as embarcações se aproximam. Desta forma obtém-se um maior controle de posicionamento para a locação do equipamento reduzindo a carga de impacto no fundo do leito submarino.

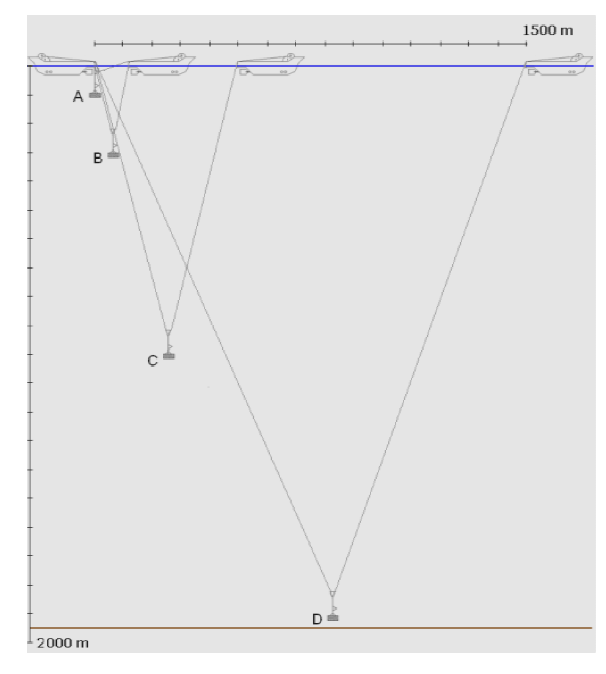

Figura 3: Método Y

\subsection{Objetivo}

O objetivo deste trabalho é desenvolver um sistema de controle cooperativo de duas embarcações dotadas de sistemas DP para operações de lançamento de estruturas submarinas. Este controle deverá ser capaz de manter parâmetros operacionais do lançamento (tais como trações e movimentos) dentro de limites estabelecidos.

Para atingir este objetivo o trabalho será subdivido nas seguintes etapas:

- Modelagem matemática do problema do controle cooperativo envolvendo múltiplas embarcações DP realizando lançamento de 
estrutura submarina, obtendo equações diferenciais que representem a dinâmica do sistema.

- Metodologia para validação da modelagem matemática desenvolvida utilizando ensaios experimentais e validação numérica através do simulador TPN (Tanque de Provas Numérico)

- Formulação de um algoritmo de controle para as embarcações dotadas de Sistema DP para realizar a operação de lançamento do equipamento respeitando seus limites operacionais.

- Avaliação do controlador proposto em ambiente de simulação numérica.

\subsection{Justificativa}

O controle conjunto de todas as embarcações e equipamentos durante as operações de lançamento ainda é um desafio tecnológico, e poderá ser uma solução para os diversos problemas encontrados nestas complexas operações. Segundo Rowe et al., (2001), o lançamento de equipamentos em águas profundas apresenta como principais desafios:

- Restrições impostas pelos equipamentos de içamento, e problemas associados a grandes cargas dinâmicas verificadas nas linhas (ressonâncias);

- Movimentos do equipamento durante lançamento e dificuldades de posicionamento adequado no leito submarino;

- Janela ambiental muito restrita para operação segura.

- Redução dos custos de instalação

Um controle cooperativo entre as embarcações, associado ao controle simultâneo dos equipamentos de içamento, podem reduzir estes problemas. Outra vantagem de se trabalhar com duas embarcações é dividir o peso estático do equipamento entre elas.

\subsection{Organização do Texto}

O Capítulo 2 apresenta uma revisão bibliográfica das áreas abordadas por esse trabalho. Os sistemas DP e suas aplicações com o foco nas operações de instalação de equipamentos submarinos. Além disso, apresenta-se uma discussão sobre aplicações de sistemas DP aplicados a diversos corpos, de forma cooperativa. 
No Capítulo 3, a modelagem matemática para o problema é proposta. $\mathrm{Na}$ seção 3.1 é apresentado o modelo linear da dinâmica de corpos flutuantes devido à ação de ondas. Na seção 3.2, apresenta-se o modelo da dinâmica do movimento horizontal e vertical do manifold. Por fim, na seção 3.3 , os dois modelos são então acoplados, resultando no conjunto de equações dinâmicas que descreverão o sistema ao longo do trabalho.

O Capítulo 4 discute a validação do modelo matemático apresentado no Capítulo 3. Na seção 4.1 é feita uma validação do modelo da embarcação desacoplada a partir de comparações com os resultados numéricos obtidos pelo programa de análise potencial de ondas WAMIT (WAMIT, 2006). Na seção 4.2, apresentam-se ensaios experimentais e a metodologia de tratamento de dados utilizados para a validação do modelo dinâmico do manifold. Na seção 4.3, apresenta-se uma validação modelo dinâmico acoplado, através da comparação com resultados do simulador no domínio do tempo TPN - Tanque de Provas Numérico.

O Capítulo 5 elabora um mapeamento da dinâmica do sistema que indica o comportamento em relação à variação da distância entre os pontos de conexão, ao período da onda e à profundidade do manifold. Através deste mapeamento foi definida a estratégia de controle a ser praticada para o método Y.

O Capítulo 6 apresenta o controle desenvolvido, que é composto pelo estimador da diferença de fase (baseado em Transformada de Hilbert) e 0 Controle de Posição efetivamente, que se apresenta por sua vez dividido em dois níveis. Um nível superior calcula os Setpoints (posições e aproamentos desejados) das embarcações e o nível inferior que controla cada embarcação através de seu sistema DP. Por fim, desenvolve-se um controle de pagamento de linha que irá operar integrado ao sistema de posicionamento proposto.

O Capítulo 7 encerra o trabalho com as conclusões e propõe sugestões para a continuação deste trabalho. 


\section{Revisão Bibliográfica}

\subsection{Análise e Operação de Lançamento Submarino}

Os desenvolvimentos dos próximos campos offshore estão sendo planejados para profundidades de $2000 \mathrm{~m}$ ou mais. Nestas profundidades as dificuldades técnicas de instalação dos sistemas submersos se tornam mais severas.

Métodos convencionais de içamento e posicionamento de equipamentos submersos podem não funcionar em águas ultraprofundas, e a indústria precisa assegurar que a instalação dos equipamentos seja feita de maneira segura e econômica para viabilizar os projetos em águas ultraprofundas.

Diante deste cenário diversas companhias se reuniram em um JIP (Joint Industry Project). O objetivo de um JIP é gerar conhecimento baseado em um esforço conjunto de várias empresas e instituições de pesquisa. Os assuntos estudados em um JIP são demasiadamente complexos ou caros para serem resolvidos por uma única empresa. Em conjunto as empresas podem compartilhar recursos e equipamentos que não estariam disponíveis a elas individualmente. As partes envolvidas, de comum acordo definem um escopo de trabalho, cronograma, condições contratuais. Assim os JIP participantes trabalham em conjunto, partilhando custos e benefícios.

Foi criado em 2001 um JIP chamado DISH (Deepwater Installation of subsea hardware) com o propósito de desenvolver soluções para os problemas técnicos associados à instalação dos equipamentos submarinos em águas profundas. (Rowe, 2001).

O DISH-JIP catalogou alguns aspectos dos problemas enfrentados na instalação dos equipamentos em águas profundas.

- Tecnologia de Içamento. Estes problemas estão relacionados ao peso dos carregamentos içados até o fundo do mar, as respostas dinâmicas que podem aumentar estas cargas, e a capacidade de içamento dos sistemas.

- Controle de carregamento e posição. Problemas relacionados em posicionar a carga no local desejado num aproamento correto e numa altitude estável no leito. 
- Efeitos do Oceano e Requisitos de janela operacional - A influência das condições ambientais na tecnologia que pode ser usada, nos requerimentos de janela operacional, e a velocidade com os quais as tarefas devem ser cumpridas dadas as janelas operacionais. Uma análise da definição da janela operacional da BGL-1 é feita por Tannuri et al. (2009).

Bunnik et al., (2006) apresentam outro problema durante a instalação de equipamentos submarinos, relacionado a forças devido a ondas e movimentos de uma estrutura submarina complexa quando passa pela zona de impacto do equipamento na entrada através da superfície da água ("zona de onda"). De acordo com os autores, grandes amplificações dinâmicas podem ser verificadas, e a existência de métodos de simulação não é capaz de determinar em detalhes as forças de onda durante a passagem nesta área. $O$ autores apresentam uma nova metodologia chamada iVOF (improved Volume of Fluid). Os resultados são comparados com testes experimentais mostrando grande aderência dos dois resultados.

Ribeiro (2008) apresenta um exemplo de uma operação de instalação de equipamento (manifold) submarino realizada no Brasil. Dada à importância deste tipo de equipamento, sua instalação representa uma parcela significativa do investimento de produção do poço. A seguir são apresentados alguns métodos de instalação do manifold.

\subsubsection{Métodos convencionais de instalação}

- Instalação Convencional

A instalação de pequenos equipamentos é feita por meio de AHTS (Anchor Handling Tug Supply). Em geral estas embarcações se destinam ao manuseio de âncoras, reboque e suprimento a plataformas de exploração de petróleo. Para lançar equipamentos submarinos, instalam-se nestas embarcações $A$ FRAMEs que são estruturas pelas quais os equipamentos submarinos são içados (Figura 4).

Outra embarcação utilizada para realizar esta operação são balsas como a BGL-1 (Balsa Guindaste de Lançamento-1). Esta balsa é equipada com 
guindaste, sendo utilizada para a instalação de jaquetas e equipamentos submarinos.

A dificuldade de se utilizar apenas uma embarcação está no problema de ressonância devido ao comprimento do cabo e da limitação do peso do equipamento a ser instalado.

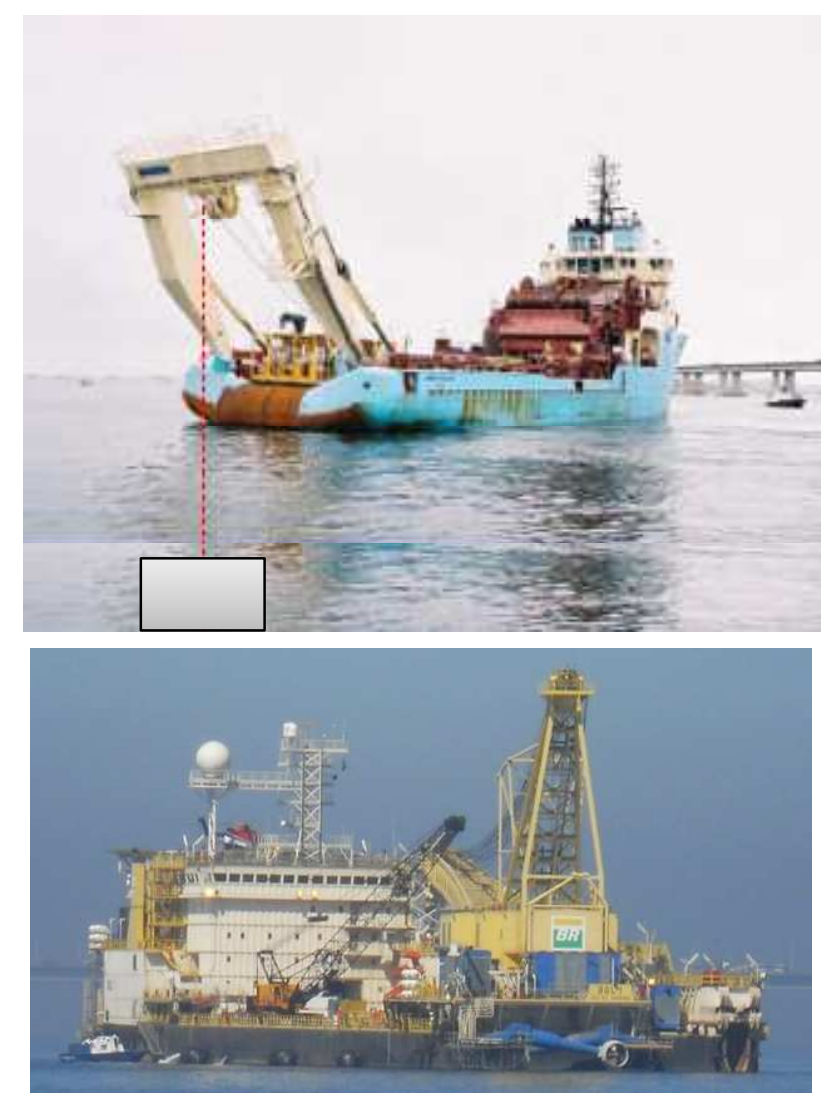

Figura 4: Instalação utilizando AHTS com A-FRAME (Ribeiro, 2008), (acima) e BGL-1 (abaixo)

- Plataformas de Perfuração

As plataformas de perfuração são embarcações utilizadas para perfurar poços que permitam o acesso a reservatórios de petróleo ou gás, mas também podem ser utilizadas para instalar equipamentos submarinos.

Nesta alternativa de instalação (Figura 5), uma balsa leva o manifold até o riser de perfuração das plataformas onde o equipamento é conectado a sua coluna pelo moon-pool, abertura na base do casco da plataforma que dá acesso a água sob a mesma, permitindo o içamento do equipamento submarino. Esta abertura fornece segurança, pois mesmo que a plataforma opere em mares 
agitados o trabalho pode ser feito com mais conforto caso fosse feito em num deck exposto.

Após a conexão do equipamento, ele é içado até o local onde será instalado. A desvantagem deste método se da pelo seu alto custo associado à alta taxa diária da plataforma. Esta taxa diária é ainda mais aumentada pela forte demanda às plataformas de perfuração, dado o cenário atual brasileiro, com um grande número de novos poços em perfuração.

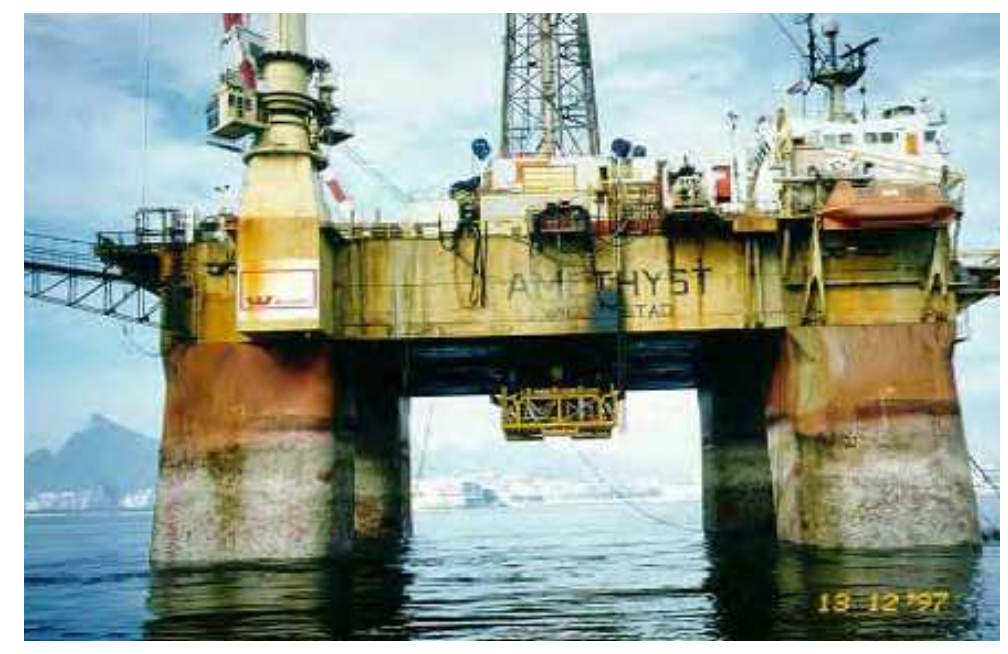

Figura 5: Instalação utilizando o Riser de Perfuração de plataformas semi submersíveis (Ribeiro, 2008)

- Método da roldana

Neste método (Figura 6) são utilizadas três embarcações: uma plataforma de perfuração e outros dois AHTS. Os cabos são suportados por um lado pelo $A$ FRAME do AHTS e por outro pelo riser de perfuração configurando uma formação em "V". A outra embarcação é utilizada para evitar os movimentos de rotação do manifold. A desvantagem deste método está no alto custo devido ao elevado número de embarcações envolvidas, pela utilização da plataforma de perfuração e dificuldade operacional de coordenar as três embarcações. 


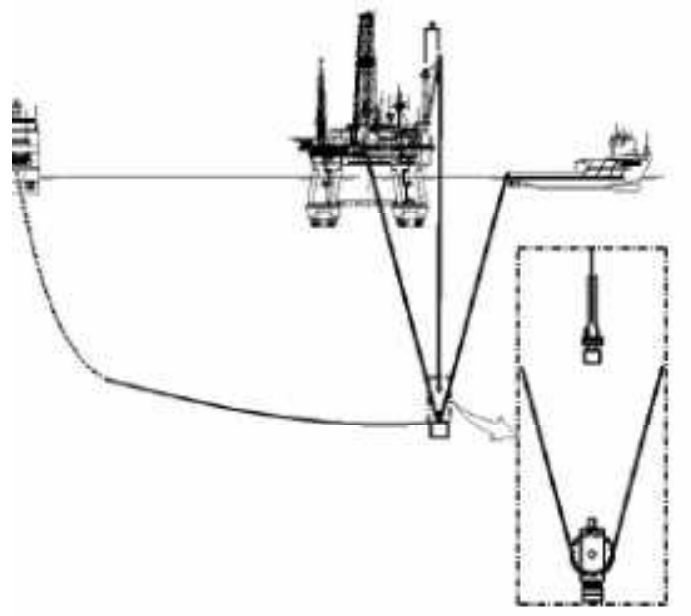

Figura 6: Instalação pelo método da Roldana (Ribeiro, 2008)

- Utilização de Sistemas Compensadores de heave

Cerqueira (2000) estuda a implementação nos cabos, equipamentos que visam reduzir os movimentos de resposta dos equipamentos em conjunto com os AHTS diminuindo as cargas dinâmicas evitando a ocorrência de afrouxamentos no cabo de lançamento (Figura 7).

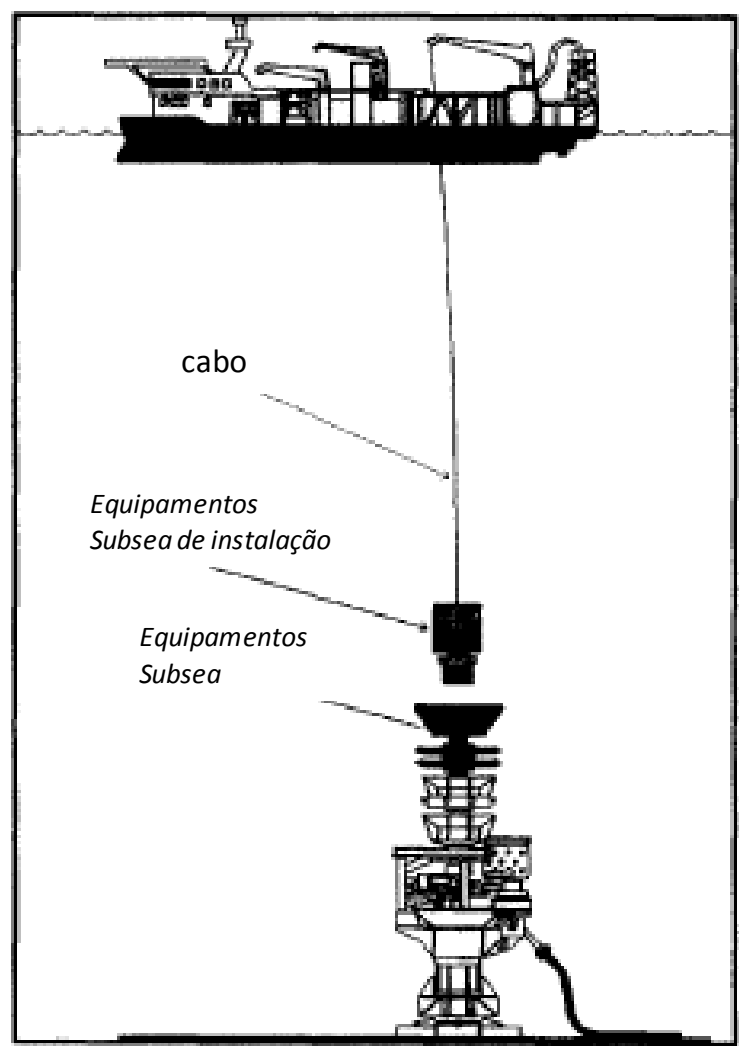

Figura 7: Utilização de sistemas compensadores de Heave (adaptado de Cerqueira, 2000) 
- Método Pendular

Em Ribeiro (2008) propõe-se um novo método de instalação, denominado método pendular. Neste método, uma embarcação leva o manifold até a região de instalação do equipamento (Figura 8a). Chegando neste local, um cabo conectado a outra embarcação, é preso ao manifold (Figura 8b) e afasta-se do local de lançamento pela mesma distância da profundidade que o manifold será instalado (Figura 8c). O equipamento é desconectado do navio içador e o manifold realiza um movimento pendular até a estabilização na posição vertical (Figura 8d). A vantagem deste método se dá na não ocorrência de afrouxamentos no cabo, pois seu lançamento é em queda livre, não utilização da sonda de perfuração e rapidez da instalação do manifold. Um fato importante a ser considerado refere-se à rotação do equipamento nos momentos iniciais de seu lançamento. Isto pode levar ao "capotamento" do equipamento, podendo danificar o equipamento. Mecanismos de estabilização do movimento são estudados em Roveri et al. (2006).

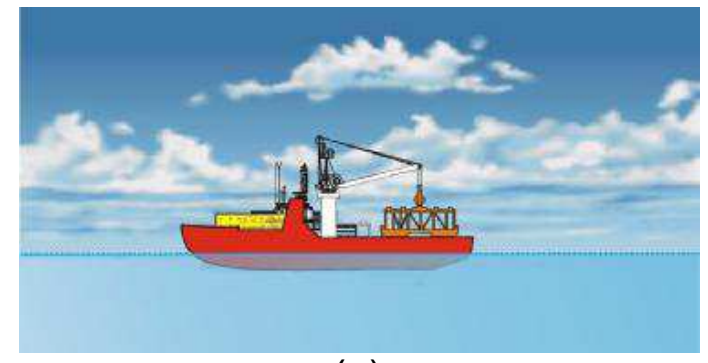

(a)

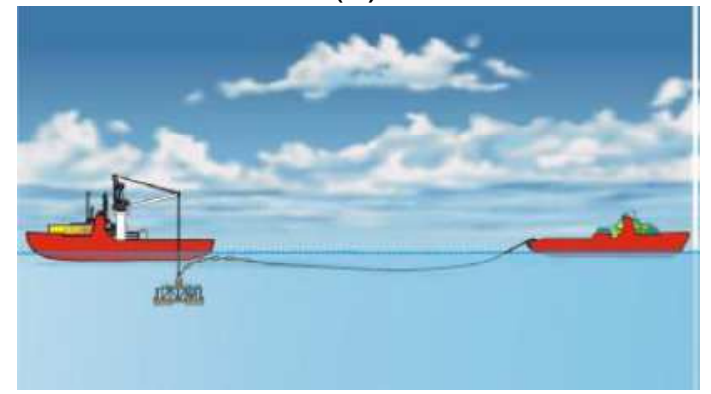

(c)

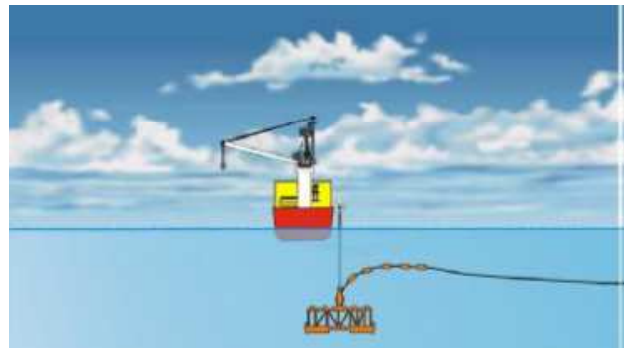

(b)

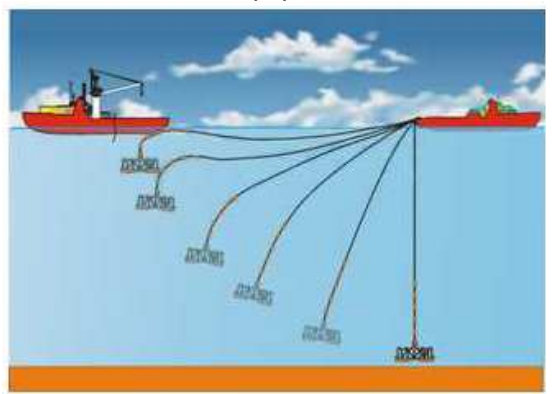

(d)

Figura 8: Método Instalação Pendular (Ribeiro, 2008)

\subsubsection{Propostas de métodos de instalação}

Diante do desafio da instalação dos manifolds, existem outras propostas sendo estudadas de métodos de instalação deste equipamento. Nessas propostas além do procedimento de instalação, técnicas avançadas de controle são 
utilizadas para viabilizar a operação. A seguir são apresentados dois procedimentos.

\section{- Método $Y$}

Neste método (Figura 9) o lançamento do manifold em águas profundas é realizado por meio de dois rebocadores DP operando de forma integrada (Santos et al., 2009), no qual os rebocadores liberam cabo e ao mesmo tempo e se afastam para promover a descida do manifold até o leito submarino. As vantagens deste método se dão: a divisão da tração dos cabos, pois o peso do manifold é dividido pelas duas embarcações e o correto posicionamento do equipamento no leito submarino, pois as embarcações podem se aproximar para garantir o posicionamento correto do equipamento com precisão. Além disso, com o posicionamento estudado no presente trabalho, é possível também reduzir os picos de tração dinâmica nos cabos de içamento.

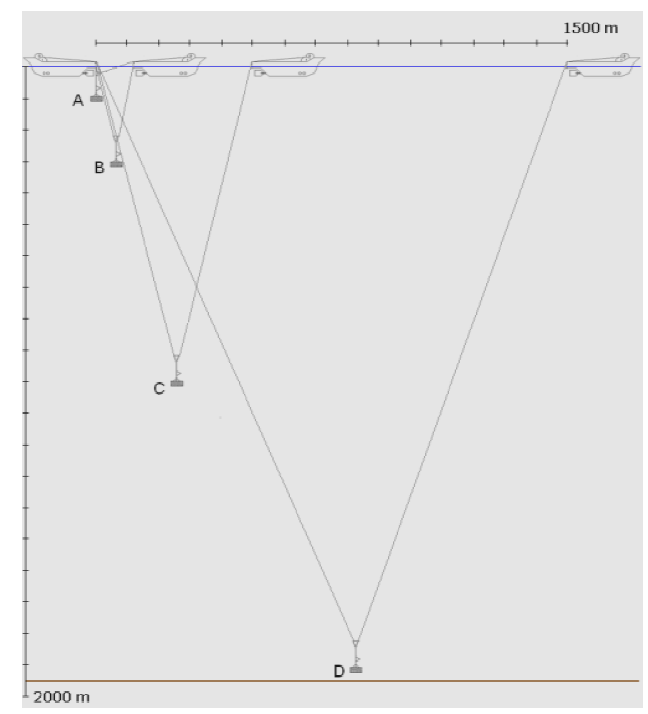

Figura 9: Método Y de Lançamento de manifold (Santos et. al., 2009)

- Instalação de propulsores nos equipamentos submarinos.

How et al. (2010) aborda o problema do posicionamento dos equipamentos submarinos (Figura 10) estudando a instalação de um equipamento com auxílio de propulsores instalados no próprio equipamento. 


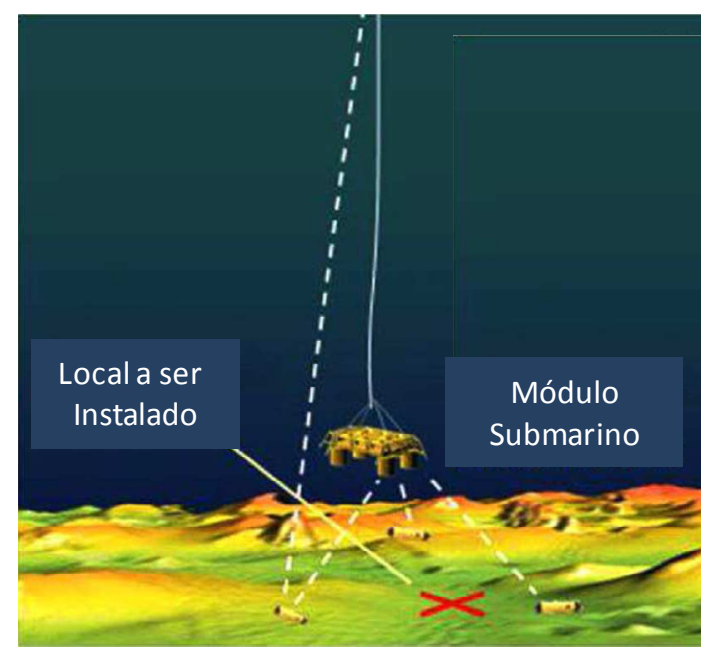

Figura 10: Instalação de propulsores auxiliares no manifold

\subsubsection{Trabalhos Acadêmicos}

A seguir são apresentadas maiores detalhes das técnicas utilizadas para a realização dos métodos de instalação acima.

\subsubsection{Método $Y$}

Mello et al. (2011) e Rateiro et al. (2011) comparam duas metodologias de procedimentos operacionais da instalação de um equipamento no leito submarino, utilizando uma embarcação (operação convencional) ou duas embarcações numa operação sincronizada em uma configuração em Y. Foram realizados ensaios experimentais simplificados nos quais, para simular 0 movimento dos navios, foram utilizados atuadores lineares. Os ensaios permitiram obter os coeficientes hidrodinâmicos do equipamento submarino. De posse desses coeficientes, simulações numéricas do modelo acoplado da dinâmica da embarcação em conjunto com o do equipamento foram realizadas para se verificar quais as melhores configurações, posições relativas das embarcações para se realizar a operação com o objetivo de se evitar 0 afrouxamento na linha.

Este projeto de pesquisa tem sua continuação no trabalho de Oshiro et. al., (2012). Neste trabalho, com a dinâmica validada por meio de ensaios experimentais, propõe-se um controle cooperativo das duas embarcações para controlar a distância relativa dentre elas de modo que a aumentar a segurança da operação e a janela operacional para realizar a operação. 


\subsubsection{Instalação de propulsores nos equipamentos submarinos}

How et al. (2010) aborda o problema do posicionamento dos equipamentos submarinos estudando a instalação de um equipamento com auxílio de propulsores instalados no próprio equipamento. É aplicada a técnica de controle neural adaptativo para projetar a lei de controle e a estabilidade é demonstrada por meios da técnica backstepping e da abordagem de Lyapunov. O controle proposto se mostra robusto às variações dos parâmetros do sistema como seus coeficientes hidrodinâmicos e medições de corrente.

Em How et al. (2011), há o aprimoramento do trabalho anterior, considerando uma análise acoplada da dinâmica e controle do sistema embarcação, guindaste e cabo sob distúrbios ambientais para o projeto de controle de posição do equipamento submarino com propulsores. Neste trabalho ele usa uma nova abordagem baseada nas funções de barreira de Lyapunov no projeto do controle de posicionamento, obtendo bons resultados em relação às especificações de segurança e de posicionamento do equipamento.

\subsection{DP Cooperativo}

Uma das áreas de pesquisa em foco ultimamente, relacionada a Sistemas de Posicionamento Dinâmico (Sistemas DP), é relativa a controle cooperativo. Este compreende técnicas de controle em nível superior, coordenando a troca de informações e os set-points dos Sistemas DP individuais de cada navio durante uma operação que envolva múltiplas embarcações DP.

Grupos de pesquisa internacionais têm abordado este problema focando controle de trajetória de múltiplas embarcações autônomas durante percurso coordenado tais como Arrichiello et al., (2006); Ihle et al., (2006); Aguiar et al., (2008); Hou, Allen, (2008); Ghabcheloo et al. (2009); Souza et al., (2010). Nesses trabalhos, por exemplo, propõem-se arquiteturas de troca de informações entre as embarcações para manter a formação, levando em conta que o compartilhamento das informações é um fator limitante, pois há grande risco de falhas de comunicação. Desta maneira, quanto menos informações forem necessárias, menor a chance de falha do sistema.

As operações com múltiplas embarcações DP têm se mostrado cada vez mais freqüentes também na área de exploração offshore, para a realização de 
complexas operações de lançamentos e instalação de estruturas e equipamentos submarinos (subsea). A utilização de controle cooperativo pode vir a aumentar a segurança e operacionalidade das mesmas. Deve-se destacar que, no Brasil, com a expansão das fronteiras de exploração de petróleo e gás, devido à descoberta de novos campos em Santos, há crescente demanda por avaliações e análises de operações deste tipo.

Pesquisas na área de controle cooperativo aplicados a operações DP tem sido iniciadas, tal como o trabalho descrito por Fujarra et al., (2008), que envolvia a operação de dois rebocadores DP. A partir daí, diversos casos reais de estudo têm levado a necessidade de um estudo mais aprofundado das técnicas de controle cooperativo. O presente trabalho objetiva contribuir neste tópico de pesquisa. 


\section{Modelagem Matemática}

No presente Capítulo, apresenta-se a modelagem matemática para o problema a ser abordado. Na seção 3.1 é apresentado o modelo linear da dinâmica de corpos flutuantes devido à ação de ondas desenvolvido por Newman, (1977). Na seção 3.2, apresenta-se o modelo da dinâmica do movimento horizontal e vertical do manifold. E por fim na seção 3.3 os dois modelos são então acoplados, resultando no conjunto de equações dinâmicas que descreverão 0 sistema ao longo do trabalho.

\subsection{Modelo da Dinâmica da Embarcação}

Nesta seção apresenta-se o modelo dinâmico da embarcação sob a ação de ondas. A embarcação considerada é o rebocador Normand Neptun, cujas dimensões e características principais são dadas na Tabela 1. Uma foto da embarcação é apresentada na Figura 11.

Tabela 1: Características do rebocador Normand Neptun

\begin{tabular}{|l|l|}
\hline \multicolumn{2}{|c|}{ Características Principais } \\
\hline Comprimento $(\mathrm{m})$ & 80,40 \\
\hline Boca $(\mathrm{m})$ & 18,00 \\
\hline Pontal $(\mathrm{m})$ & 9,50 \\
\hline Calado $(\mathrm{m})$ & 7,77 \\
\hline Deslocamento (ton) & 3663,00 \\
\hline
\end{tabular}

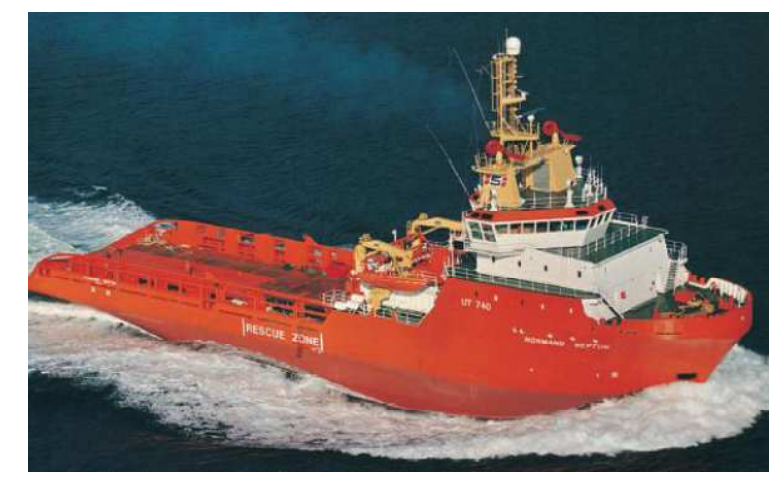

Figura 11: Foto Normand Neptun (Mello, et al., 2011)

O casco foi modelado segundo uma superfície tridimensional (Figura 12) e utilizou-se o programa WAMIT para o cálculo dos coeficientes hidrodinâmicos potenciais, que serão apresentados na modelagem matemática a seguir. Este é um programa amplamente utilizado para resolver o problema de comportamento de corpos no mar. O programa se baseia na teoria potencial 
em que para os problemas de comportamento no mar, os efeitos de viscosidade são pequenos, podendo ser desprezados ou, alternativamente, pode-se propor correções externas simplificadas, que as incorporam quando necessário.

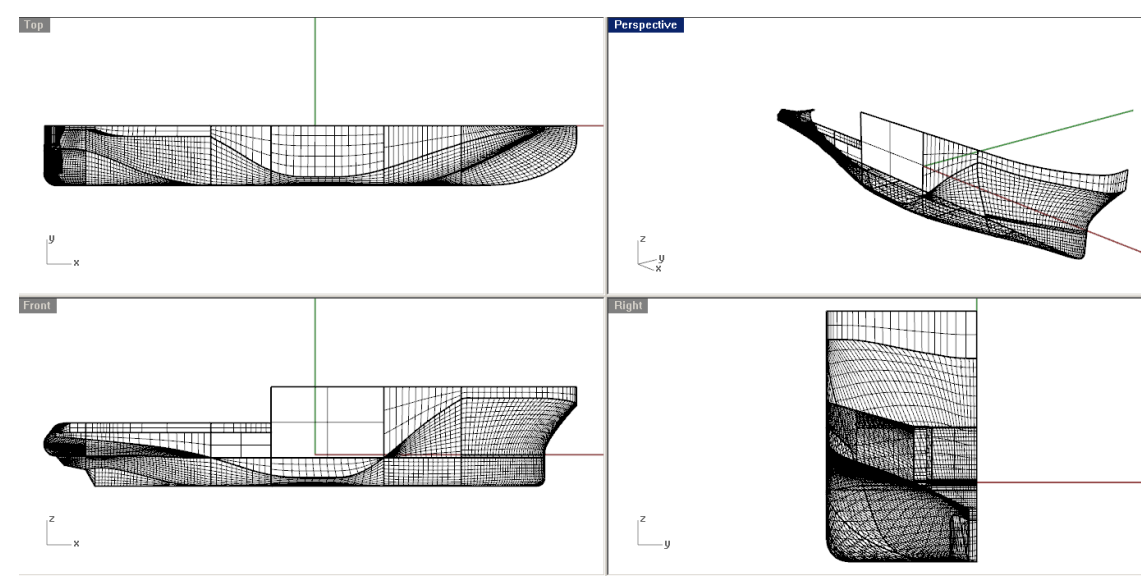

Figura 12: Malha tridimensional do rebocador

\subsubsection{Definição dos referenciais utilizados}

O modelo do sistema consiste na dinâmica das embarcações considerando os movimentos nos seis graus de liberdade. Para descrever estes movimentos é utilizado um sistema de coordenadas fixo ao corpo cuja origem se encontra no centro de massa do mesmo (Figura 13). Considera-se a simetria no plano longitudinal, e que os eixos coordenados são alinhados com os eixos principais de inércia do corpo.

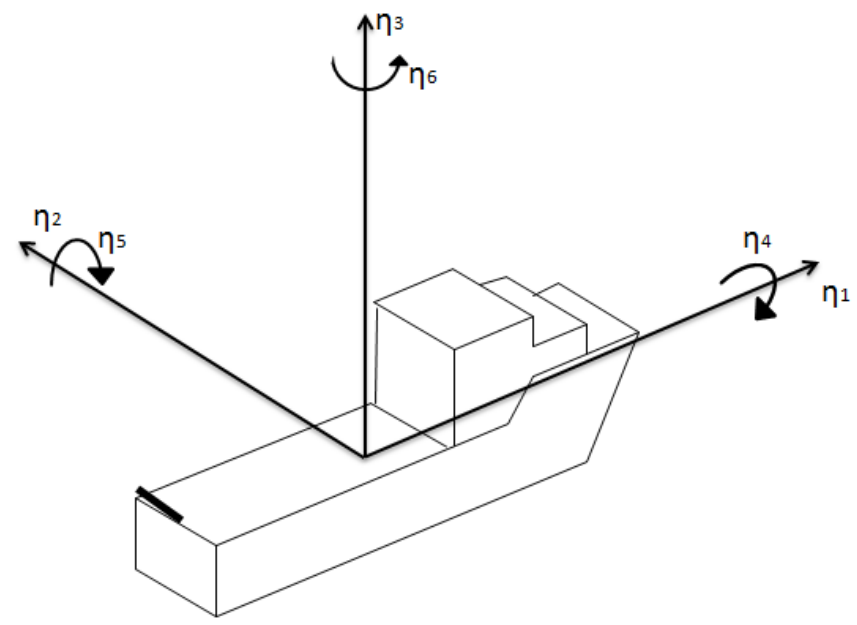

Figura 13: Definições dos movimentos de uma embarcação (SNAME, 1950) 
O vetor de movimento $\boldsymbol{\eta}$ é definido por:

$$
\boldsymbol{\eta}=\left(\eta_{1} ; \eta_{2} ; \eta_{3} ; \eta_{4} ; \eta_{5} ; \eta_{6}\right)
$$

Sendo que $\eta_{1}, \eta_{2}$ e $\eta_{3}$ representam os movimento de translação da embarcação de surge, sway e heave respectivamente e $\eta_{4}, \eta_{5}$ e $\eta_{6}$ representam os movimentos de rotação da embarcação roll, pitch e yaw.

A direção de incidência relativa de onda segue os seguintes referenciais (Figura 14):

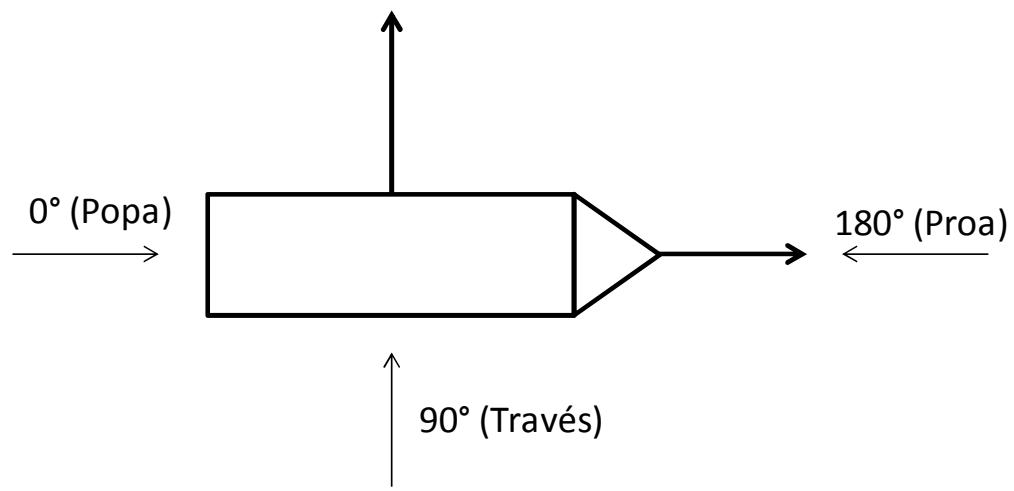

Figura 14: Referência de Incidência de Onda

\subsubsection{Equação do Movimento}

O modelo matemático do movimento do navio pode descrito como em Souza Jr. et. al., (2009) por um modelo linear dado por:

$$
\left(\boldsymbol{M}_{E}+\boldsymbol{M}_{\boldsymbol{A}}(\omega)\right) \ddot{\boldsymbol{\eta}}+\left(\boldsymbol{D}_{E X T}+\boldsymbol{D}_{P}(\omega)\right) \dot{\boldsymbol{\eta}}+\boldsymbol{K} \boldsymbol{\eta}=\boldsymbol{\tau}_{W}
$$

Onde:

$\boldsymbol{M}_{\boldsymbol{E}}$ (Matriz de Inércia): representa a massa e momentos de inércia de corpo rígido da embarcação. Para a embarcação considerada, a matriz é dada por:

$$
\boldsymbol{M}_{\boldsymbol{E}}=\left[\begin{array}{cccccc}
m & 0 & 0 & 0 & 0 & 0 \\
0 & m & 0 & 0 & 0 & 0 \\
0 & 0 & m & 0 & 0 & 0 \\
0 & 0 & 0 & I x & 0 & 0 \\
0 & 0 & 0 & 0 & I y & 0 \\
0 & 0 & 0 & 0 & 0 & I z
\end{array}\right]
$$

Nota-se que a matriz de inércia é diagonal, pois a equação de movimento está escrita em relação ao centro de massa do corpo, com os eixos alinhados aos 
eixos principais de inércia da embarcação. Seus valores estão indicados na Tabela 2.

Tabela 2: Valores da Matriz de Iné
\begin{tabular}{|c|c|}
\hline$m$ (ton) & 7240 \\
\hline$I x$ (ton. $\left.\mathrm{m}^{2}\right)$ & 147000 \\
\hline$I y$ (ton. $\left.\mathrm{m}^{2}\right)$ & 2750000 \\
\hline$I z$ (ton. $\left.{ }^{2}\right)$ & 2750000 \\
\hline
\end{tabular}

$\boldsymbol{M}_{\boldsymbol{A}}(\omega)$ (Matriz de Inércia Adicional): esta matriz, multiplicada pela aceleração do corpo, fornece a força e momento hidrodinâmico de reação que o fluido aplica sobre o corpo devido ao seu movimento. Estes coeficientes são dependentes da frequência de oscilação do corpo $(\omega)$. Como mencionado, no presente trabalho esta matriz é obtida a partir da análise hidrodinâmica potencial do casco, utilizando-se o programa WAMIT. A matriz é definida por:

$\boldsymbol{M}_{\boldsymbol{A}}(\omega)=\left[\begin{array}{cccccc}m_{11}(\omega) & 0 & m_{13}(\omega) & 0 & m_{15}(\omega) & 0 \\ 0 & m_{22}(\omega) & 0 & m_{24}(\omega) & 0 & m_{26}(\omega) \\ m_{31}(\omega) & 0 & m_{33}(\omega) & 0 & m_{35} & 0 \\ 0 & m_{42}(\omega) & 0 & m_{44}(\omega) & 0 & m_{46}(\omega) \\ m_{51}(\omega) & 0 & m_{53}(\omega) & 0 & m_{55}(\omega) & 0 \\ 0 & m_{62}(\omega) & 0 & m_{64}(\omega) & 0 & m_{66}(\omega)\end{array}\right]$

Para o problema estudado a variação dos valores das inércias adicionais de heave e pitch e do acoplamento heave e pitch são os mais importantes. A seguir eles são apresentados em forma gráfica na Figura 15. Na curva da massa adicional de heave $\left(m_{33}\right)$, destaca-se na linha em vermelho o valor da massa efetiva do corpo $(m)$. Na curva da inércia adicional de pitch $\left(m_{55}\right)$, destaca-se em linha vermelha o valor do momento de inércia de pitch $(I y)$. Verifica-se, a partir da comparação das curvas com os valores da massa e momento de inércia, que as inércias adicionais são de fato relevantes na dinâmica da embarcação considerada. 

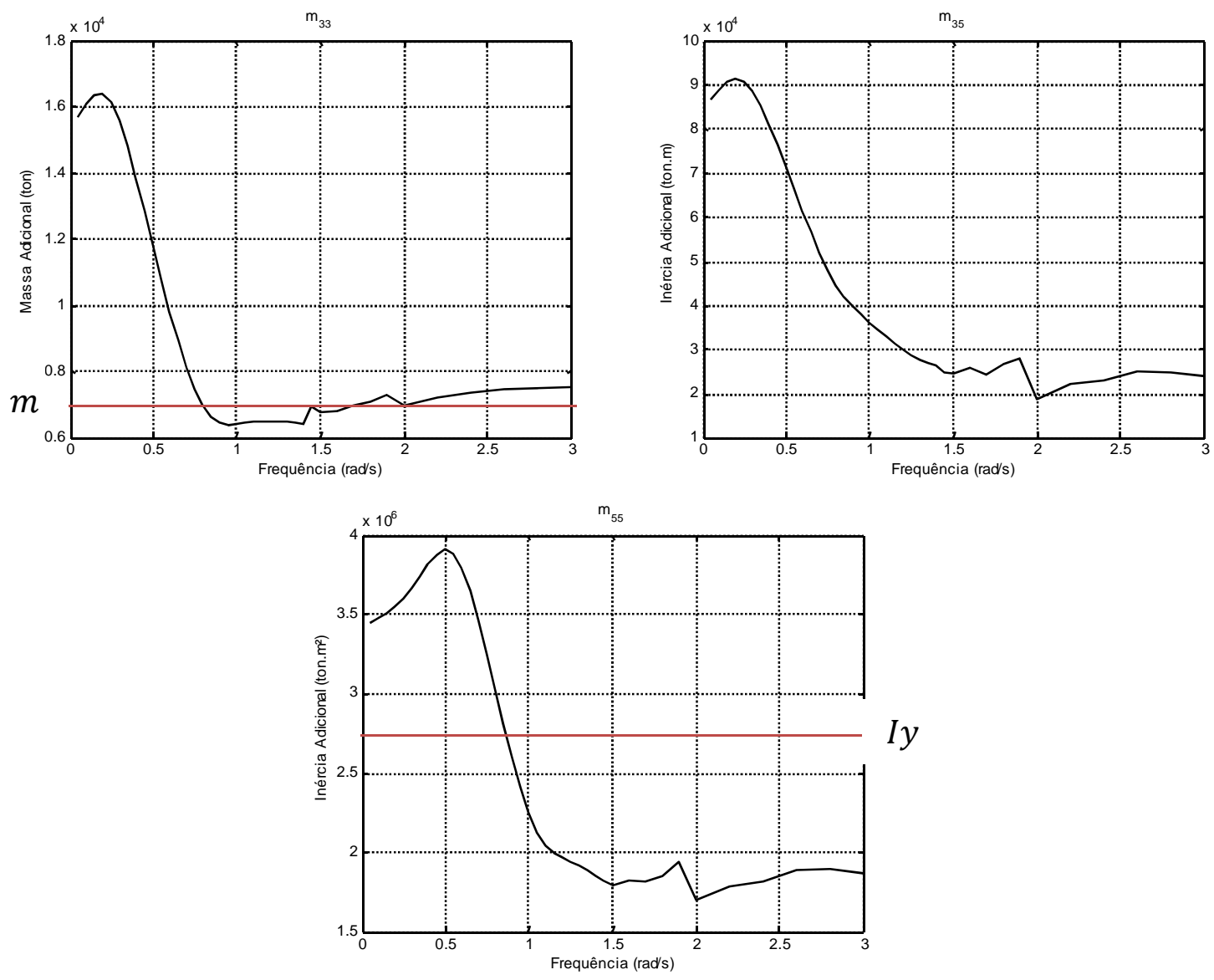

Figura 15: Valores da Inércia Adicional

$\boldsymbol{D}_{\boldsymbol{P}}(\omega)$ (Matriz de Amortecimento Potencial): o amortecimento potencial se deve ao fato de que o corpo, ao oscilar, irradia ondas que se propagam para longe do corpo representando um fluxo de energia de acordo com Simos, (2011). Os coeficientes de amortecimento potencial também variam de acordo com a frequência de oscilação do corpo ( $\omega$ ). A matriz é dada por (3.4). A Figura 16 apresenta o amortecimento potencial para os movimentos de heave $\left(b_{33}\right)$ e pitch $\left(b_{55}\right)$, bem como o termo cruzado $\left(b_{35}\right)$.

$\boldsymbol{D}_{\boldsymbol{P}}(\omega)=\left[\begin{array}{cccccc}b_{11}(\omega) & 0 & b_{13}(\omega) & 0 & b_{15}(\omega) & 0 \\ 0 & b_{22}(\omega) & 0 & b_{24}(\omega) & 0 & b_{26}(\omega) \\ b_{31}(\omega) & 0 & b_{33}(\omega) & 0 & b_{35}(\omega) & 0 \\ 0 & b_{42}(\omega) & 0 & b_{44}(\omega) & 0 & b_{46}(\omega) \\ b_{51}(\omega) & 0 & b_{53}(\omega) & 0 & b_{55}(\omega) & 0 \\ 0 & b_{62}(\omega) & 0 & b_{64}(\omega) & 0 & b_{66}(\omega)\end{array}\right]$ 

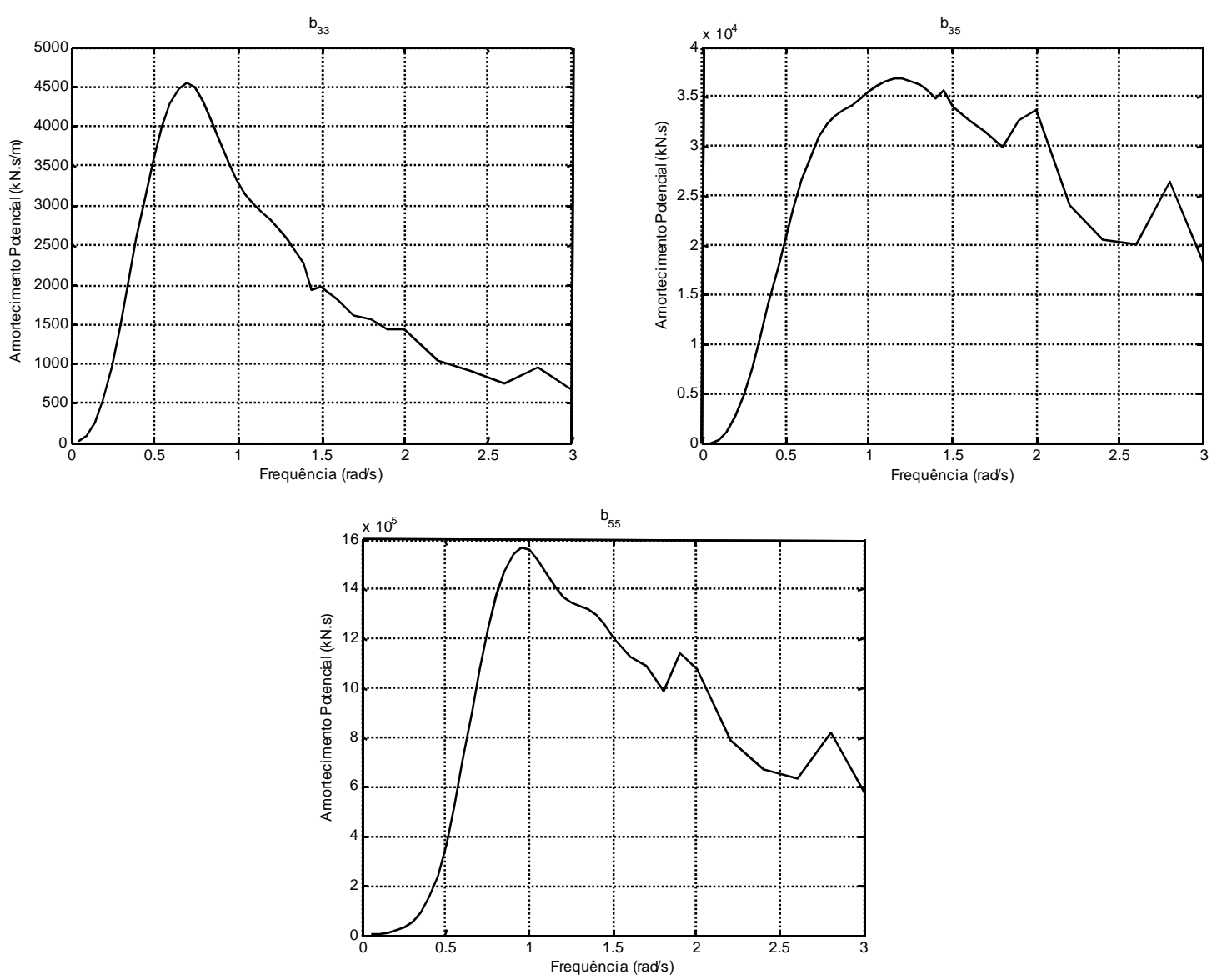

Figura 16: Valores de Amortecimento Potencial

$\boldsymbol{D}_{\boldsymbol{E X T}}$ (Matriz de amortecimento externo): que representa os efeitos viscosos não modelados pela teoria potencial. Para uma embarcação das dimensões típicas do rebocador considerado, deve-se considerar o amortecimento externo em heave, roll e pitch, dados por:

$\boldsymbol{D}_{\text {EXT }}=\left[\begin{array}{cccccc}0 & 0 & 0 & 0 & 0 & 0 \\ 0 & 0 & 0 & 0 & 0 & 0 \\ 0 & 0 & D_{E X T_{33}} & 0 & 0 & 0 \\ 0 & 0 & 0 & D_{E X T_{44}} & 0 & 0 \\ 0 & 0 & 0 & 0 & D_{E X T_{55}} & 0 \\ 0 & 0 & 0 & 0 & 0 & 0\end{array}\right]$

Seus respectivos valores são apresentados na

Tabela 3.

Tabela 3: Valores de amortecimento externo considerados

\begin{tabular}{|l|l|}
\hline$D_{E X T_{33}}(\mathrm{kN} . \mathrm{s} / \mathrm{m})$ & 1512,7 \\
\hline$D_{E X T_{44}}(\mathrm{kN} . \mathrm{m} / \mathrm{rad} / \mathrm{s})$ & 10872 \\
\hline
\end{tabular}




\section{\begin{tabular}{|l|l|}
\hline$D_{E X T_{55}}(\mathrm{kN} . \mathrm{m} / \mathrm{rad} / \mathrm{s})$ & 553290 \\
\hline
\end{tabular}}

Nas curvas de amortecimento potencial para os movimentos de heave $\left(b_{33}\right)$ e pitch $\left(b_{55}\right)$, destacam-se as linhas em vermelho do valor do amortecimento externo em heave $\left(D_{E X T_{33}}\right)$ e pitch $\left(D_{E X T_{55}}\right)$. Verificam-se, a partir da comparação com as curvas de amortecimento potencial (Figura 17), que os amortecimentos externos são relevantes na dinâmica da embarcação considerada.
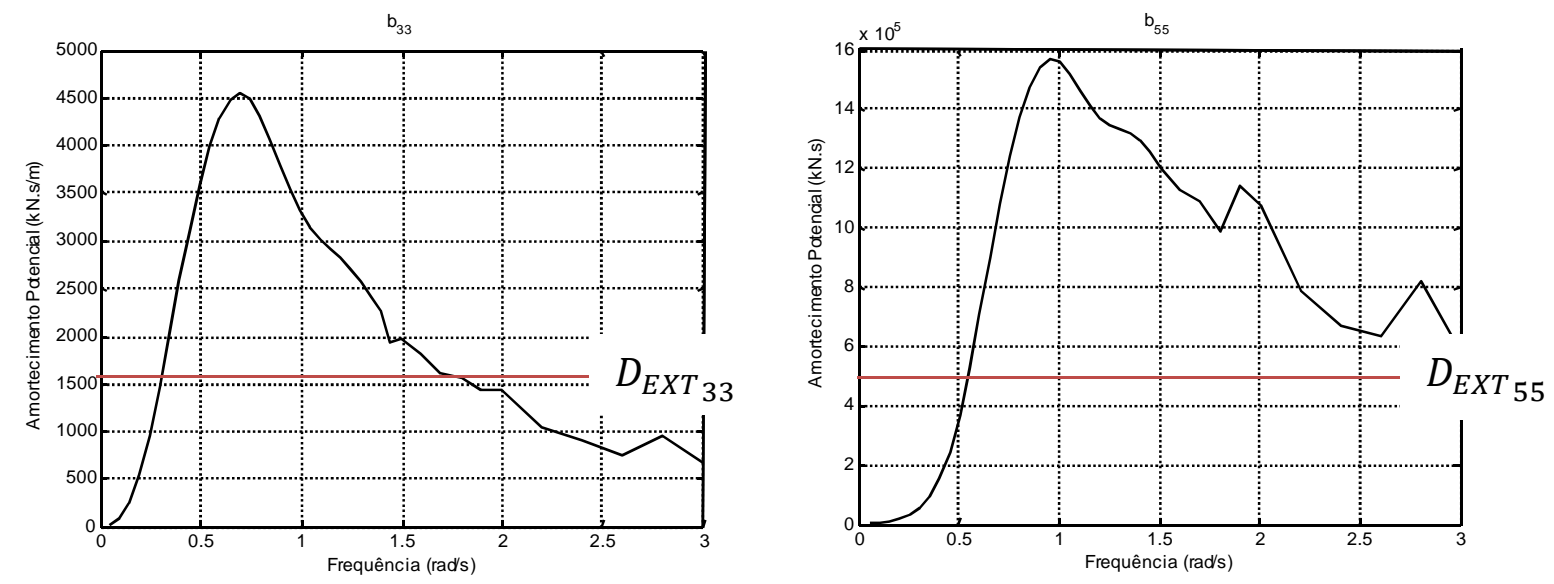

Figura 17: Comparação valores de amortecimento potencial e externo

$\boldsymbol{K}$ (Matriz de Restauração): que matriz representa a força e momento hidrostático exercidos sobre o casco, sendo dada por:

$\boldsymbol{K}=\left[\begin{array}{cccccc}0 & 0 & 0 & 0 & 0 & 0 \\ 0 & 0 & 0 & 0 & 0 & 0 \\ 0 & 0 & c_{33} & 0 & c_{35} & 0 \\ 0 & 0 & 0 & c_{44} & 0 & c_{46} \\ 0 & 0 & c_{35} & 0 & c_{55} & 0 \\ 0 & 0 & 0 & c_{46} & 0 & 0\end{array}\right]$

Sendo os parâmetros e os respectivos valores apresentados

- $\quad c_{33}$ : restauração em heave $(12290,6 \mathrm{kN} / \mathrm{m})$

- $c_{44}$ : restauração em roll $(56278 \mathrm{kN} / \mathrm{rad})$

- $c_{55}$ : restauração em pitch $(4986770 \mathrm{kN} / \mathrm{rad})$

- $\quad c_{35}$ : parcela de acoplamento do movimento de heave e pitch devido à assimetria do casco $(62362 \mathrm{kN} . \mathrm{m} / \mathrm{rad})$

- $\quad c_{46}$ : parcela de acoplamento do movimento de roll e yaw devido à assimetria do casco. $(5,70 \mathrm{kN} \cdot \mathrm{m} / \mathrm{rad})$ 
$\boldsymbol{\tau}_{\boldsymbol{w}}$ (Vetor de força e momento devido a ondas): as forças de onda consideradas foram as de primeira ordem. Nesta abordagem a amplitude da onda incidente é proporcional a sua força e a frequência da onda é a mesma da força que ela gera (Faltinsen, 1990). Estas forças foram calculadas a partir do programa WAMIT. A seguir são apresentadas as forças de onda em heave e pitch (Figura 18) das embarcações.
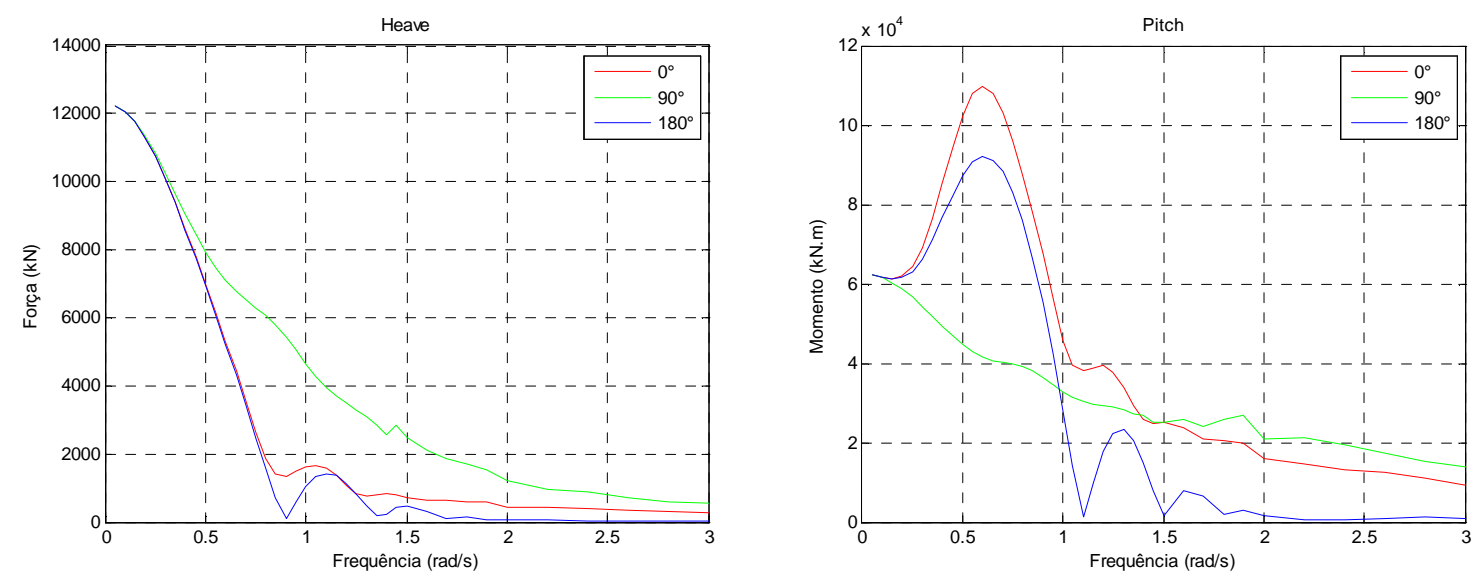

Figura 18: Forças de Excitação em Ondas

Observa-se que para frequências de onda da ordem de $0,7 \mathrm{rad} / \mathrm{s}$ (períodos de $8 \mathrm{~s}$ ) ocorrem os maiores momentos de pitch e, portanto os maiores movimentos no ponto de conexão.

\subsection{Modelo da dinâmica do manifold suspenso por cabos}

Nesta seção, será apresentado o desenvolvimento de um modelo da dinâmica do manifold suspenso por cabos. Os eixos coordenados adotados, bem como as dimensões principais do manifold em estudo são dados na Figura $19 \mathrm{e}$ Tabela 4. O manifold é assumido em formato de um paralelepípedo. 


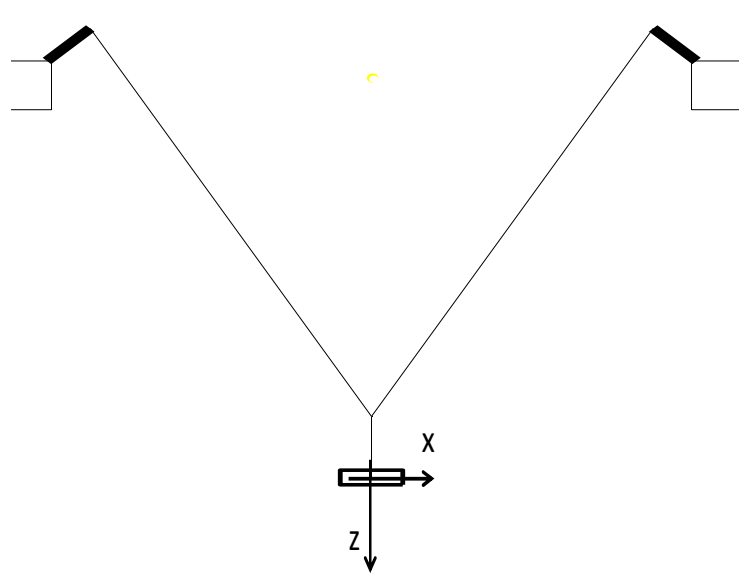

Figura 19: Eixos de coordenadas considerados para o manifold

Tabela 4: Dimensões Principais do manifold

\begin{tabular}{|c|c|}
\hline Peso no ar $(\mathrm{t})$ & 100,0 \\
\hline M66 & 355,1 \\
\hline Volume $\left(\mathrm{m}^{3}\right)$ & 12,7 \\
\hline Altura $(\mathrm{m})$ & 3,7 \\
\hline Lm: Largura $(\mathrm{m})$ & 6,0 \\
\hline Cm: Comprimento $(\mathrm{m})$ & 11,8 \\
\hline
\end{tabular}

Foram adotadas algumas hipóteses simplificadoras para o problema:

- Os planos de simetria longitudinais dos navios são coincidentes, ou seja, os navios estão alinhados (Figura 20).

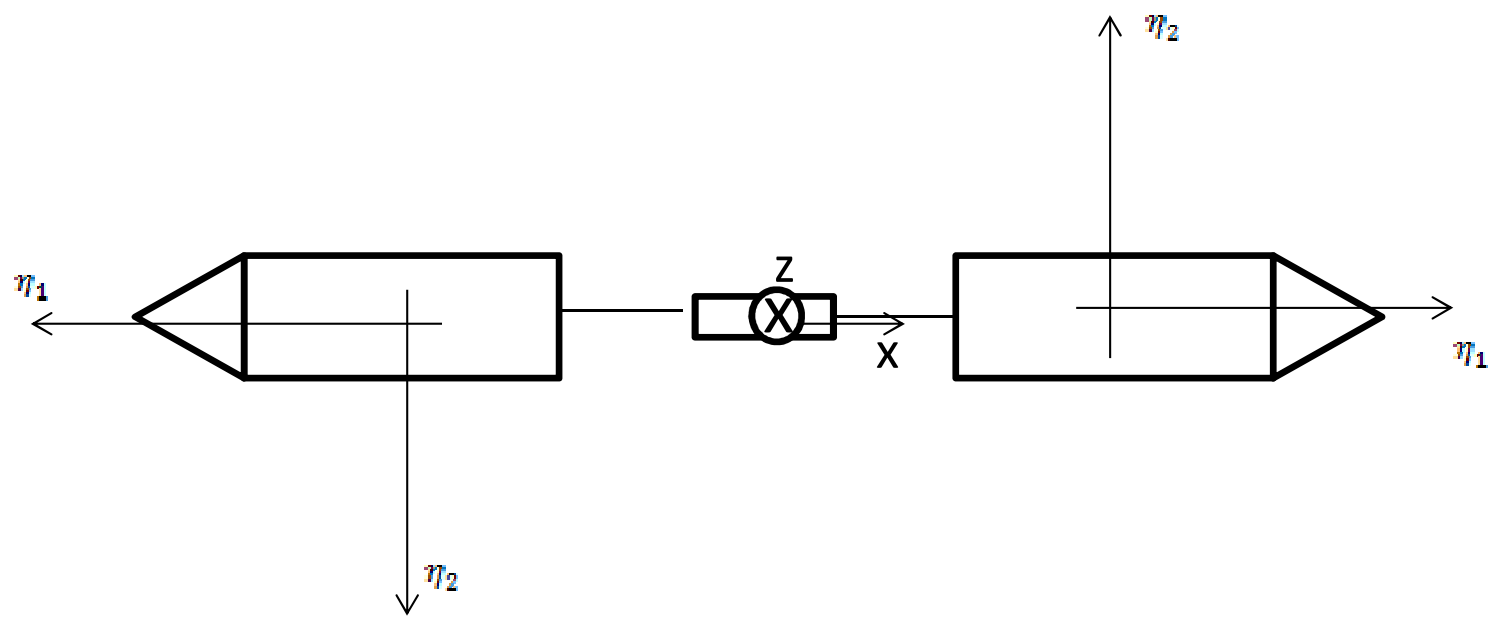

Figura 20: Hipótese Navios Alinhados - vista de topo

- Considera-se movimento translacional plano contido no eixo xz (definido pelos planos de simetria das embarcações). Não se considerou o movimento de rotação do manifold em torno do eixo y. 
- As linhas foram modeladas como molas lineares quando sob tração, e resultando força nula quando sob compressão. O peso e a dinâmica própria do cabo e suas forças de arrasto não foram incluídos.

- Admite-se que o manifold está submerso a uma profundidade tal que os efeitos de superfície livre e do fundo podem ser ignorados na dinâmica do corpo.

A Figura 21 (esq) apresenta a definição de configurações geométricas adotadas e a Figura 21(dir) apresenta o diagrama de forças do manifold, quando suspenso por duas linhas em configuração $\mathrm{Y}$.
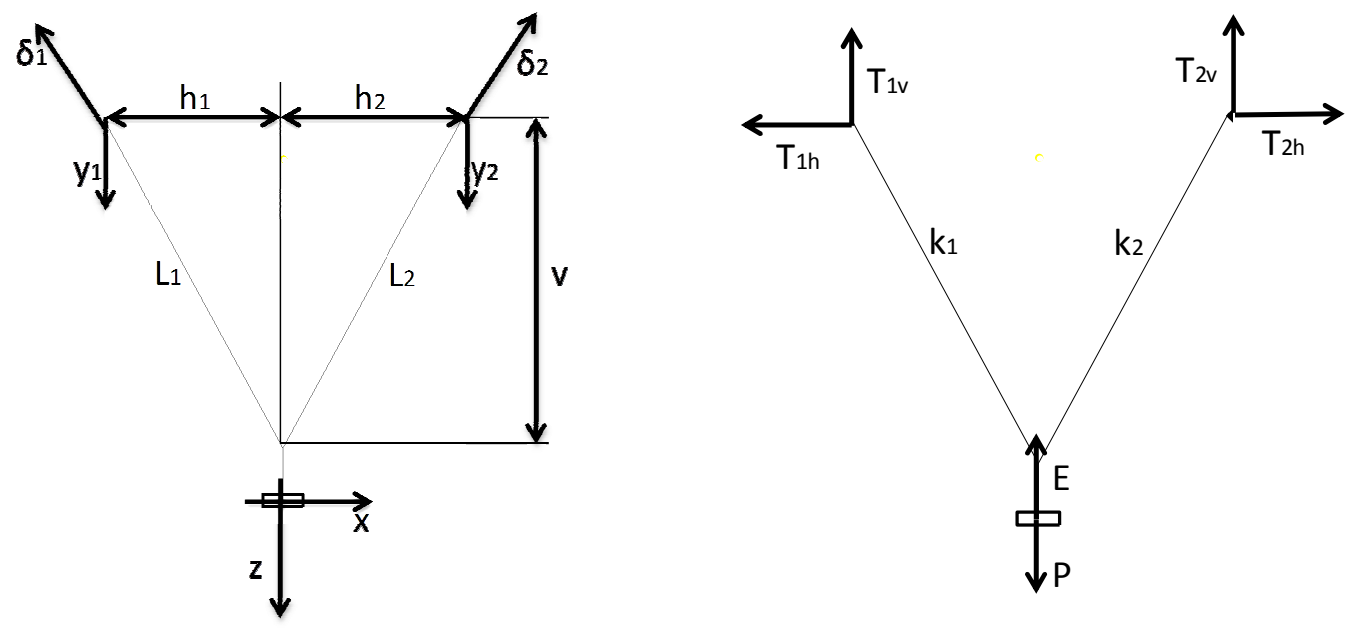

Figura 21: Definições dos parâmetros geométricos da dinâmica do manifold (esq.) Definições das forças atuantes na dinâmica do manifold (dir.)

A aplicação das leis de movimento ao manifold como apresenta (den Hartog, 1947) resulta:

$$
\begin{aligned}
& \left(M_{m}+M_{z}\right) \ddot{z}+C_{1 z} \dot{z}+C_{2 z} \dot{z}|\dot{z}|+T_{1 v}+T_{2 v}=P-E \\
& \left(M_{m}+M_{x}\right) \ddot{x}+C_{x} \dot{x}+T_{1 h}+T_{2 h}=0
\end{aligned}
$$

Sendo os parâmetros e seus respectivos valores dados por:

$M_{m}:$ Massa do manifold (100ton)

$M_{z}$ : Massa Adicional em Vertical do manifold (350ton)

$M_{x}$ : Massa Adicional em Horizontal do manifold (70ton)

$P$ : Peso do manifold (980kN)

E: Empuxo do manifold (500kN)

z: Posição vertical absoluta do manifold

$x$ : Posição horizontal absoluta do manifold

$y_{1}, y_{2}$ : Posição vertical do ponto de conexão.

$\mathrm{C}_{\mathrm{X}}$ : Coeficiente de amortecimento linear horizontal do manifold 
$C_{1 z}$ : Coeficiente de amortecimento linear vertical do manifold

$C_{2 z}$ : Coeficiente de amortecimento vertical quadrático do manifold, definido por

$C_{2 z}=\frac{1}{2} \rho C_{M} L_{M} C_{D}$

Na qual:

$C_{M} L_{M}$ : Comprimento e largura do manifold, respectivamente.

$C_{D}$ : Coeficiente de Arrasto.

$T_{1,2 v}$ : Projeção Vertical da Tração no Cabo 1 ou 2

$T_{1,2 h}$ : Projeção Horizontal da Tração no Cabo 1 ou 2

As projeções das trações nos cabos são calculadas a partir das seguintes expressões:

$$
\begin{aligned}
& T_{1 v}=k_{1} \delta_{1} \frac{v}{\sqrt{v^{2}+h_{1}^{2}}} a \\
& T_{2 v}=k_{2} \delta_{2} \frac{v}{\sqrt{v^{2}+h_{2}^{2}}} b \\
& T_{1 h}=k_{1} \delta_{1} \frac{h_{1}}{\sqrt{v^{2}+h_{1}^{2}}} a \\
& T_{2 h}=k_{2} \delta_{2} \frac{h_{2}}{\sqrt{v^{2}+h_{2}^{2}}} b
\end{aligned}
$$

Sendo $\delta_{1}$ e $\delta_{2}$ as elongações dos cabos dadas por:

$$
\begin{aligned}
& \delta_{1}=\sqrt{\left(v+z-y_{1}\right)^{2}+\left(h_{1}+x\right)^{2}}-L_{1} \\
& \delta_{2}=\sqrt{\left(v+z-y_{2}\right)^{2}+\left(h_{2}-x\right)^{2}}-L_{2}
\end{aligned}
$$

Na qual $y_{1}$ e $y_{2}$ são as amplitudes do movimento no ponto de conexão das linhas com as embarcações. Pela hipótese de que o cabo não sofre compressão, definem-se:

$$
\begin{array}{r}
a: 1 \text { se } \delta_{1}>0 \\
0 \text { se } \delta_{1}<0 \\
b: 1 \text { se } \delta_{2}>0 \\
0 \text { se } \delta_{2}<0
\end{array}
$$

Os valores de $k_{1}$ e $k_{2}$ representam a constante elástica do cabo, $v$ a profundidade do manifold e $h_{1}, h_{2}$ a metade da distância das embarcações. A Figura 21 apresenta estas variáveis. 


\subsection{Modelo da Dinâmica Acoplada}

O modelo matemático considerado no presente trabalho contempla a dinâmica da embarcação apresentada na seção 3.1 e a dinâmica do manifold apresentada na seção 3.2, tendo as trações nos cabos como elementos de acoplamento entre as mesmas.

É importante ressaltar que este modelo acoplado apresenta as mesmas simplificações apresentadas na seção 3.2, relativas a se considerarem apenas os movimentos transversais, a dinâmica simplificada do cabo de içamento e os movimentos translacionais do manifold apenas.

O modelo acoplado inclui as forças apresentadas na Figura 22 e é descrito pelas equações (3.11) abaixo. Destaca-se que as duas embarcações são consideradas idênticas, portanto os parâmetros (massas e amortecimentos) são os mesmos.

$$
\begin{aligned}
& \left(M_{E}+M_{A}(\omega)\right) \ddot{\boldsymbol{\eta}}_{1}+\left(D_{E X T}+D_{P}(\omega)\right) \dot{\eta}_{1}+K \eta_{1}=\tau_{W 1}+\tau_{T 1} \\
& \left(M_{E}+M_{A}(\omega)\right) \ddot{\boldsymbol{\eta}}_{2}+\left(D_{E X T}+D_{P}(\omega)\right) \dot{\eta}_{2}+K \boldsymbol{\eta}_{2}=\tau_{W 2}+\tau_{T 2}
\end{aligned}
$$

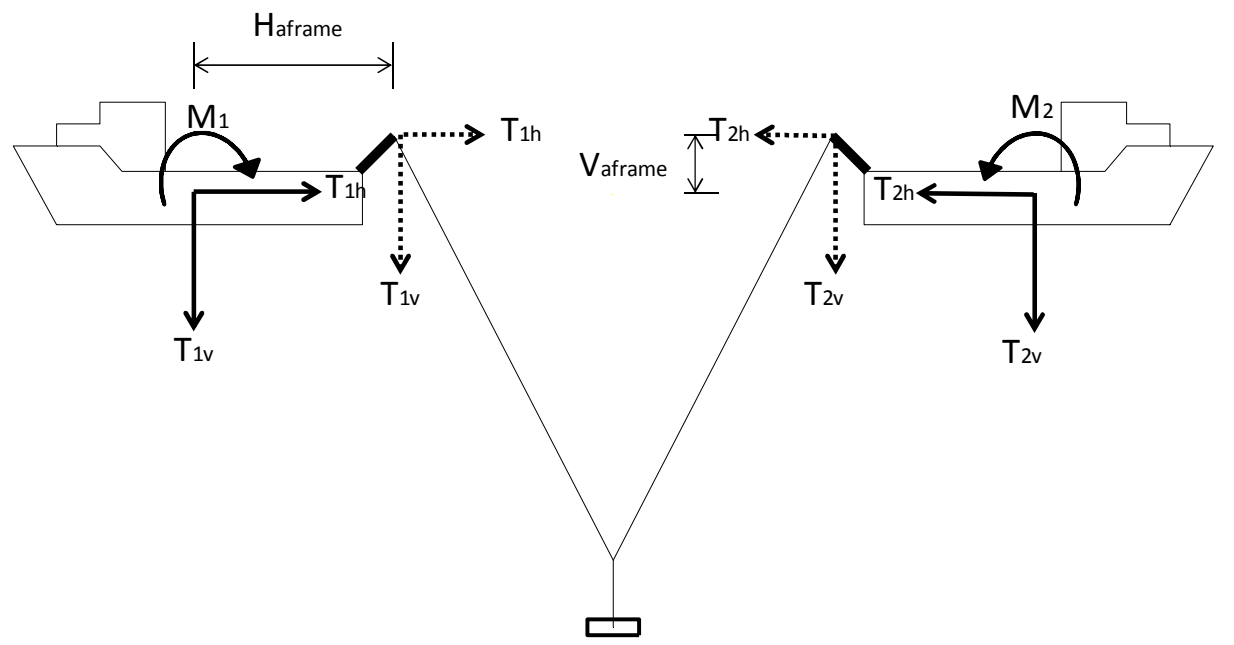

Figura 22: Modelo da Dinâmica Acoplada

$\mathrm{O}$ vetor $\boldsymbol{\tau}_{\mathbf{T}}$ representa as forças e momentos resultantes devido à tração nos cabos, transferido para o CG da embarcação, dado por: 
$\boldsymbol{\tau}_{\boldsymbol{T}}=\left[\begin{array}{c}T_{i h} \\ 0 \\ T_{i v} \\ 0 \\ M_{i} \\ 0\end{array}\right]$

As forças de tração foram definidas pela equação (3.9) apresentadas pela seção 3.2 e o momento é definido por:

$M_{i}=T_{i v} H_{\text {aframe }}+T_{i h} V_{\text {aframe }}$

Sendo:

$H_{\text {aframe }}$ : Distância horizontal do centro de gravidade da embarcação e o ponto de conexão

$V_{\text {aframe }}$ : Distância vertical do centro de gravidade da embarcação e o ponto de conexão 


\section{Validação do Modelo Matemático}

$\mathrm{Na}$ dinâmica do problema em questão existem termos não lineares tais como o afrouxamento dos cabos e amortecimento quadrático. A utilização de um simulador de sistemas oceânicos multicorpos de grande porte, tal como 0 TPN(Nishimoto, et al., 2003) seria uma opção viável, dado que considera todos os efeitos necessários para o estudo. Entretanto, como será exposto adiante, o projeto e análise do sistema de controle de posicionamento demanda um número muito grande de simulações, a fim de se obter o comportamento dinâmico do sistema em função de diversos parâmetros (comprimento do cabo, distância entre embarcações, frequência de onda, etc.). Assim, a utilização do TPN torna-se inadequada, dado o tempo de processamento para cada análise e o trabalho necessário para a configuração dos diversos modelos para simulação. O TPN foi utilizado posteriormente para validar o simulador no domínio do tempo descrito no Capítulo 3.

Portanto, verificou-se a necessidade de se criar um simulador no domínio do tempo específico para resolver as equações diferenciais descritas na seção 0 , considerando-se as hipóteses simplificadoras descritas naquela seção. A metodologia de validação deste simulador será apresentada neste Capítulo.

Primeiramente será validado o modelo da dinâmica do navio em ondas, demonstrando que o simulador recupera os resultados do WAMIT para o navio desacoplado. Em seguida os coeficientes de amortecimento do manifold serão calibrados de acordo com os ensaios experimentais realizados. E por último, o modelo acoplado será comparado ao simulador numérico TPN.

Ao final, será verificado que o simulador desenvolvido apresenta resultados consistentes com os experimentos e com as simulações no TPN. Com isso, considera-se que o mesmo é adequado para as fases seguintes de projeto e análise do sistema de controle.

\subsection{Validação da Dinâmica da Embarcação}

O primeiro passo para a validação do simulador como um todo consiste na validação do modelo da dinâmica das embarcações desacopladas excitadas por forças de ondas, dado pela equação (3.1). Para tanto, compararam-se os resultados de movimentos obtidos pelo simulador desenvolvido com 0 
programa WAMIT. Este, além de possuir um módulo para o cálculo das forças hidrodinâmicas, massas adicionais e amortecimento potencial, possui um módulo para a integração das equações de movimento lineares do corpo flutuante excitado por ondas.

A comparação é feita através dos RAOs (Response Amplitude Operators) da embarcação calculados pelos dois programas. O RAO representa os movimentos do corpo (amplitude e fase) quando excitado por uma onda de amplitude unitária. Pode-se considerá-lo como uma função de transferência que relaciona a amplitude de onda incidente com a resposta linear do sistema dinâmico. Uma das hipóteses na utilização dos RAOs é que a resposta da embarcação a ondas seja linear.

A validação para três incidências de onda são apresentas nas figuras: $0^{\circ}$ grau (Figura 23), $90^{\circ}$ graus (Figura 24) e $180^{\circ}$ graus (Figura 25). Pode-se verificar que há uma coincidência completa entre os resultados obtidos pelo simulador desenvolvido, baseado na equação ( 3.1), e os resultados obtidos pelo WAMIT, o que confirma a adequada representação da dinâmica da embarcação.
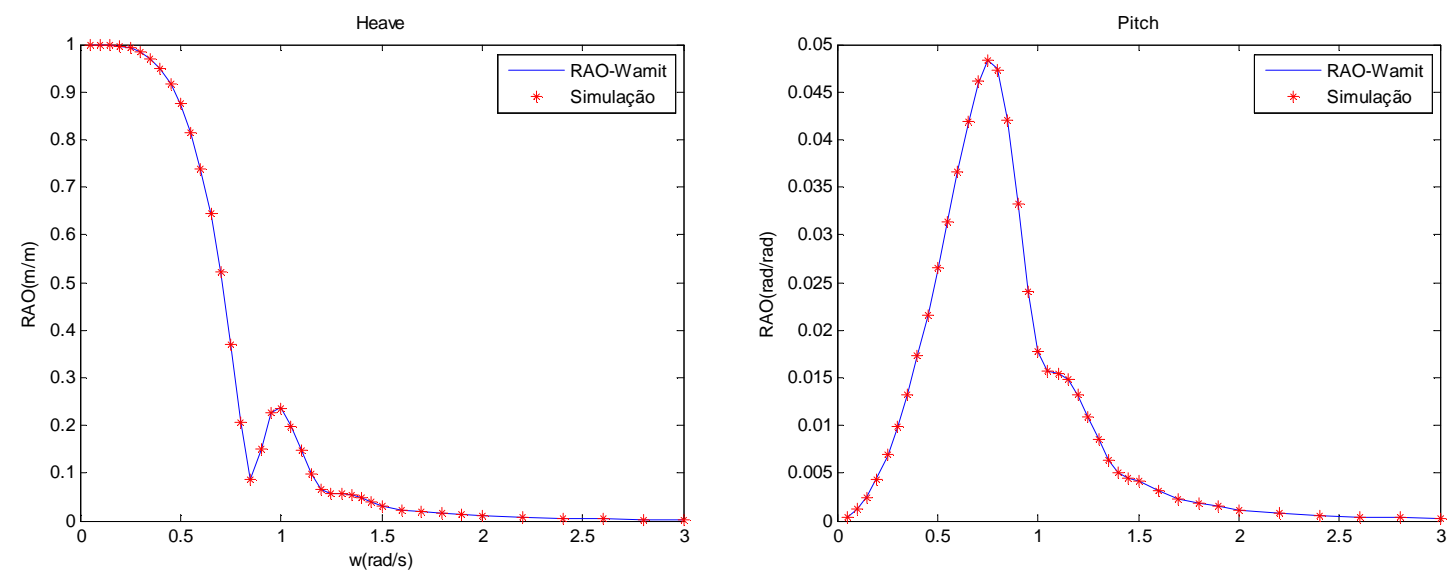

Figura 23: Incidência de $0^{\circ}$ (Popa) 

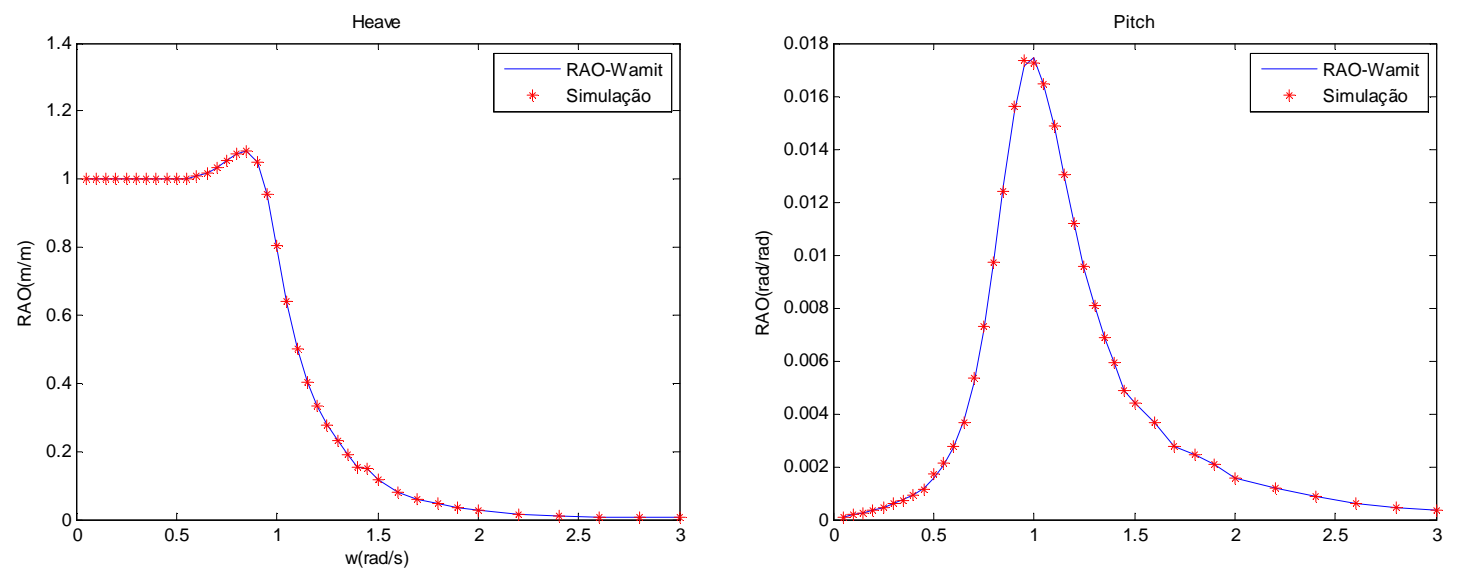

Figura 24: Incidência de $90^{\circ}$ (Través)
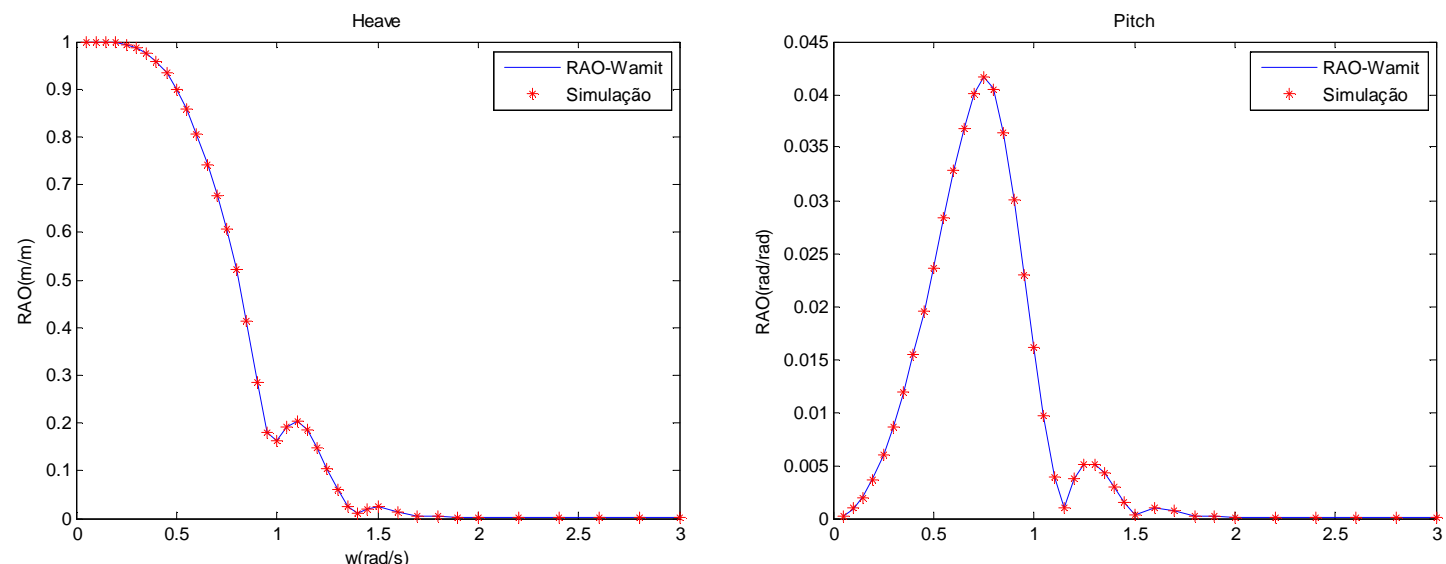

Figura 25: Incidência de $180^{\circ}$ (Proa)

\subsection{Validação do Modelo do manifold}

Para se determinar o coeficiente de amortecimento vertical do manifold foram feitos ensaios experimentais. Estes ensaios foram realizados em tanque de provas com um sistema simplificado nos quais as embarcações foram simuladas através de movimentos verticais harmônicos impostos.

Em Mello, et al., (2011) se descreve os ensaios realizados pela equipe do TPN em um projeto encomendado pela empresa Subsin que está realizando estudos de viabilidade desta operação, com auxílio da FINEP.

Esta seção descreve as comparações realizadas entre os resultados experimentais e as simulações numéricas do modelo simplificado desenvolvido sob as mesmas condições. As simulações consideraram a imposição do movimento no topo da linha de içamento, tal como feito no ensaio experimental. O objetivo desta comparação era a validação do modelo dinâmico do sistema 
manifold incluindo as linhas, bem como o ajuste do seu coeficiente de amortecimento linear e quadrático.

O experimento foi realizado numa escala de 1:35 uma profundidade de $100 \mathrm{~m}$, com as configurações geométricas apresentadas na Figura 26.
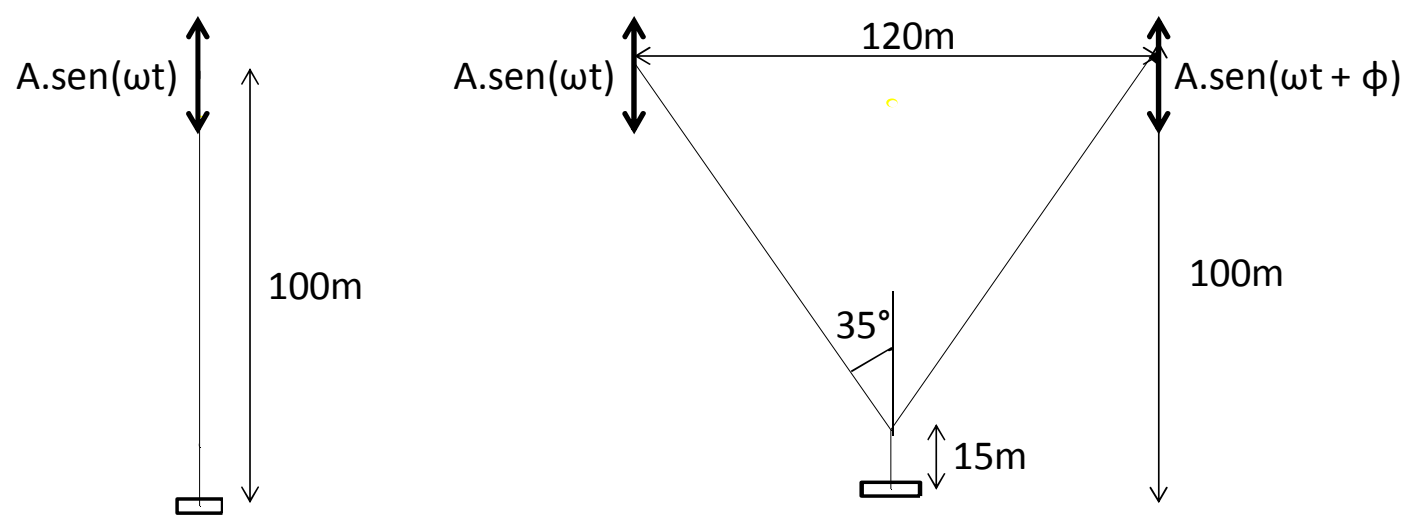

Figura 26: Configuração do ensaio: (esq.) Método Convencional; (dir.) Método Y

\subsubsection{Aparato Experimental}

Nesta seção apresenta-se o aparato experimental utilizado para a realização dos ensaios de análise de lançamento do manifold, utilizando o método convencional e o Método $Y$ (Figura 27).
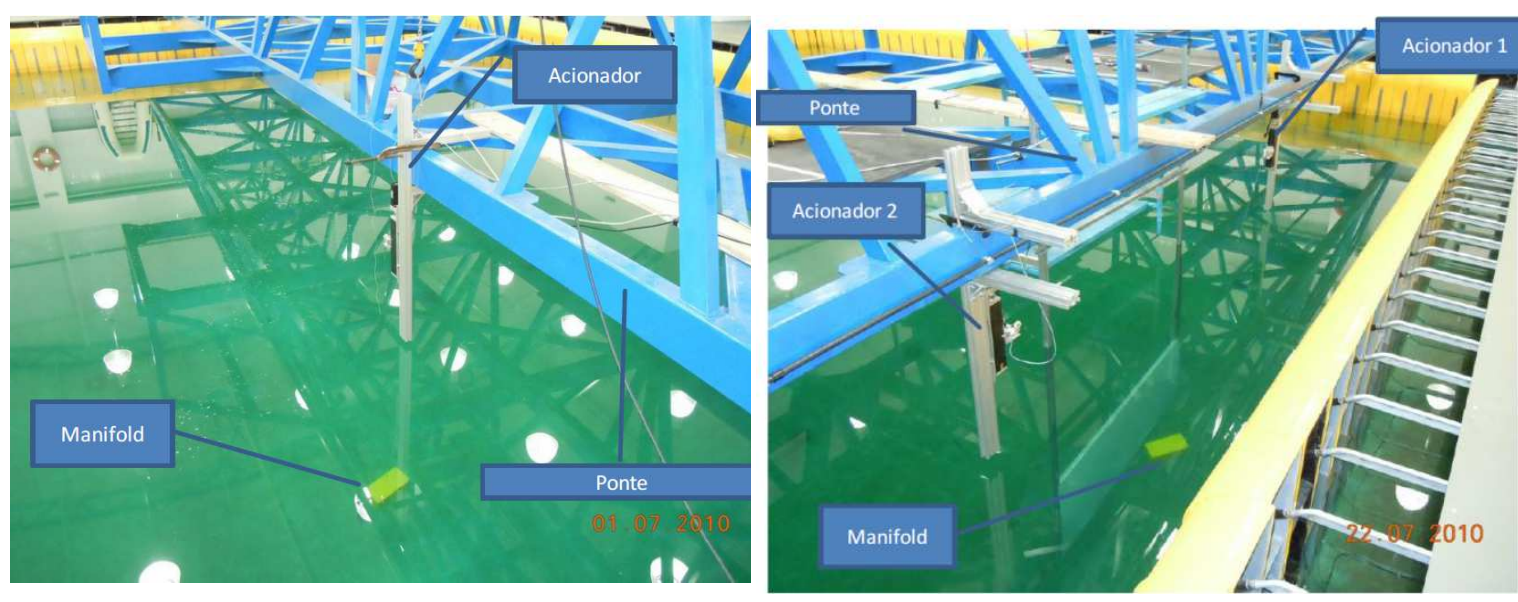

Figura 27: Montagem experimental dos ensaios: (esq.) Lançamento convencional; (dir.) Método Y

Para simular as embarcações, foram projetados sistemas que simulam 0 movimento vertical do ponto de conexão com os cabos de içamento. Sistemas que medem as forças nos cabos também foram projetados. 
Os principais componentes são: dois servos acionadores, um microcontrolador para gerar o sinal senoidal de referencial e células de carga para medir a forças no cabo e o modelo do manifold.

Para excitação do movimento vertical nas linhas, foram projetados e construídos dois servo-acionadores lineares (Figura 28). Eles possuem uma potência de $400 \mathrm{~W}$ e um deslocamento total de 0,28m. Estes equipamentos simulam o movimento vertical que as ondas induzem no navio.

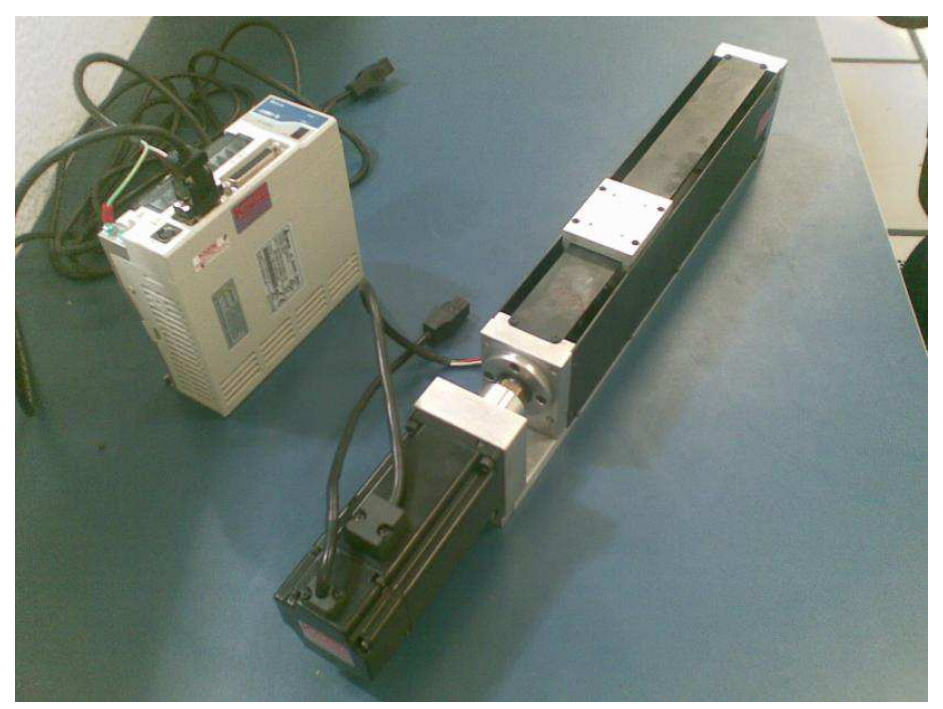

Figura 28: Servo-acionadores lineares

Um sistema eletrônico microprocessado de comando (Figura 29) também foi projetado e construído, para a geração dos pulsos de controle para geração de movimento senoidal pelo servo-acionador.

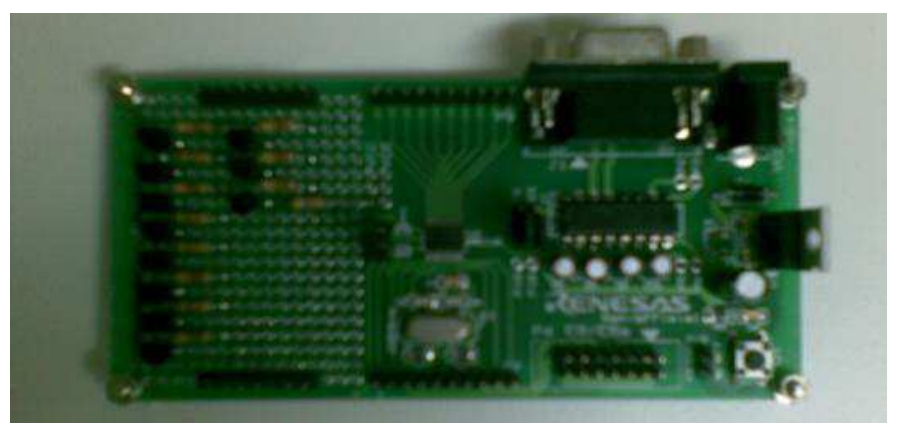

Figura 29: Microprocessador gerador de pulsos de controle

Um programa desenvolvido em linguagem $\mathrm{C}$ envia, pela porta serial, a amplitude, frequência, número de ciclos e diferença de fase às duas placas de geração de pulsos. Um algoritmo de inicialização e finalização suaves do 
ensaio (fade-in, fade-out) também foi implementado, para evitar início ou finalização brusca do ensaio.

Foram utilizadas células de carga (Figura 30) de fundo de escala de 10kgf, montadas sobre o carro do acionador linear e ligadas aos cabos por meio de roldanas de baixo atrito.

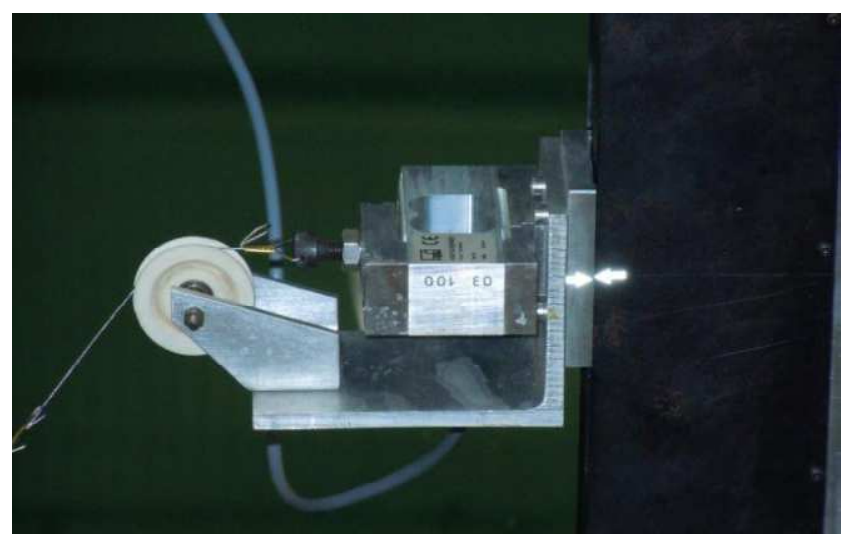

Figura 30: Célula de Carga

Um sistema de aquisição de dados e condicionamento dos sinais da célula de carga também foi utilizado.

\subsubsection{Ensaios realizados}

Os ensaios realizados para o caso convencional são apresentados na Tabela 5 (dados em escala real) e na

Tabela 6 (dados em escala de modelo). Estes ensaios representam as profundidades de $100 \mathrm{~m}$ e $800 \mathrm{~m}$ na escala real da operação. Para a configuração de $100 \mathrm{~m}$, foi utilizado um cabo com comprimento de $2,86 \mathrm{~m}$. Para simular a configuração de $800 \mathrm{~m}$, devido à limitação da profundidade do tanque, foi utilizado o mesmo comprimento do cabo colocando em série com uma mola.

Tabela 5: Ensaios Convencionais - Escala Real

\begin{tabular}{|c|c|c|}
\hline Prof $(\mathrm{m})$ & $\mathrm{AE} / \mathrm{L}(\mathrm{kN} / \mathrm{m})$ & Amplitude Movimento $(\mathrm{m})$ \\
\hline 100 & 17500 & 0,$35 ; 0,54 ; 0,70 ; 0,84 ; 0,98 ; 1,05 ; 1,26$ \\
\hline 800 & 2187,5 & 0,$35 ; 0,54 ; 0,70 ; 0,84 ; 0,98 ; 1,05 ; 1,26 ; 1,33 ; 1,40$ \\
\hline
\end{tabular}

Tabela 6: Ensaios Convencionais - Escala Ensaio

\begin{tabular}{|c|c|c|}
\hline Prof $(\mathrm{m})$ & AE/L $(\mathrm{kN} / \mathrm{m})$ & \multicolumn{1}{|c|}{ Amplitude Movimento $(\mathrm{cm})$} \\
\hline 2,86 & $14,29(\mathrm{cabo})$ & 1,$00 ; 1,54 ; 2,00 ; 2,40 ; 2,80 ; 3,00 ; 3,60$ \\
\hline 2,86 & $\begin{array}{l}1,79(\text { cabo }+ \\
\text { mola em série) }\end{array}$ & 1,$00 ; 1,54 ; 2,00 ; 2,40 ; 2,80 ; 3,00 ; 3,60 ; 3,80 ; 4,00$ \\
\hline
\end{tabular}


Os ensaios realizados para o caso do Método $Y$ são apresentados na Tabela 7 (escala real) e Tabela 8 (escala de modelo). Os cabos utilizados neste ensaio são feitos de aço, cujo módulo de resistência à tração $(E A=1750 \mathrm{MN})$. A rigidez deste cabo em escala real é de $17500 \mathrm{kN} / \mathrm{m}$ e na escala do ensaio é de 14,29 $\mathrm{kN} / \mathrm{m}$ para a profundidade real de $100 \mathrm{~m}$. Para a profundidade de $800 \mathrm{~m}$ a rigidez do cabo real é de $2187,5 \mathrm{kN} / \mathrm{m}$ enquanto para a escala de ensaio é de $1,79 \mathrm{kN} / \mathrm{m}$.

Tabela 7: Ensaios Método Y - Escala Real

\begin{tabular}{|c|c|l|}
\hline Prof. $(\mathrm{m})$ & $\begin{array}{l}\text { Diferença de } \\
\text { Fase (graus) }\end{array}$ & \multicolumn{1}{c|}{ Amplitude Movimento (m) } \\
\hline 100 & 0 & $\begin{array}{l}0,35 ; 0,54 ; 0,70 ; 0,84 ; 0,98 ; 1,05 ; 1,26 ; 1,33 ; 1,40 ; 1,50 ; 1,65 ; \\
1,85 .\end{array}$ \\
\hline 100 & 30 & 0,$35 ; 0,84 ; 1,05 ; 1,33 ; 1,50 ; 1,85$ \\
\hline 100 & 60 & 0,$35 ; 0,84 ; 1,05 ; 1,33 ; 1,50 ; 1,85$ \\
\hline 100 & 90 & 0,$35 ; 0,84 ; 1,05 ; 1,33 ; 1,50 ; 1,85$ \\
\hline 100 & 120 & 0,$35 ; 0,84 ; 1,05 ; 1,33 ; 1,50 ; 1,85$ \\
\hline 100 & 150 & 0,$35 ; 0,84 ; 1,05 ; 1,33 ; 1,50 ; 1,85$ \\
\hline 100 & 180 & $\begin{array}{l}0,35 ; 0,54 ; 0,70 ; 0,84 ; 0,98 ; 1,05 ; 1,26 ; 1,33 ; 1,40 ; 1,50 ; 1,65 ; \\
1,85 .\end{array}$ \\
\hline
\end{tabular}

Tabela 8: Ensaios Método Y - Escala Ensaio

\begin{tabular}{|c|c|l|}
\hline Prof. $(\mathrm{m})$ & $\begin{array}{l}\text { Diferença de } \\
\text { Fase (graus) }\end{array}$ & \multicolumn{1}{c|}{ Amplitude Movimento $(\mathrm{cm})$} \\
\hline 2,86 & 0 & $\begin{array}{l}1,00 ; 1,54 ; 2,00 ; 2.40 ; 2,80 ; 3,00 ; 3,60 ; 3,80 ; 4,00 ; 4,29 ; 4,71 ; \\
5,27 .\end{array}$ \\
\hline 2,86 & 30 & 1,$00 ; 2.40 ; 3,00 ; 3,80 ; 4,29 ; 5,27$ \\
\hline 2,86 & 60 & 1,$00 ; 2.40 ; 3,00 ; 3,80 ; 4,29 ; 5,27$ \\
\hline 2,86 & 90 & 1,$00 ; 2.40 ; 3,00 ; 3,80 ; 4,29 ; 5,27$ \\
\hline 2,86 & 120 & 1,$00 ; 2.40 ; 3,00 ; 3,80 ; 4,29 ; 5,27$ \\
\hline 2,86 & 150 & 1,$00 ; 2.40 ; 3,00 ; 3,80 ; 4,29 ; 5,27$ \\
\hline 2,86 & 180 & $\begin{array}{l}1,00 ; 1,54 ; 2,00 ; 2.40 ; 2,80 ; 3,00 ; 3,60 ; 3,80 ; 4,00 ; 4,29 ; 4,71 ; \\
5,27\end{array}$ \\
\hline
\end{tabular}

\subsubsection{Estimação dos valores de amortecimento linear e quadrático}

Os valores do amortecimento linear e quadrático foram obtidos variando-se 0 valor do amortecimento linear $C_{1 z}$ da equação (3.7) entre 300 e 600 kN.s/m e o coeficiente de arrasto $C_{D}$ do coeficiente de amortecimento quadrático $C_{2 z}$ entre 2.5 a 5 .

O critério utilizado para se determinar a melhor combinação é baseado na minimização do funcional $E_{G}$ apresentado pela expressão abaixo. 
$E_{i}=\frac{\sum \frac{\left|X e n s_{i, \text { Max }}^{j}-X \operatorname{sim}_{i, \text { Max }}^{j}\right|}{\bar{X} e n s_{i}^{j}}+\frac{\left|X e n s_{i, \text { Min }}^{j}-X \operatorname{sim}_{i, \text { Min }}^{j}\right|}{\bar{X} e n s_{i}^{j}}}{2 n}$

$E_{G}=\frac{\sum E_{i}}{5}$

Na qual:

$i$ : índice do ensaio considerado para a calibração do modelo. Foram considerados cinco ensaios: lançamento convencional com profundidades de $100 \mathrm{~m}$ e $800 \mathrm{~m}$ e ensaios em $\mathrm{Y}$ com defasagem de $0^{\circ}, 90^{\circ}$ e $180^{\circ}$ entre movimentos de topo impostos.

j: índice da amplitude de onda regular simulada em cada ensaio. Este número varia de ensaio para ensaio.

$n$ : número de amplitudes de onda consideradas no ensaio.

Xens $_{i, \text { Max }}^{j}$, Xens $_{i, \text { Min }}^{j}$ : Valor máximo e mínimo das trações para cada amplitude de onda $j$ do ensaio $i$.

$X \operatorname{sim}_{i, \text { Max }}^{j}, X \operatorname{sim}_{i, \text { Min }}^{j}$ : Valor máximo e mínimo das trações para cada amplitude de onda $j$ da simulação numérica do ensaio $i$.

$\bar{X} e n s_{i}^{j}$ : Valor médio da tração no cabo de içamento do ensaio.

$E_{i}$ : Erro percentual ponderado do ensaio $i$.

$E_{G}$ : Erro percentual ponderado global

Neste critério foram comparados os valores das trações máximas e trações mínimas do ensaio experimental e das simulações para cada um dos valores do amortecimento linear e quadrático. Estes valores foram ponderados pelo valor médio do ensaio. Isto porque para as simulações com amplitudes de onda maiores os valores das trações se tornam altos dificultando a recuperação através do modelo numérico e, portanto obtendo grandes erros relativos. Isto poderia privilegiar a seleção dos melhores parâmetros apenas para os valores de grandes amplitudes da onda. 
O resultado desta calibração apresentada em uma curva de nível é apresentado na Figura 31. A barra lateral indica o valor de erro associado a cada cor.

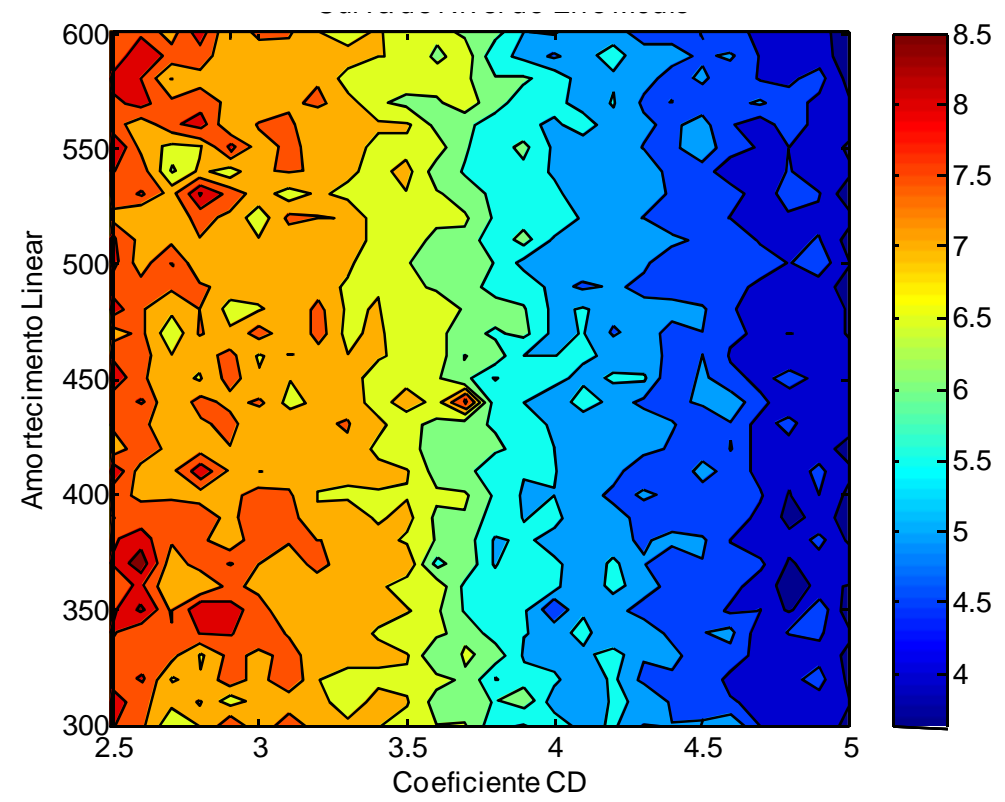

Figura 31: Erro percentual ponderado para cada um dos valores do amortecimento linear e quadrático

O fator predominante para a avaliação do erro ponderado é a parcela quadrática. Observa-se que o valor do Erro ponderado médio varia de 8,5\% para o coeficiente $C_{D}$ de 2,5 até um valor de quase $4 \%$ para o coeficiente $C_{D}$ de 5. Desta maneira foi escolhido o valor do coeficiente de arrasto $C_{D}$ igual a 50 que equivale ao valor de $173 \mathrm{kN} . \mathrm{s}^{2} / \mathrm{m}^{2}$ calculado a partir da equação (3.8). De posse do valor do coeficiente de amortecimento quadrático foi traçado um gráfico apenas com a variação do valor do amortecimento linear (Figura 32). Embora não haja uma tendência claramente definida, escolheu o ponto de mínimo valor do erro ponderado, obtendo-se $530 \mathrm{kN}$.s $/ \mathrm{m}$ para o coeficiente de amortecimento linear. 


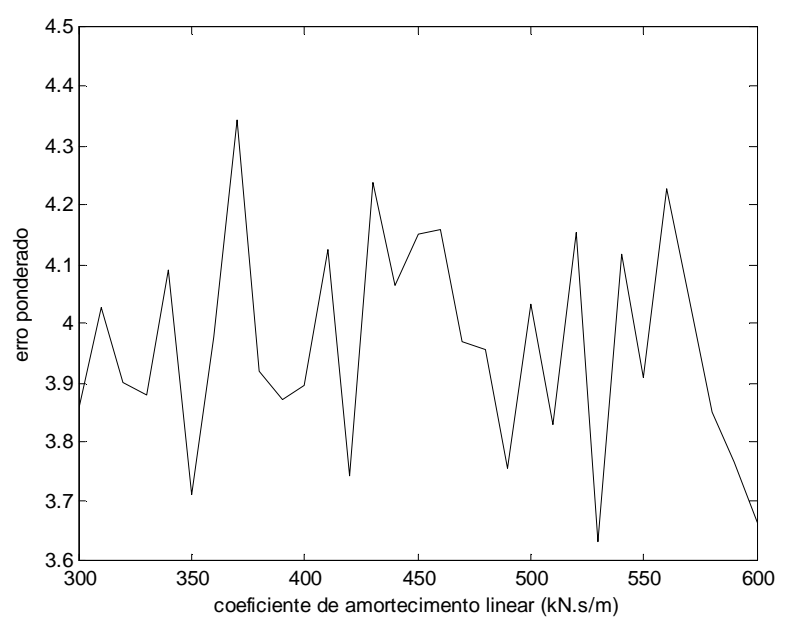

Figura 32: Estimação coeficiente de amortecimento linear

\subsubsection{Resultado da Calibração}

Como mencionado, a calibração dos parâmetros considerou 5 ensaios diferentes. Nesta seção, apresentam-se os resultados comparativos entre a tração medida no experimento e a calculada por simulação, considerando-se os ensaios usados no processo de calibração. Na seção seguinte, o modelo numérico é usado para prever a tração nas linhas de içamento para outros ensaios que não foram usados no processo de calibração.

Para os experimentos de lançamento convencional, sob duas profundidades $100 \mathrm{~m}$ e $800 \mathrm{~m}$, os resultados são apresentados na Figura 33. Nos gráficos, apresentam-se o valor máximo e mínimo da tração ao longo de um ciclo, obtidos por simulação e medidos nos ensaios, para diversas amplitudes de movimentos impostos.
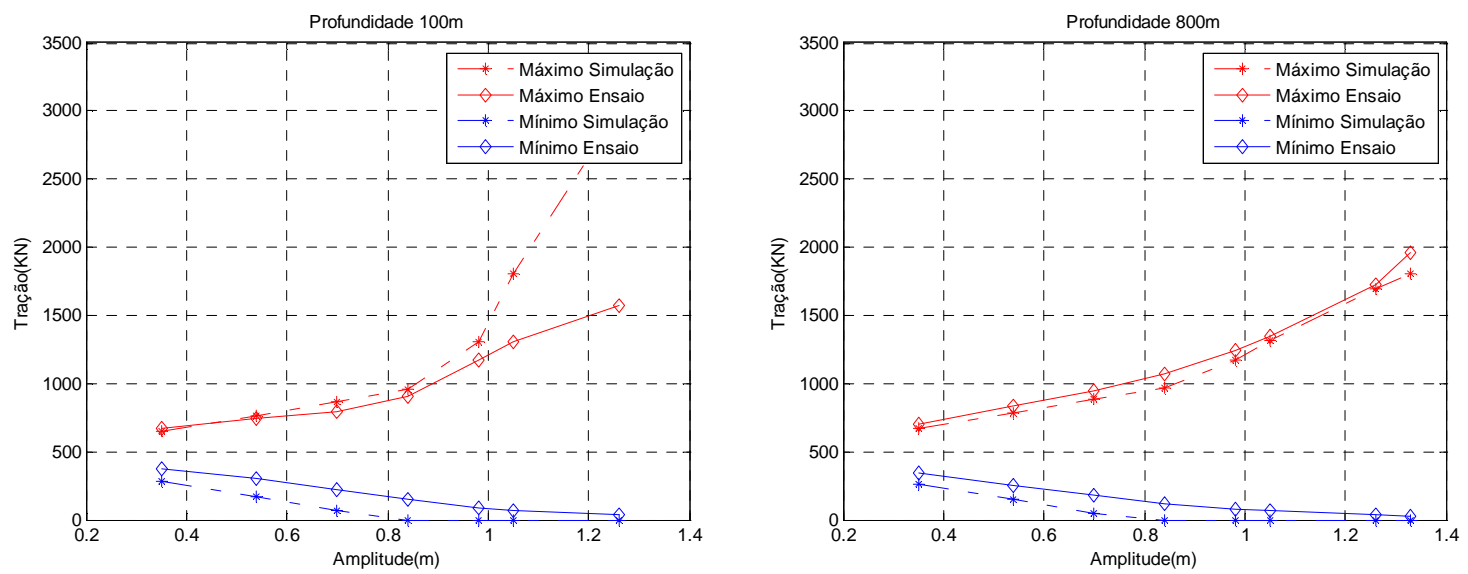

Figura 33: Lançamento Convencional - comparação Ensaios e Simulações 
$\mathrm{Na}$ Figura 34 são apresentadas as séries temporais do lançamento convencional para as amplitudes de onda de $0,54 \mathrm{~m}, 0,98 \mathrm{~m}$ e $1,26 \mathrm{~m}$.

\section{Amplitude de $0,54 \mathrm{~m}$}
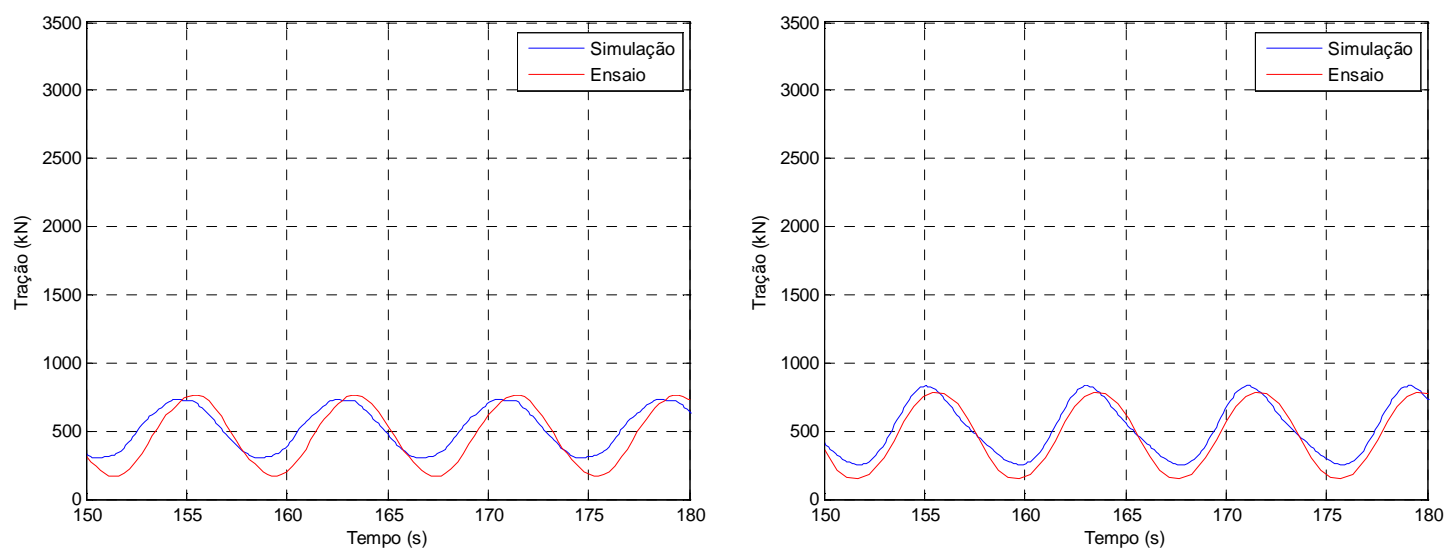

Amplitude de 0,98m
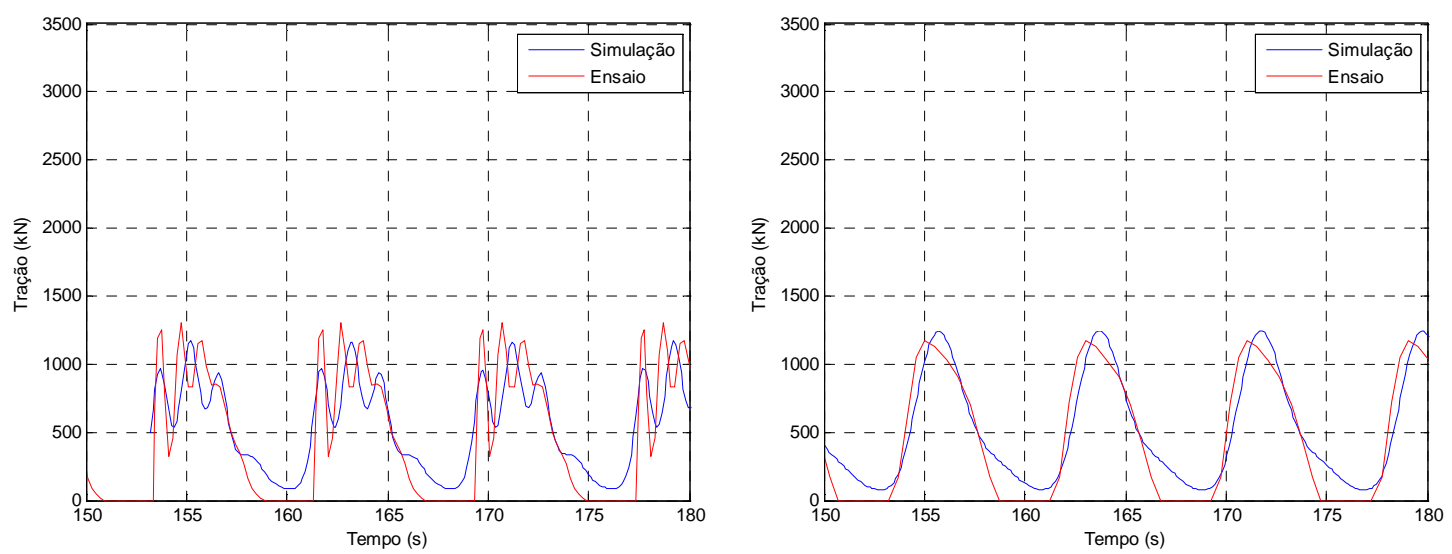

Amplitude de 1,26m
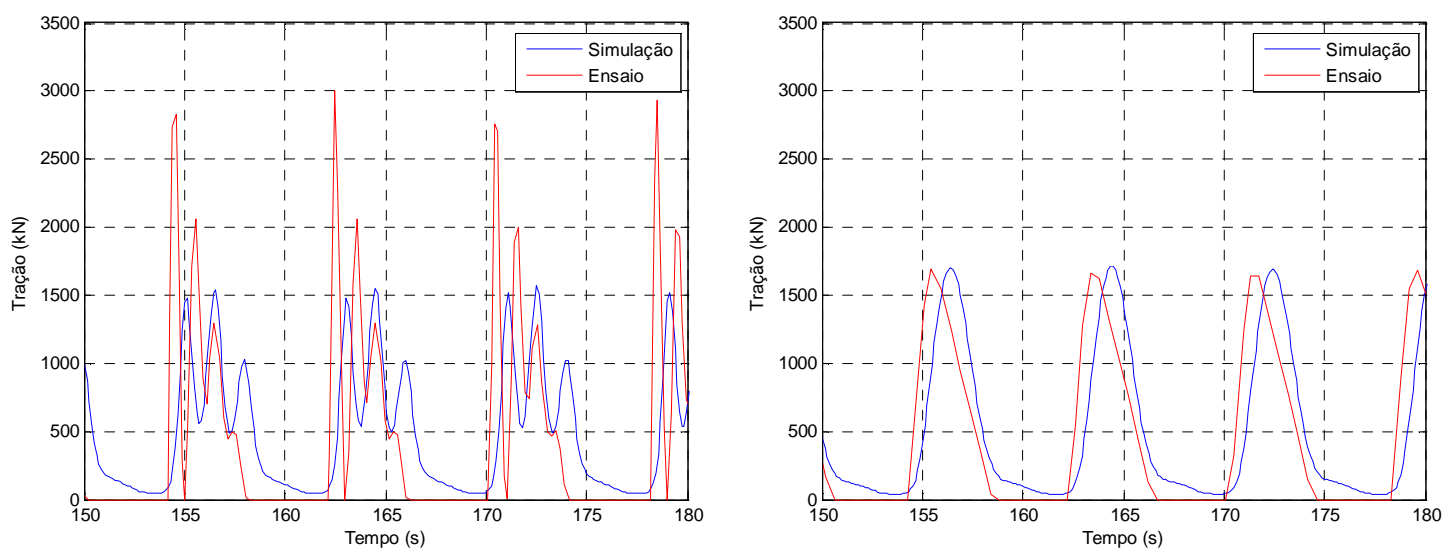

Figura 34: Simulações Método Convencional 100m (esquerda) 800m (direita) 
Analisando as séries acima se conclui que:

- Para amplitudes pequenas, quando não ocorre afrouxamento no cabo, o modelo numérico recupera bem os valores da tração do ensaio.

- Aumentando-se os valores das amplitudes o modelo numérico recupera o momento que começa a ocorrer o afrouxamento no cabo apesar de não recuperar exatamente o valor das trações máximas.

- Para valores de amplitudes altas, o modelo numérico não consegue recuperar os picos de amplitude da tração, porém a forma do gráfico é coerente com o ensaio.

- A tração no ensaio, embora alcance valores muito baixos, não assume valor nulo. Isto pode ser explicado por pequenos offsets no sistema de medição baseado em células de carga.

Posteriormente realizaram-se ensaios utilizando 0 método $Y$ para $a$ profundidade de $100 \mathrm{~m}$ e considerando-se três defasagens dos movimentos $\left(0^{\circ}\right.$, $90^{\circ}$ e $180^{\circ}$ ). A Figura 35 apresenta os resultados comparativos.
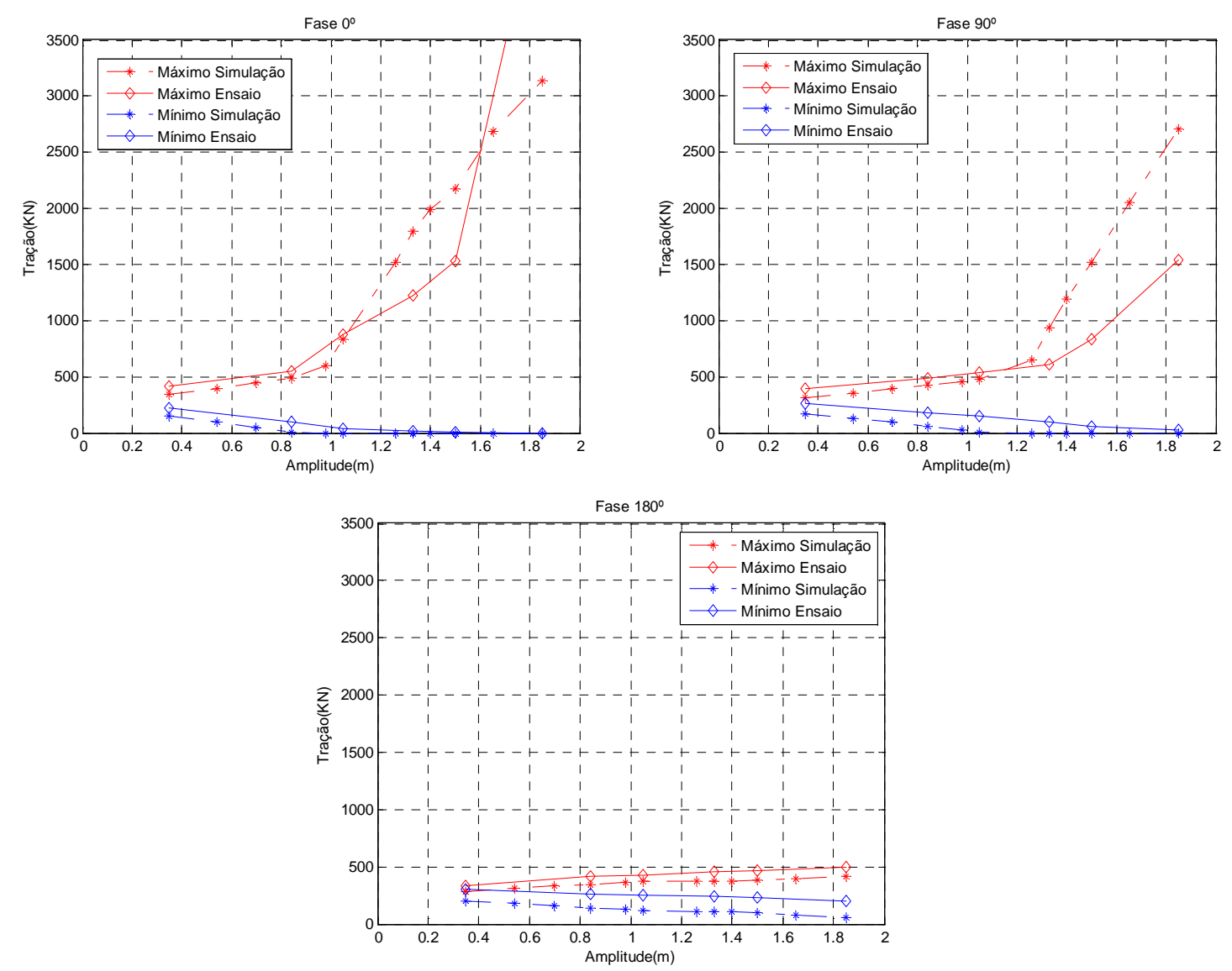

Figura 35: Calibração Modelo Y 
Na Figura 36 são apresentadas as séries temporais para o caso de amplitude de $1,5 \mathrm{~m}$ para as defasagens de $0^{\circ}, 90^{\circ}$ e $180^{\circ}$. Escolheu-se um dos cabos para se realizar a comparação, mas o comportamento de ambos é bastante semelhante.

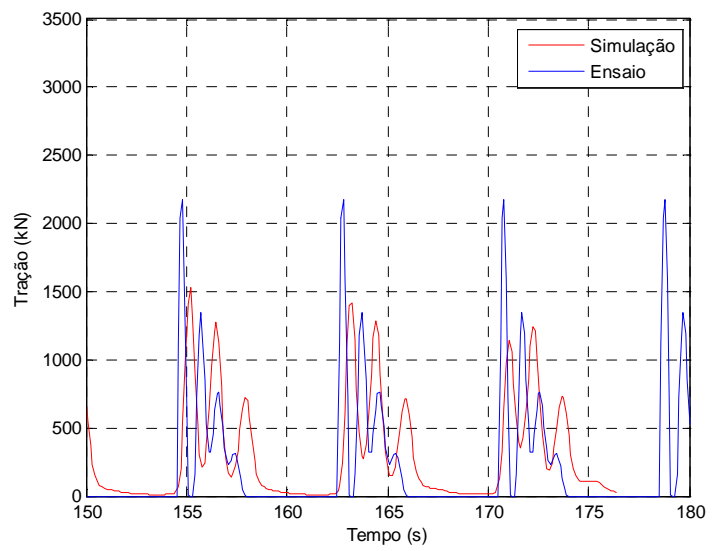

$0^{\circ}$ de defasagem

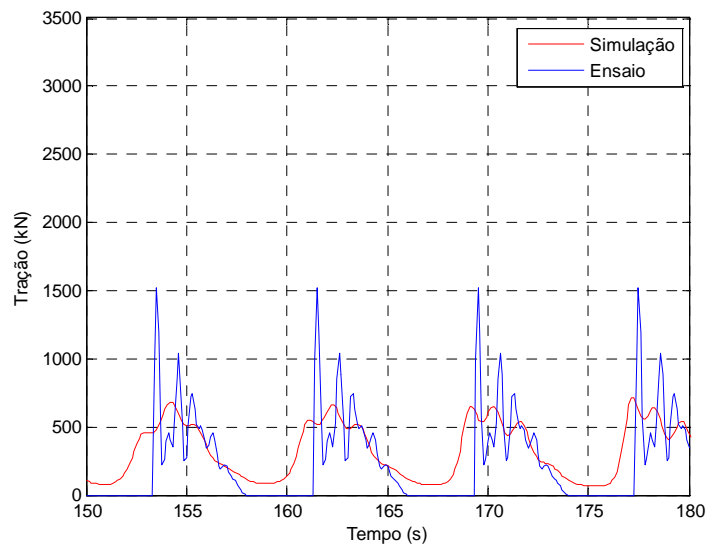

$90^{\circ}$ de defasagem

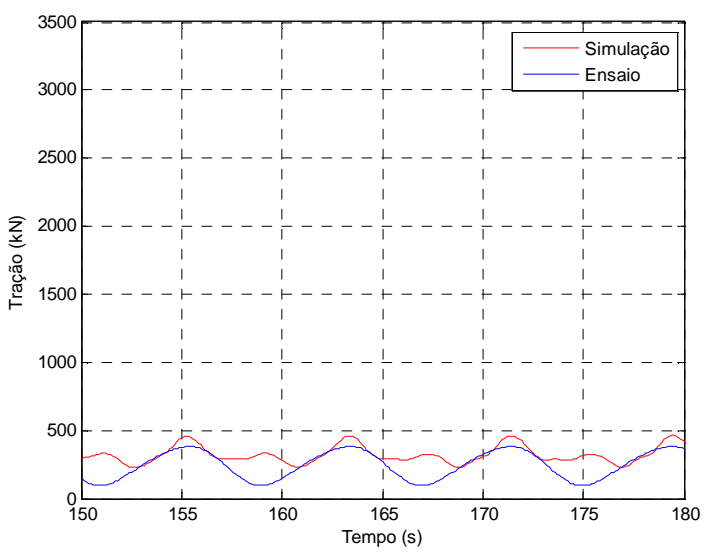

$180^{\circ}$ de defasagem

Figura 36: Simulações Método Y: Comparação das trações do ensaio e do modelo numérico

Analisando as séries acima se conclui que:

- Para a defasagem de $180^{\circ}$ as amplitudes do movimento são pequenas, portanto não ocorre afrouxamento no cabo e o modelo numérico recupera bem os valores da tração do ensaio.

- Para a defasagem de $90^{\circ}$ o modelo numérico recupera o momento que começa a ocorrer o afrouxamento no cabo apesar de não recuperar exatamente o valor das trações máximas.

- Para a defasagem de $0^{\circ}$ o modelo numérico não consegue recuperar os picos de amplitude da tração, porém a forma do gráfico é coerente com o ensaio. 


\subsubsection{Resultado da Validação}

A Figura 37 apresenta os casos que não foram utilizados na calibração dos parâmetros do coeficiente de amortecimento linear e quadrático. Esta validação tem o objetivo de mostrar que mesmo estes casos que não foram usados na calibração dos coeficientes, o modelo numérico conseguiu recuperar os resultados do ensaio com razoável coerência.
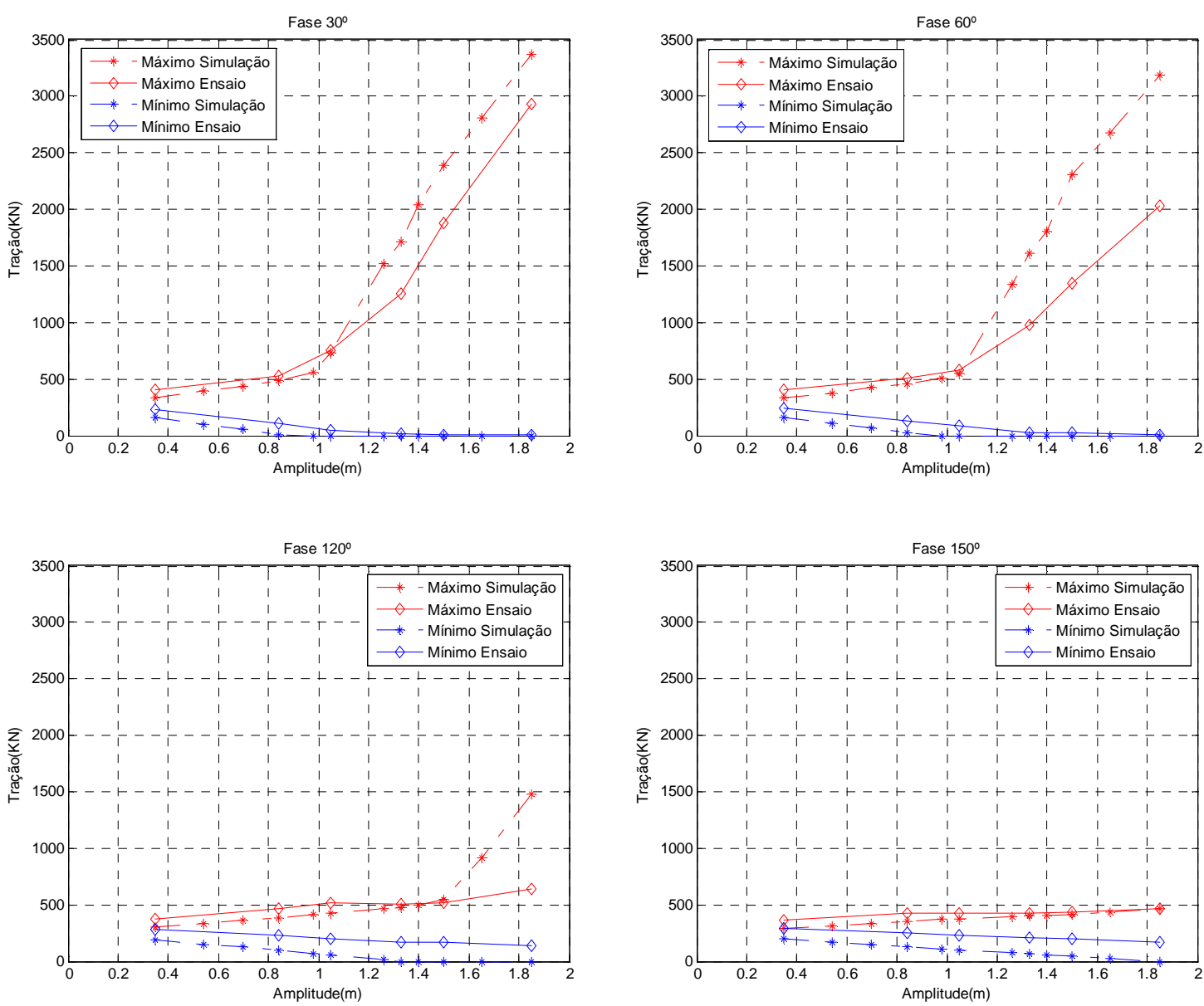

Figura 37: Validação Modelo $Y$

Na Figura 38 são apresentadas as séries temporais para o caso de amplitude de $1,5 \mathrm{~m}$ para as defasagens de $30^{\circ}, 60^{\circ}, 120^{\circ}$ e $150^{\circ}$. 


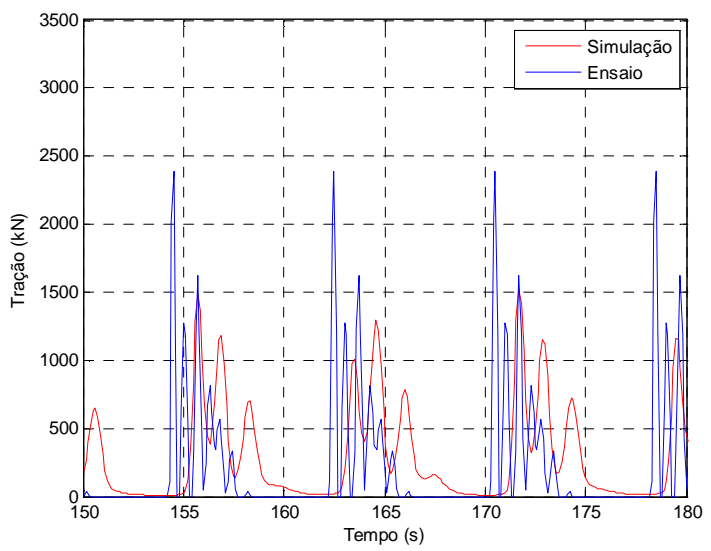

$30^{\circ}$ de defasagem

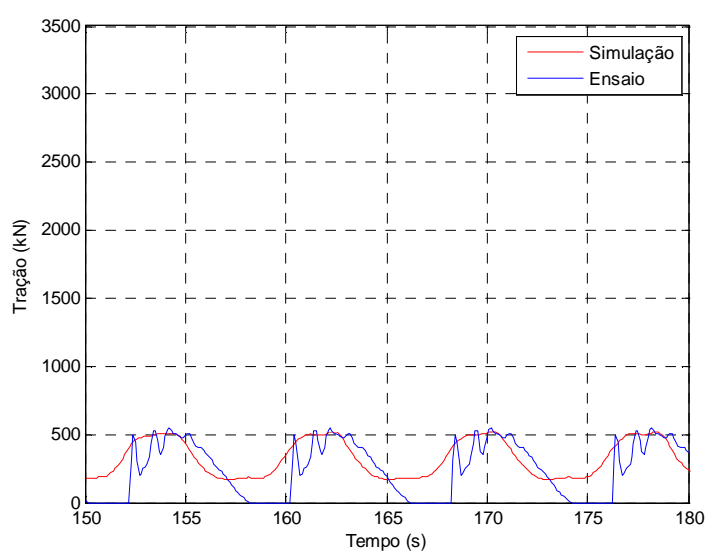

$120^{\circ}$ de defasagem

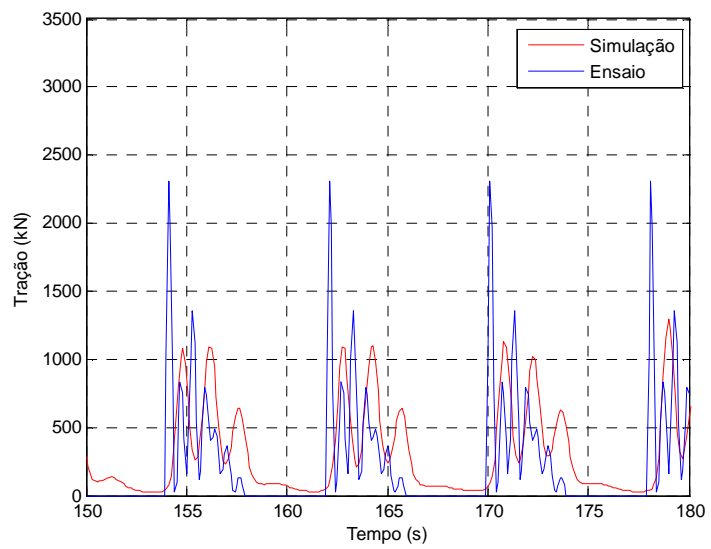

$60^{\circ}$ de defasagem

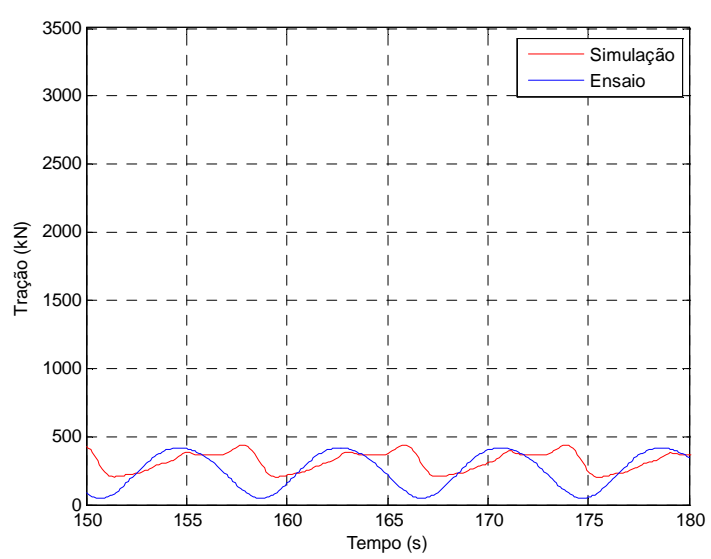

$150^{\circ}$ de defasagem

Figura 38: Séries Temporais Validação Modelo Y

Analisando estas séries temporais as mesmas conclusões dos resultados da calibração podem ser atribuídas. Desta forma considera-se o modelo da dinâmica do movimento do manifold validado, pois estes ensaios não foram utilizados na calibração dos coeficientes, mas mesmo assim o modelo numérico recuperou os resultados do ensaio experimental.

Logo foi possível caracterizar o fenômeno do afrouxamento do cabo. $O$ afrouxamento do cabo (Figura 39) é causado pelo rápido movimento induzido do manifold. Devido ao arrasto, o movimento de descida do equipamento é menor que o lançamento do cabo, assim o cabo fica frouxo. Quando o movimento se reverte, a grande inércia (massa e a massa adicional) do manifold causa um grande pico de tração no cabo. 


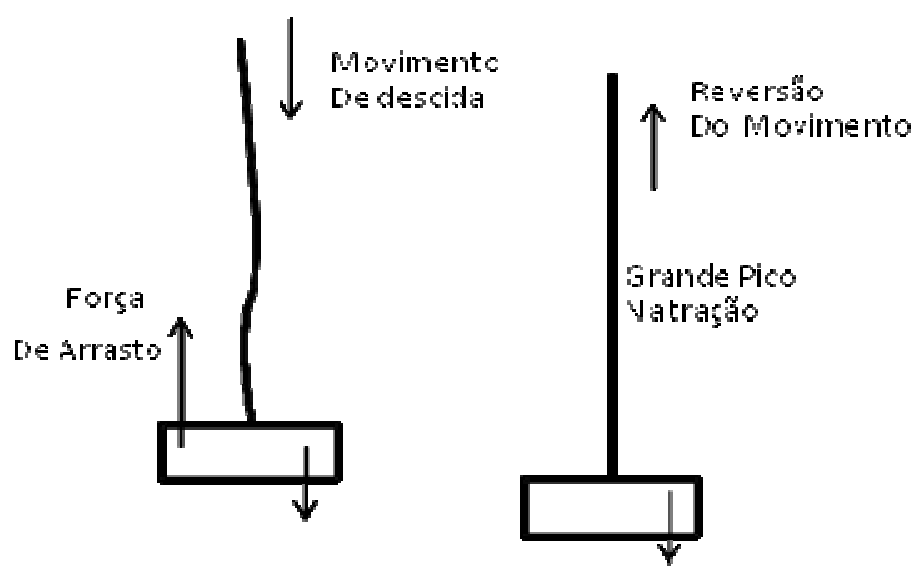

Figura 39: Fenômeno Afrouxamento no Cabo

\subsection{Validação do Modelo Acoplado}

A proposta da dinâmica acoplada foi validada comparando-se com o simulador numérico TPN que contempla um modelo acoplado completo. As simulações foram realizadas considerando-se a distância entre os pontos de conexão das linhas içamento de 120m e 160m (Figura 40).

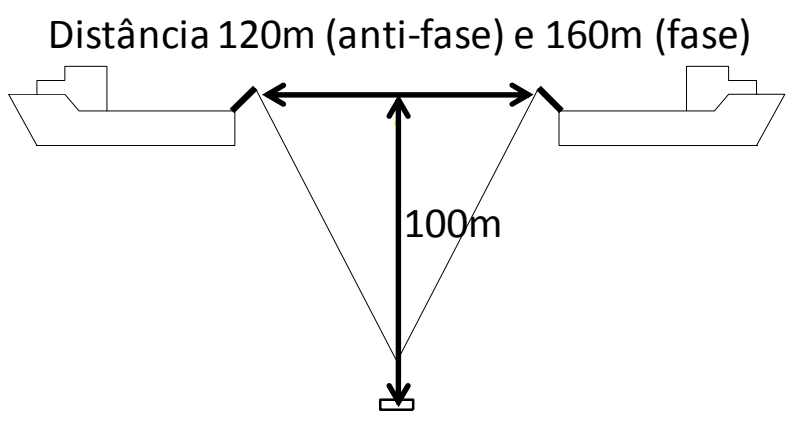

Figura 40: Consideração das simulações do Método Y

Para uma onda com período de $8 \mathrm{~s}$, os dois pontos de conexão apresentam movimentos de oposição de fase para uma distância de $120 \mathrm{~m}$, enquanto no segundo caso $(160 \mathrm{~m})$ se movimenta em fase.

Foram consideradas três incidências de onda. Uma onda alinhada com a proa, e outras com incidências de $15^{\circ}$ e $30^{\circ}$ em relação à proa (Figura 41). 


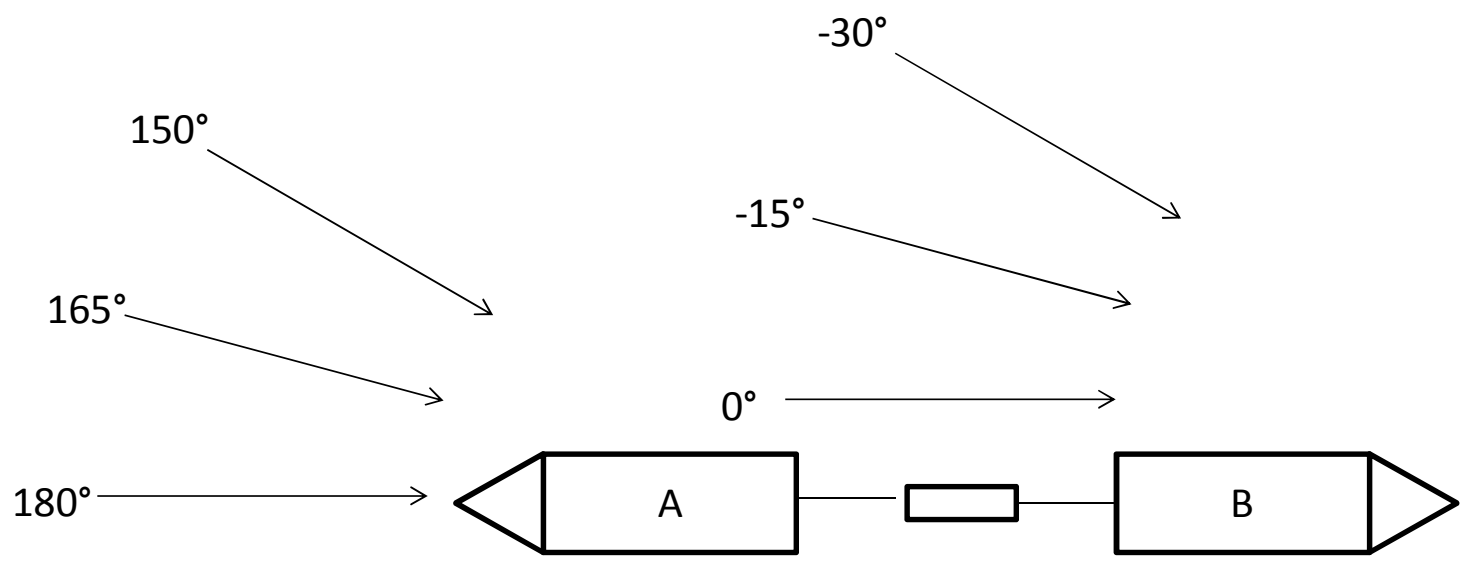

Figura 41: Incidências de onda consideradas nas simulações

Para a simulação com a distância de $120 \mathrm{~m}$ (Figura 42) não ocorreu afrouxamento. Isto era esperado, pois os pontos de conexão estão sujeitos a movimentos em oposição de fase. Neste caso, o modelo proposto recuperou os valores do simulador TPN.

Para a distância de 160m (Figura 43), os pontos de conexão se moviam em fase levando a trações elevadas e afrouxamentos no cabo. O modelo proposto recuperou o comportamento do gráfico das tensões.

Dado que a proposta deste modelo é ser utilizado para o projeto de controle e análise do comportamento da dinâmica, pode-se considerar o resultado aceitável. Muitos efeitos dinâmicos modelados no TPN podem explicar tais diferenças como os movimentos angulares do manifold e os movimentos fora do plano considerado (Figura 20), bem como a dinâmica da linha devido a sua massa própria. 
Incidência de Onda: $180^{\circ}$
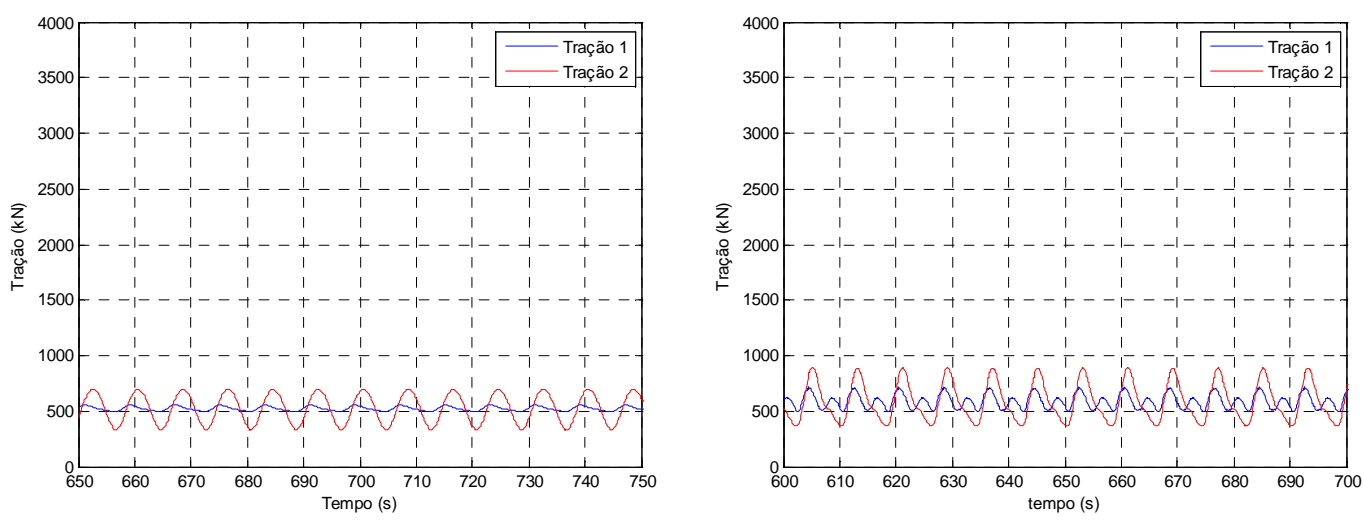

Incidência de Onda: $165^{\circ}$
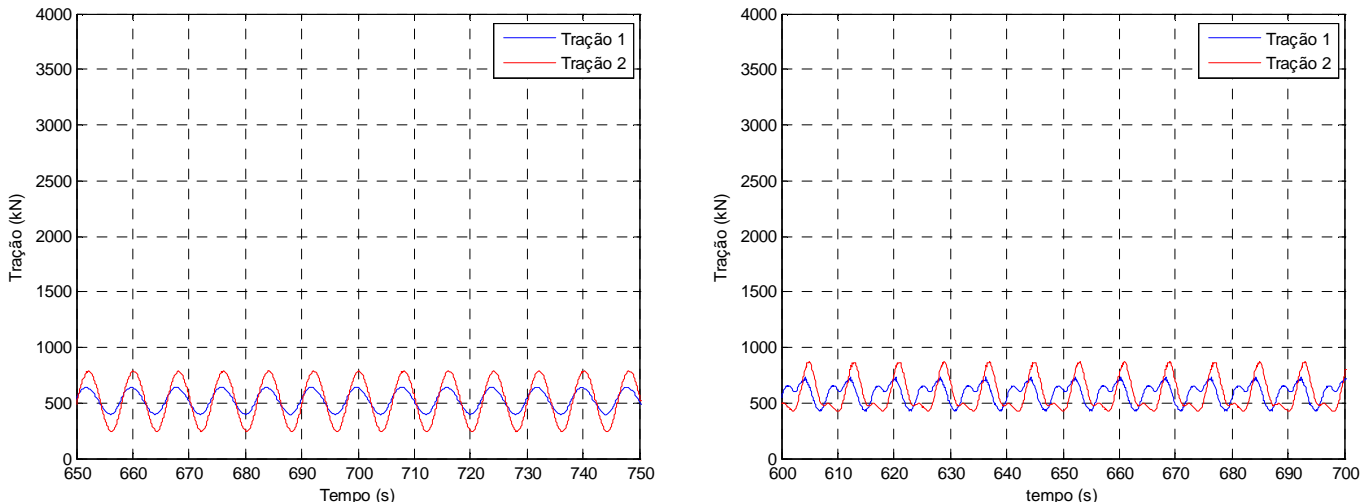

Incidência de Onda: $150^{\circ}$
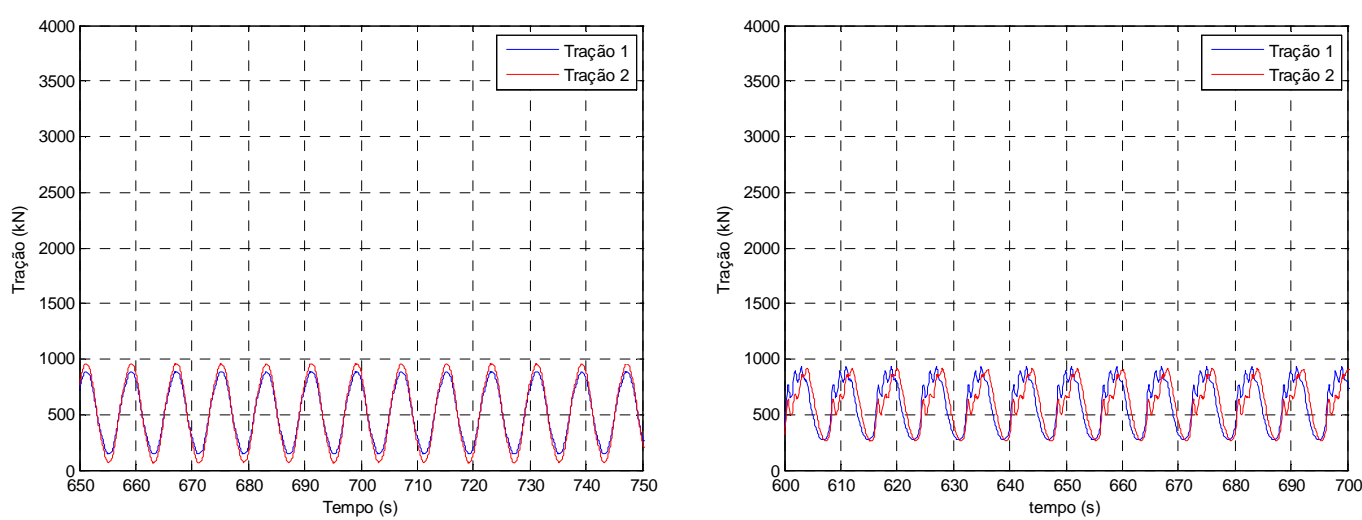

Figura 42: Simulação distância de 120m entre as os pontos de conexão: Modelo Desenvolvido (esq) TPN (dir) 
Incidência de Onda: $180^{\circ}$
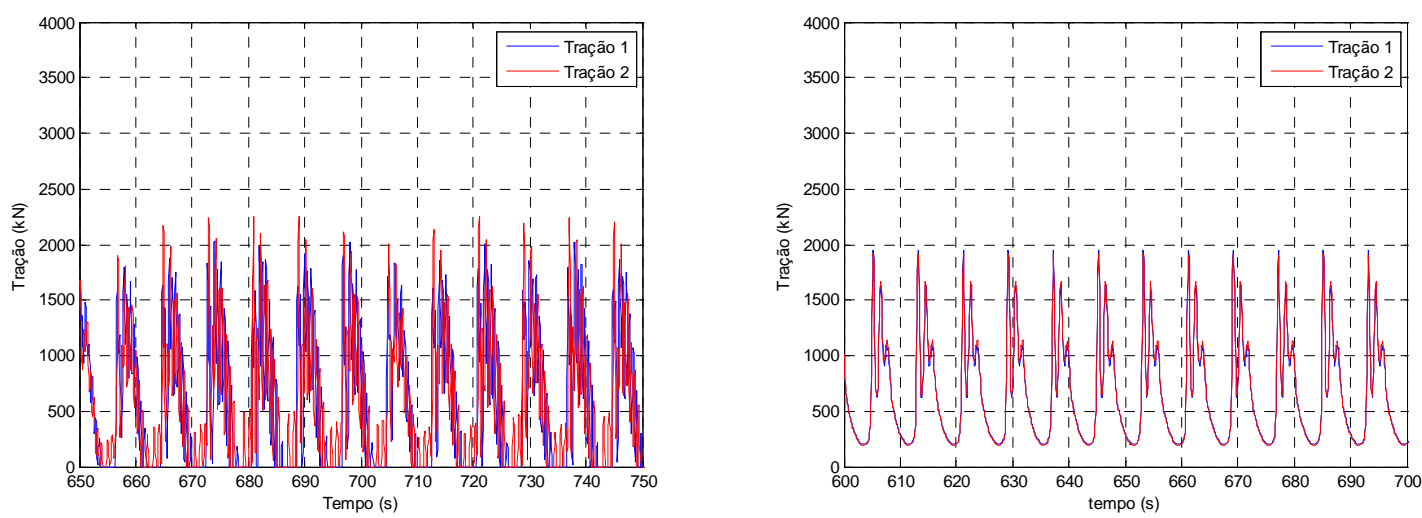

Incidência de Onda: $165^{\circ}$
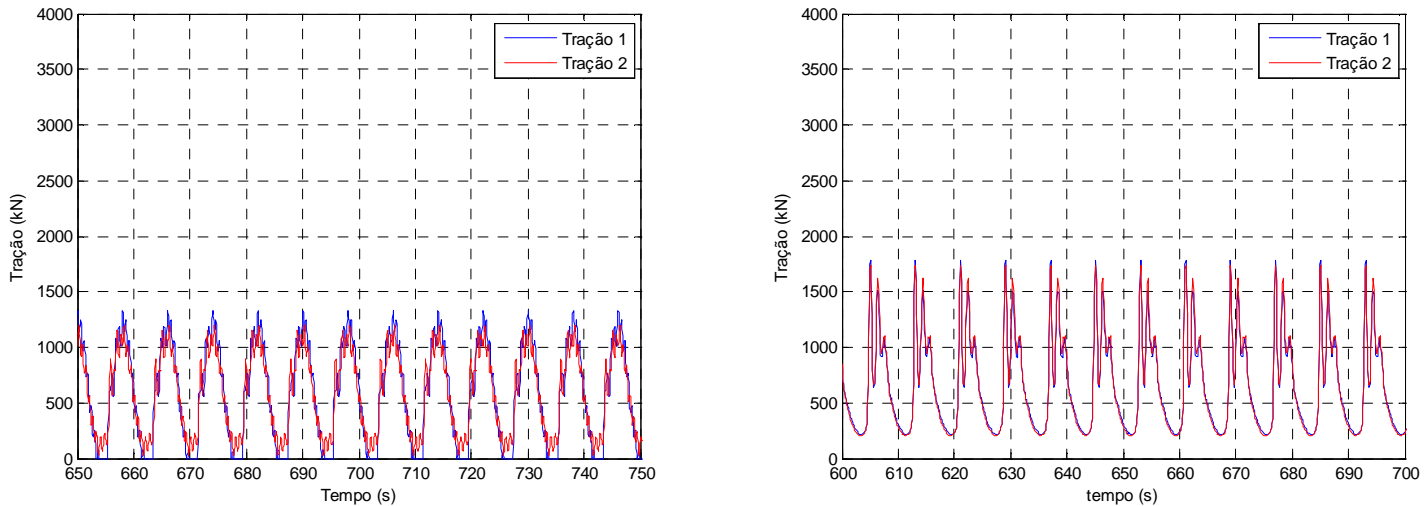

Incidência de Onda: $150^{\circ}$
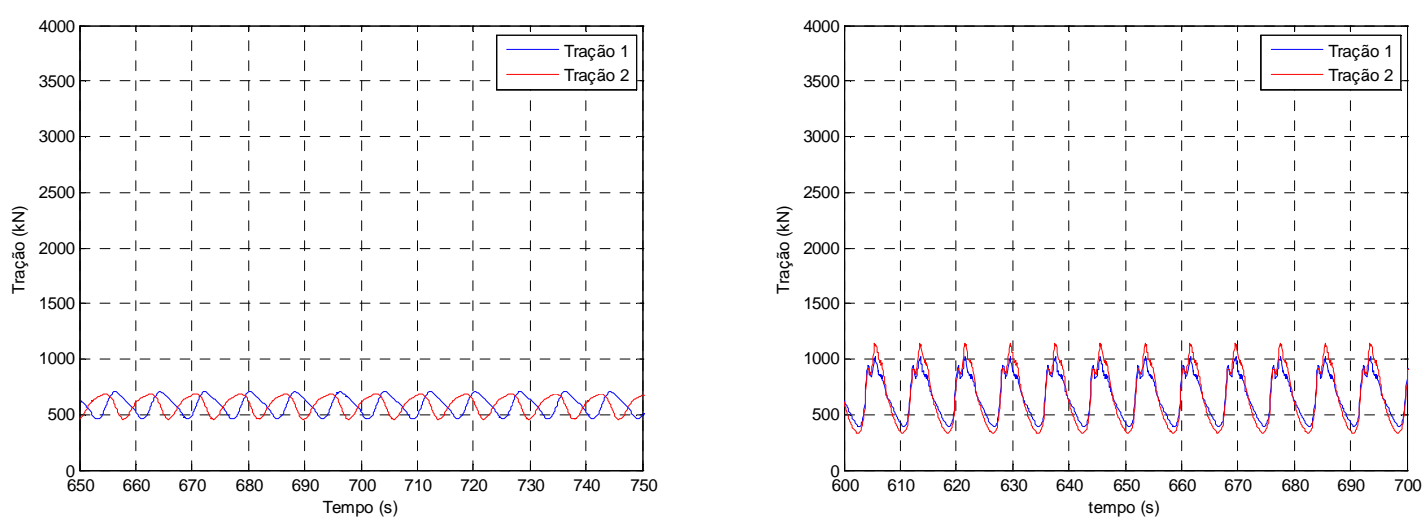

Figura 43: Simulação distância de 160m entre os pontos de conexão: Modelo Desenvolvido (esq) TPN (dir) 


\section{Análise Dinâmica}

Nesta seção, apresenta-se a análise da dinâmica do sistema completo (embarcações, linhas e manifold) considerando-se a variação de diversos parâmetros, tais como: distância entre embarcações, profundidade do manifold e características da onda incidente.

Os resultados serão apresentados sob a forma de "mapas dinâmicos", que correspondem aos gráficos de cores indicando parâmetros operacionais, como a tração nas linhas ou a ocorrência de afrouxamento. De posse destes mapas, será possível obter conclusões acerca da melhor abordagem para o sistema de posicionamento das embarcações.

Uma análise dinâmica é necessária para o entendimento do presente problema em função dos principais parâmetros operacionais. Em alguns casos, pode-se recorrer a análises estáticas para a definição das estratégias de controle e posicionamento. O trabalho de Tannuri, et. al., (2009) trata da comparação de análise estática e dinâmica na análise de um problema de posicionamento dinâmico.

\subsection{Período da onda pela distância entre as embarcações}

Inicialmente, procedeu-se a elaboração de um mapeamento que indique o comportamento dinâmico do sistema em relação à variação da distância entre os pontos de conexão e do período da onda. Para este mapeamento, conforme é indicado na Figura 44 consideraram-se:

- Ondas regulares com amplitude de $1 \mathrm{~m}$ e $1,4 \mathrm{~m}$

- Períodos da onda entre 3s a 10s.

- Distância variando de $50 \mathrm{~m}$ a $500 \mathrm{~m}$. 


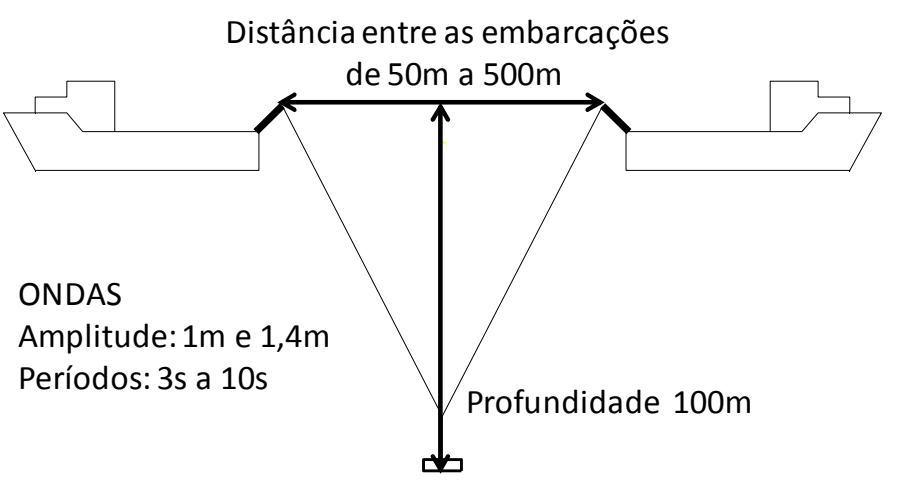

Figura 44: Mapeamento Dinâmico: Distância por período

Nas figuras, a cor verde indica a não ocorrência de afrouxamento (tração sempre maior que zero) e em vermelho a ocorrência deste fenômeno.

Na Figura 45 considera-se a imposição dos movimentos verticais nos pontos de conexão. O ponto de conexão move-se em fase (e sem dinâmica) em relação ao ponto em que ocupa na superfície da onda e ponto de conexão que se move de acordo com a dinâmica do navio. Isto equivale à simulação de ( 3.7 ) apenas.

A análise do movimento imposto foi realizada para se avaliar quais as diferenças entre simular as embarcações como imposição de movimentos verticais (ensaio) e considerando a dinâmica das embarcações.

A Figura 46 e a Figura 47 apresentam o mesmo fenômeno considerando a dinâmica dos navios. 
Amplitude de Onda de $1 \mathrm{~m}$

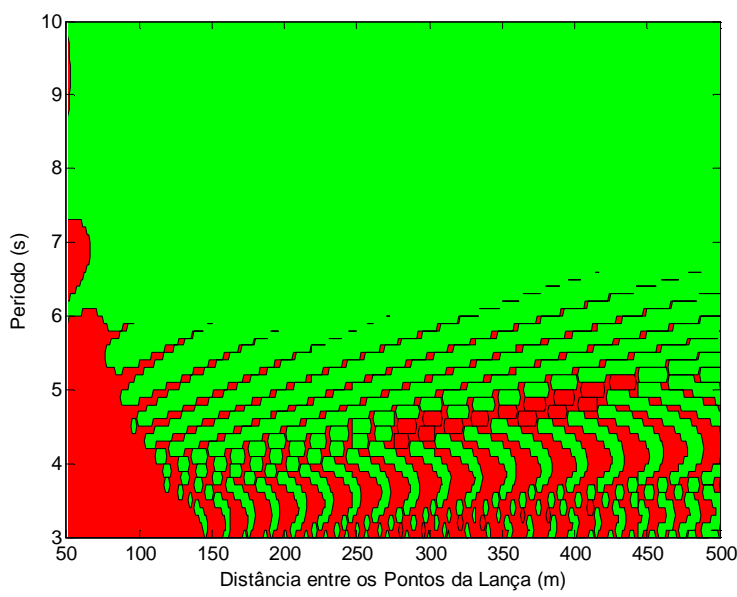

Amplitude de Onda de 1,4m

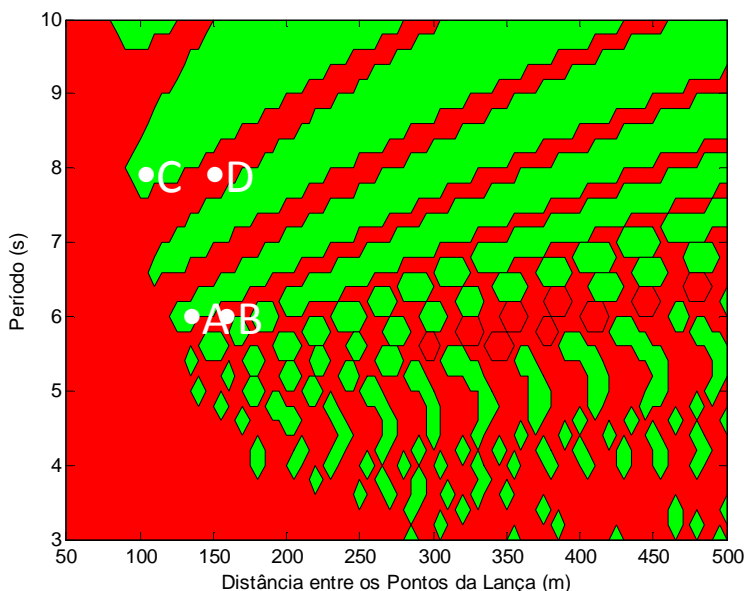

Figura 45: Mapas Dinâmicos - Imposição de Movimentos Verticais

Amplitude de Onda de $1 \mathrm{~m}$

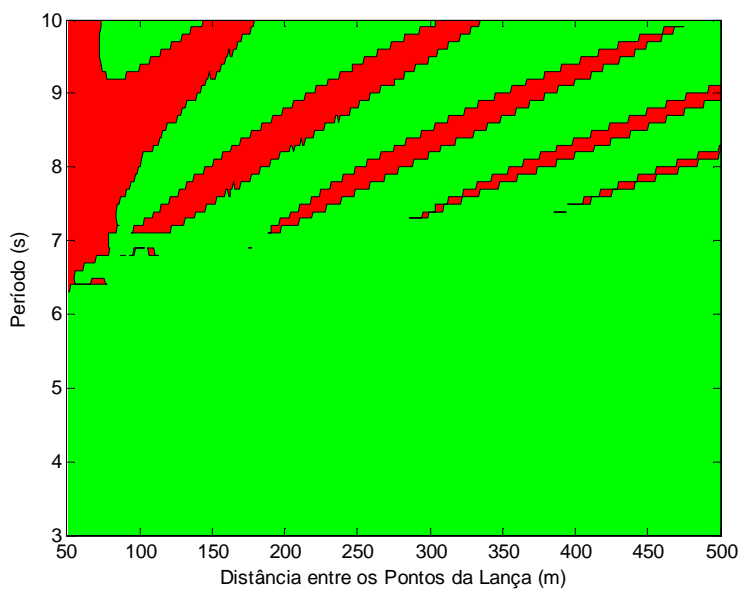

Amplitude de Onda de 1,4m

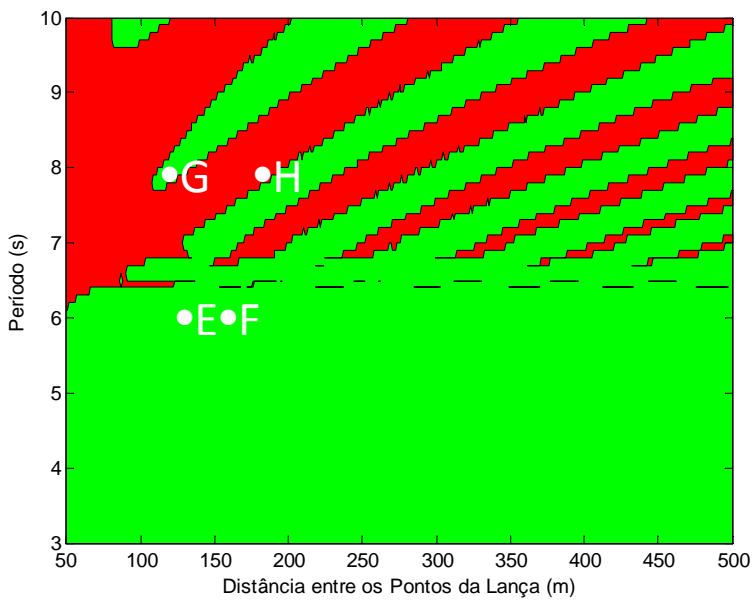

Figura 46: Mapas Dinâmicos - Dinâmica dos Navios

Amplitude de Onda de $1 \mathrm{~m}$

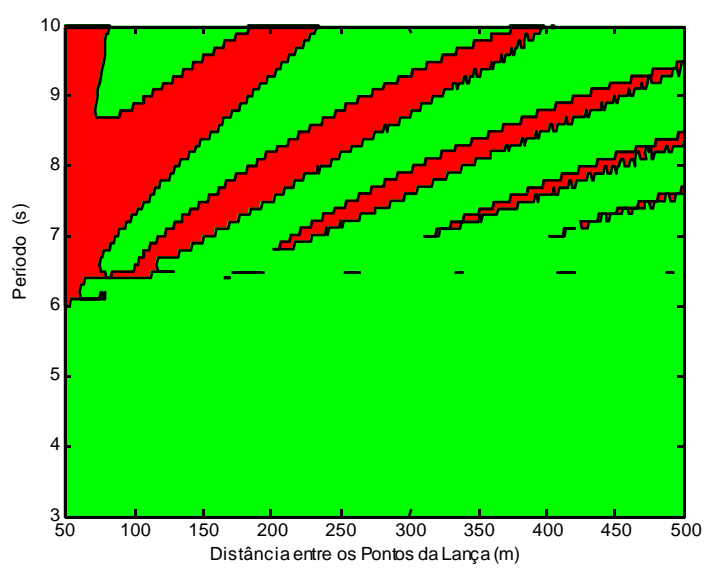

Amplitude de Onda de 1,4m

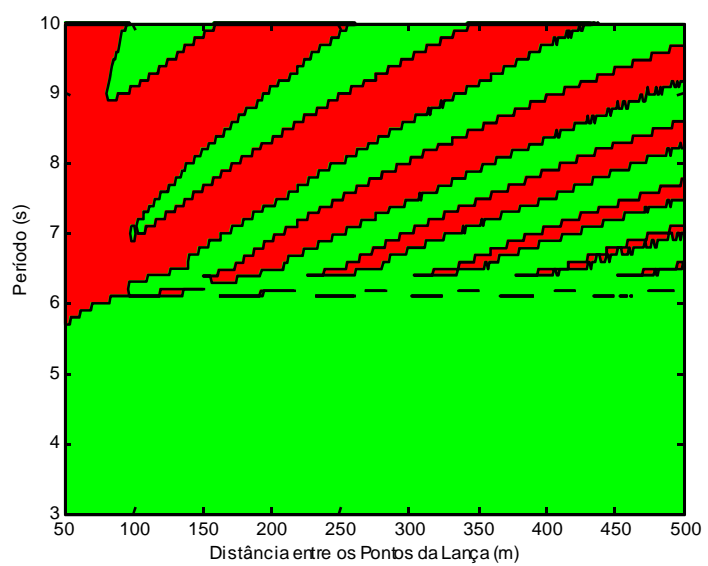

Figura 47: Mapas Dinâmicos - Dinâmica dos Navios - Incidência 30 Proa 
A análise direta dos mapas acima permite concluir que:

- É fundamental considerar a dinâmica dos navios na análise do sistema de lançamento, dado que há uma grande diferença entre os mapas dinâmicos da Figura 45 e da Figura 46.

- A incidência da onda não interfere significativamente nos resultados apresentados nos mapas dinâmicos como mostra os mapas da Figura 46 e da Figura 47. Desta maneira não há a necessidade gerar os mapas para a incidência de $15^{\circ}$ em relação à proa porque vão apresentar resultados semelhantes.

- Considerando o mapa da Figura 46, verifica-se que para ondas regulares com períodos da ordem de 8s, há uma região em que as embarcações devem ser posicionadas, na faixa de 100 a 150m, que garantirão a não ocorrência de afrouxamento. A não ocorrência de afrouxamento se repete para distâncias maiores (200m a $250 \mathrm{~m}$, como por exemplo), porém deve-se atentar para as maiores trações estáticas nestes casos (a linha apresenta maior ângulo com a horizontal), tal como ilustrado na Figura 48.

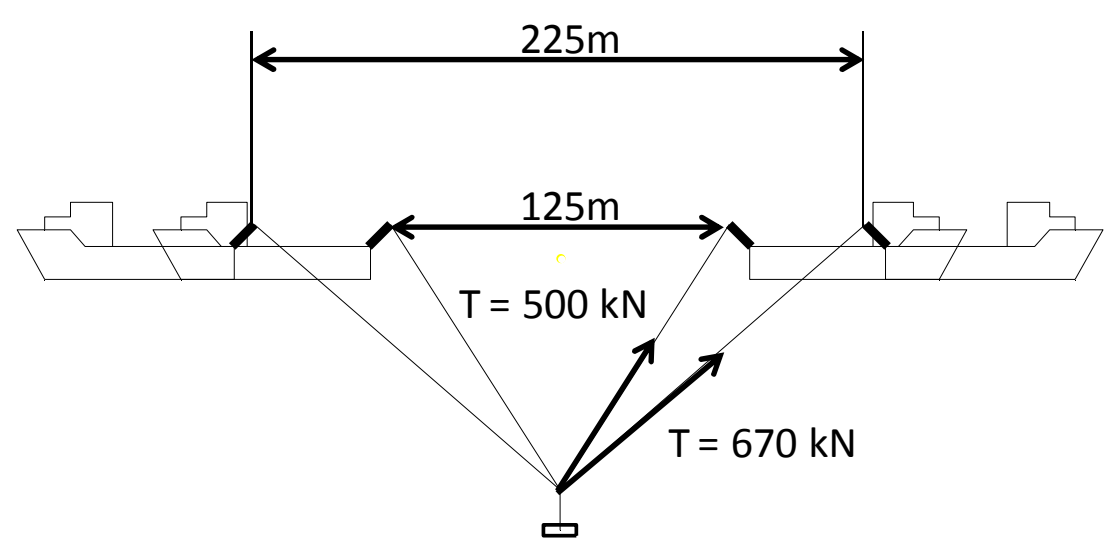

Figura 48: Aumento da Tração Estática com aumento da distância entre as embarcações

- Para ondas regulares com períodos menores ou iguais a $6 \mathrm{~s}$ a dinâmica do navio impede que os pontos de conexão se movam muito, como é mostrado na simulação F da Figura 51. Nesta simulação, mesmo os movimentos dos pontos de conexão estando em fase, não ocorre afrouxamento no cabo. Nota-se que se fosse considerada apenas a imposição do movimento vertical (simulação B) da Figura 50 iria ocorrer afrouxamento no cabo. 
- Para ondas regulares com períodos maiores que 6s, este efeito do 'filtro' imposto pela dinâmica do navio não ocorre. Como nota-se na simulação $\mathrm{H}$ da Figura 51, há uma amplificação do movimento do ponto de conexão, pois este é o período natural do movimento de pitch da embarcação (Figura 23). Nota-se uma amplitude bem maior que a amplitude imposta de $1,4 \mathrm{~m}$ da simulação $\mathrm{D}$.

- Pode-se notar também a diminuição nos valores das trações sempre que os movimentos dos pontos de conexão estiverem em oposição de fase (Comparando-se as simulações A com B, C com D, E com F, G com H) das Figura 50 e

\subsection{Distância entre as embarcações pela profundidade do manifold}

Outra análise realizada foi o mapa dinâmico que relaciona a distância entre as embarcações e a profundidade do manifold. Para este mapeamento, tal como ilustrado na Figura 49, consideraram-se:

- Ondas regulares com amplitude de $1 \mathrm{~m}$ e $1,4 \mathrm{~m}$

- Períodos da onda de $6 \mathrm{~s}, 8 \mathrm{~s}$ e $10 \mathrm{~s}$.

- Distância variando de $50 \mathrm{~m}$ a $1200 \mathrm{~m}$.

- Profundidade variando de $50 \mathrm{~m}$ a $1200 \mathrm{~m}$.

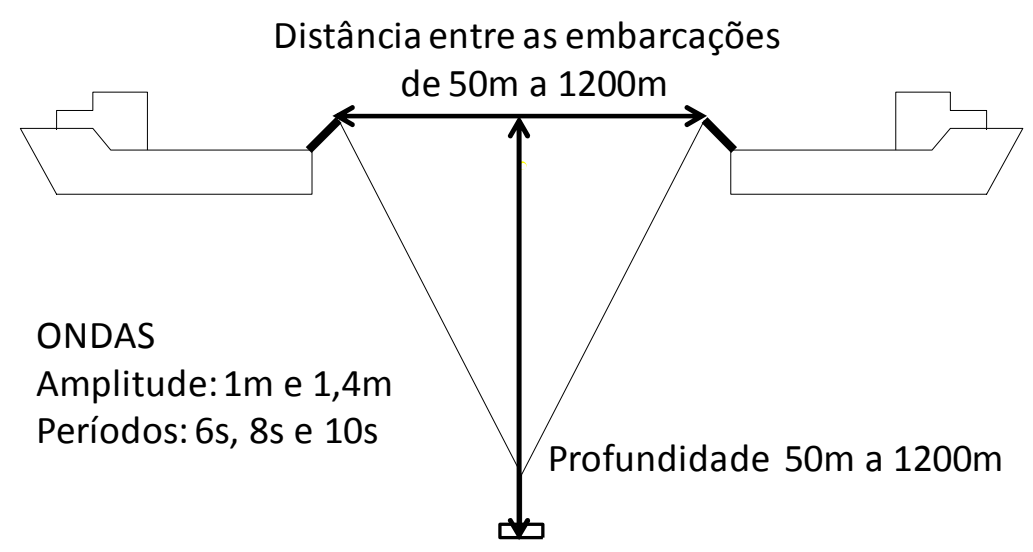

Figura 49 Mapeamento Dinâmico: Distância por profundidade

Neste mapeamento buscaram-se verificar quais seriam as dificuldades enfrentadas pelo controle conforme fosse realizado o lançamento do manifold. A seguir são apresentados os resultados no mesmo padrão do item anterior. 
A

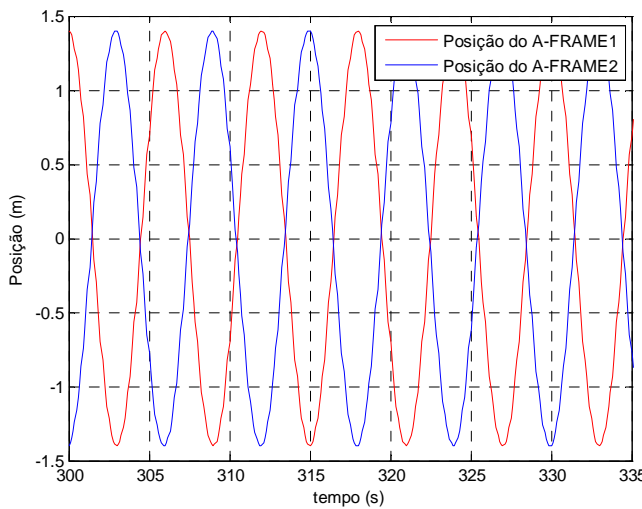

B

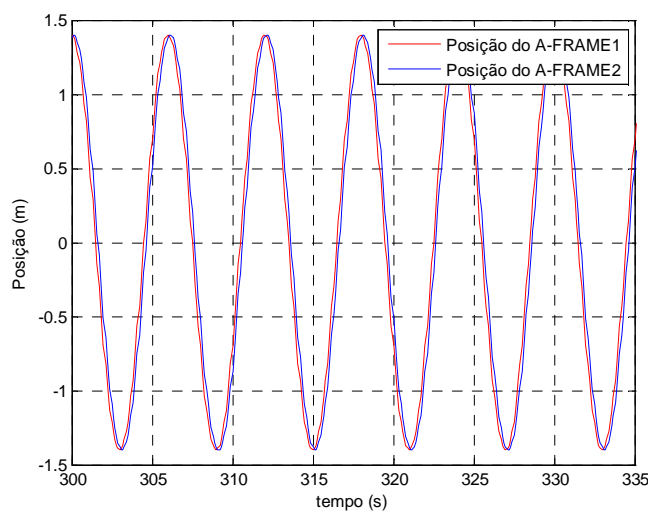

C

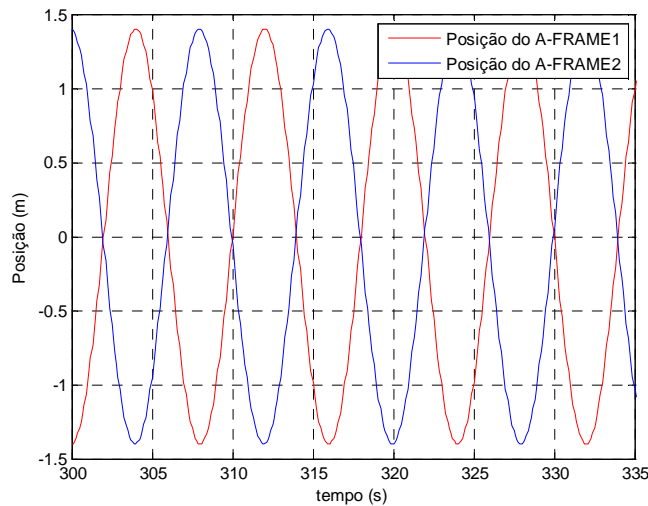

D

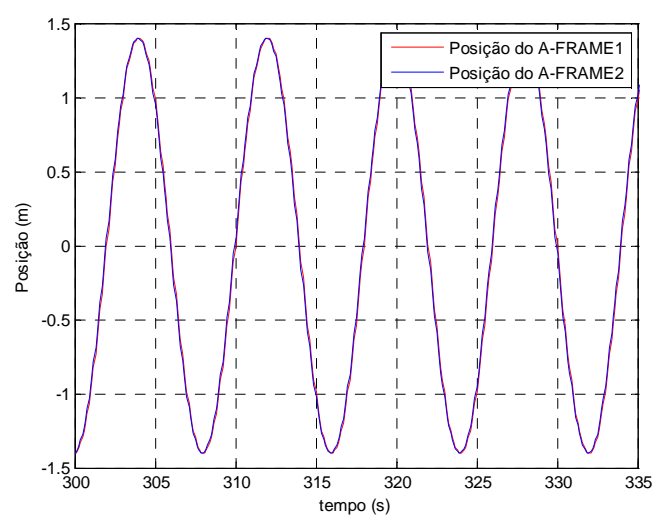

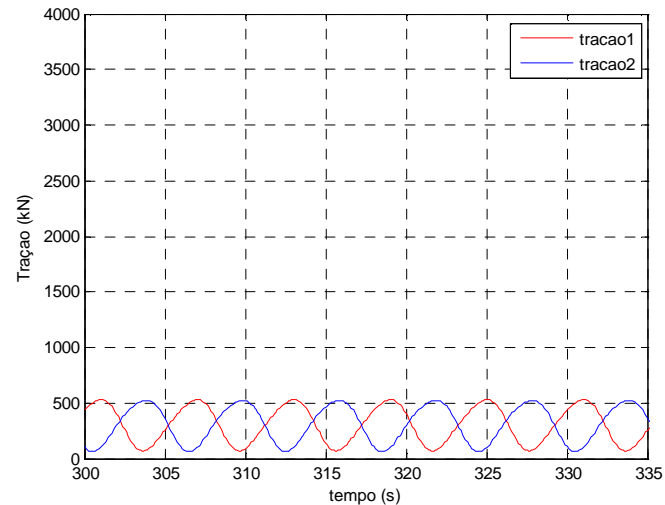
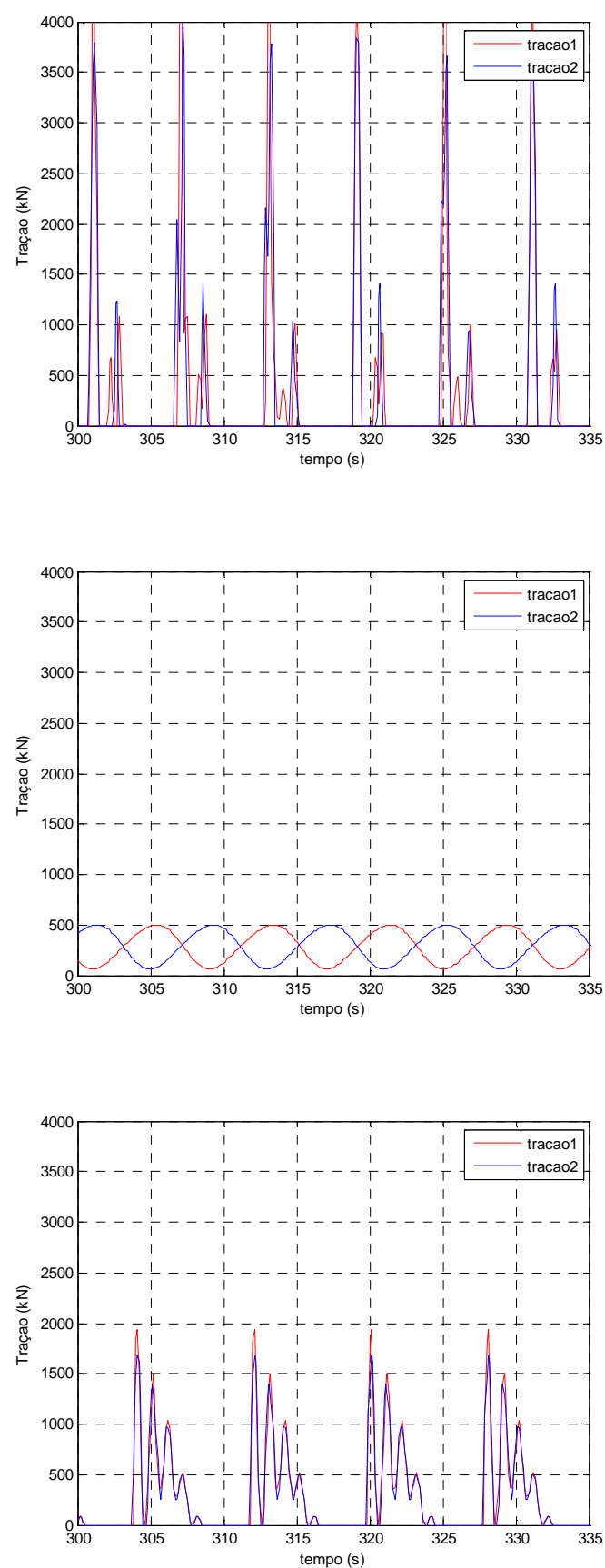

Figura 50: Movimento Imposto 

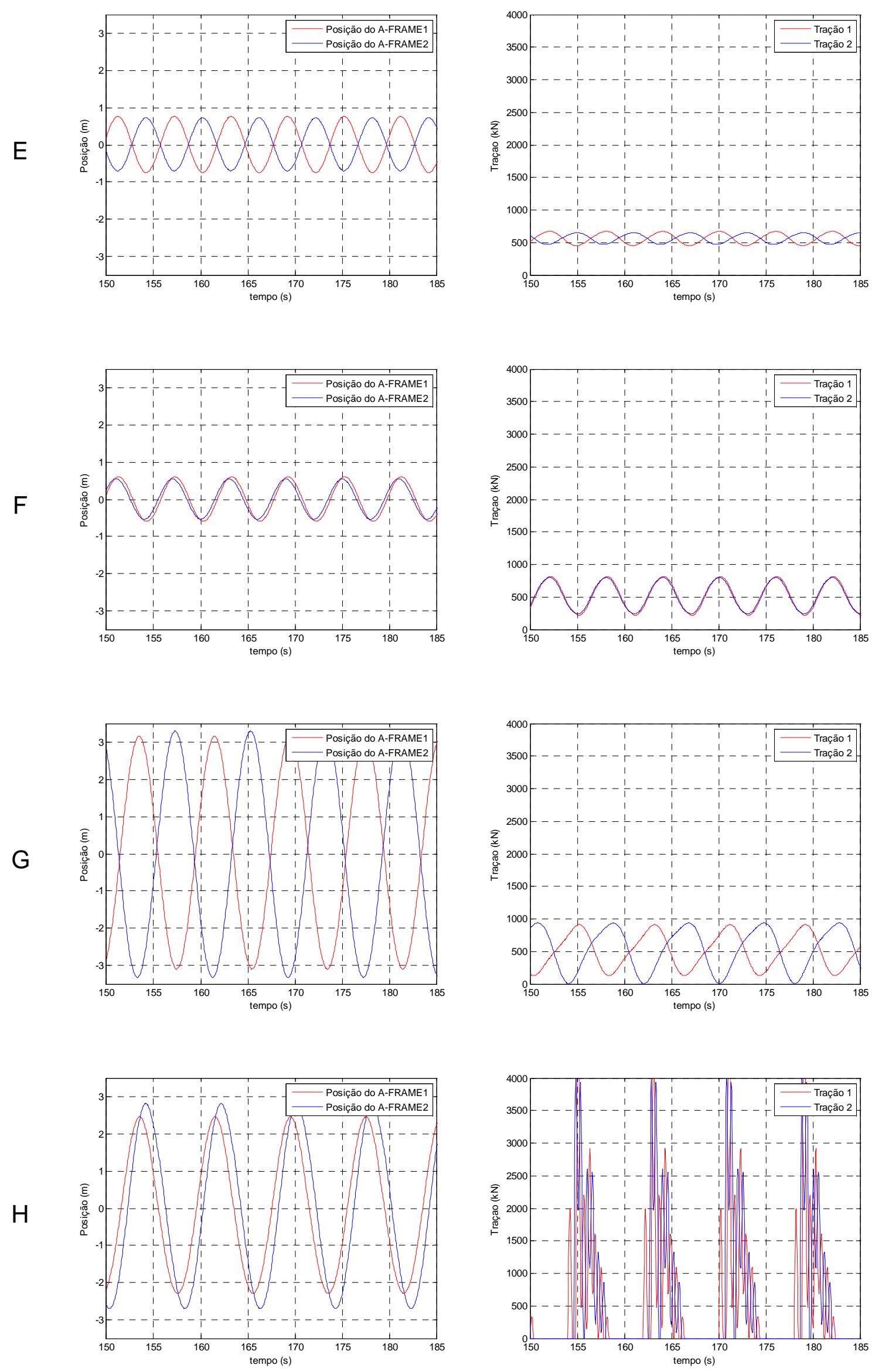

Figura 51: Movimento Acoplado 
Para ondas regulares com períodos de $6 \mathrm{~s}$ e amplitude de 1,4m (Figura 52) seria possível realizar a operação de içamento do manifold percorrendo a diagonal do mapeamento proposto. O que o controle deve fazer é sempre manter a proporcionalidade entre distância entre as embarcações e a profundidade do manifold. A reta indicada, por exemplo, equivale ao lançamento com o ângulo de abertura de $53^{\circ}$, conforme indicado na Figura 53.

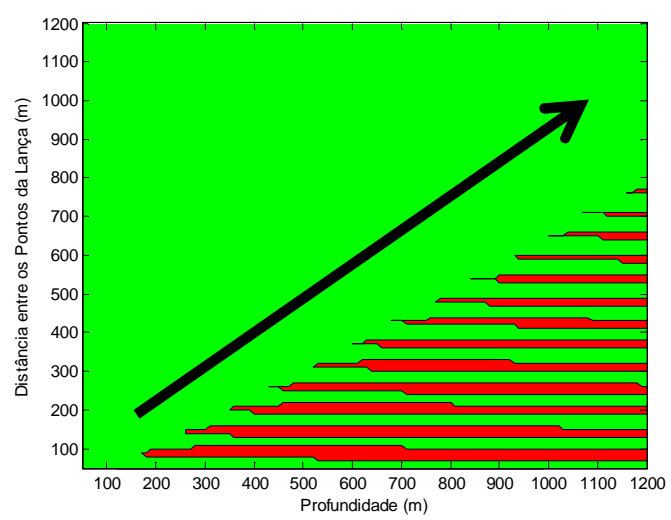

Figura 52 Mapeamento Dinâmico: Distância por Profundidade - período de onda de 6s

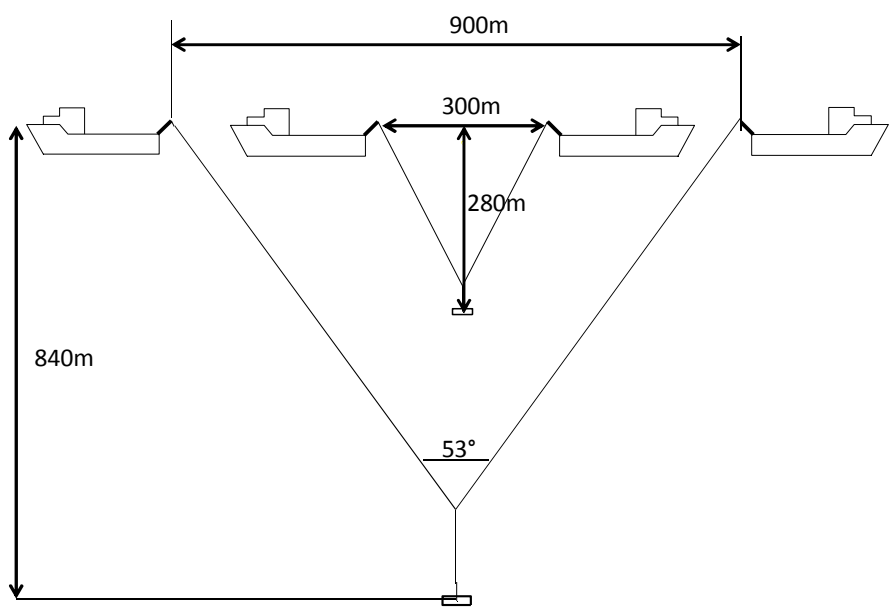

Figura 53 Possível configuração para lançamento com período de onda de $6 \mathrm{~s}$

No entanto para ondas com período de 8s e 10s (Figura 54), a distância entre as embarcações deve ser muito elevada para que seja possível um lançamento contínuo, o que não é viável dada a elevada tração estática que isto ocasionaria nos cabos. Por exemplo, para uma profundidade do manifold se $100 \mathrm{~m}$ as embarcações já deveriam estar a 800m de distância o que inviabiliza a operação. 

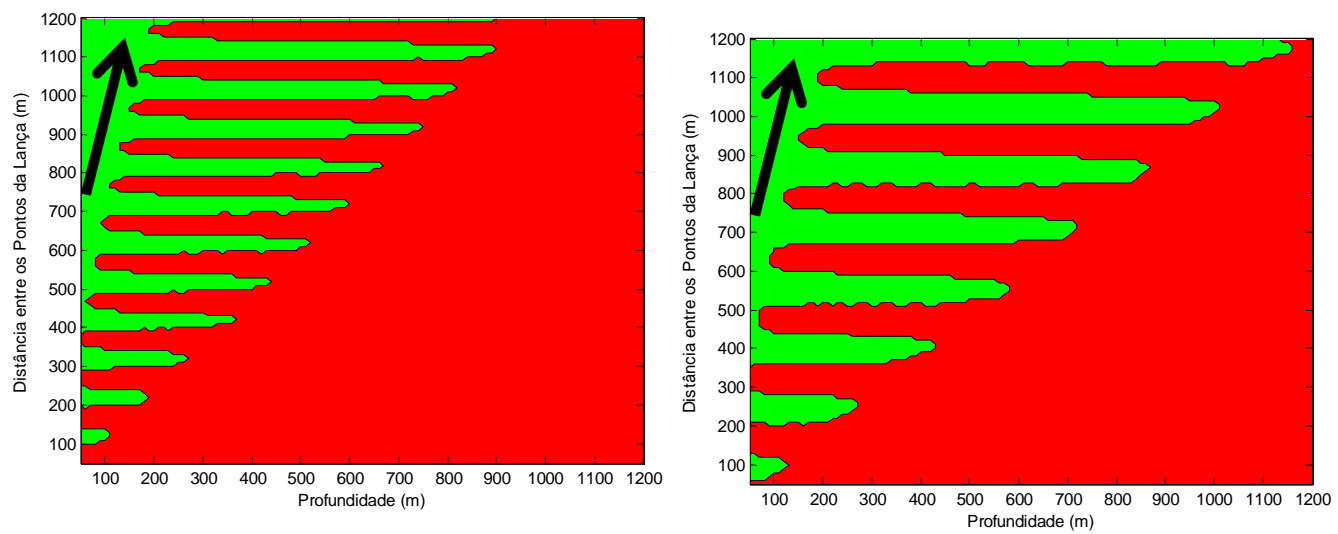

Figura 54 Mapeamento Dinâmico: Distância por Profundidade - período de onda 8s (esq.) e 10s (dir.)

Pode ser concluído que controlando somente as posições das embarcações não é suficiente para realizar a operação de lançamento do manifold para períodos de onda maiores que $6 \mathrm{~s}$. É necessário um controle adicional, o controle de içamento. Assim um controle de içamento combinado ao controle de posição pode manter as embarcações para operarem nas regiões de não afrouxamento durante o içamento. 


\section{Controle}

Pela análise do mapeamento dinâmico apresentado no Capítulo 5, concluiu-se que para reduzir os esforços nas linhas de içamento, deseja-se que os pontos de conexão estejam se movimentando em oposição de fase, e adicionalmente necessita-se de um controle de içamento. Com isso, reduz-se a solicitação axial nas linhas e a ocorrência de afrouxamento.

Portanto, desenvolveu-se um controlador que utiliza as medidas dos movimentos verticais dos pontos de conexão das linhas nas duas embarcações de lançamento e tem como objetivo reposicionar os navios (através do sistema DP dos mesmos) para que estes dois movimentos mantenham-se em oposição de fase. O trabalho de Oshiro, et. al., (2012) apresenta este controlador.

Este controlador compreende um estimador da diferença de fase dos movimentos dos pontos de conexão, um algoritmo de controle que define os set-point das embarcações e o controle do sistema DP das embarcações. A variável de entrada do controlador é a diferença de fase entre os movimentos dos pontos de conexão, e como variável de saída (variável manipulada), o setpoint de posicionamento axial das embarcações.

Para estimar a diferença de fase em tempo real entre os movimentos dos dois pontos de conexão foi utilizada a transformada de Hilbert. Esta recebe as medidas de posição, aguarda o sinal completar um período de oscilação completo e faz a estimativa da diferença de fase média dos sinais.

O controlador com base na estimativa da diferença de fase entre os movimentos do ponto de conexão reposiciona as embarcações de modo a manter esse movimento em oposição de fase.

A Figura 55 apresenta o diagrama de blocos do controle proposto. $O$ algoritmo de controle superior envia o comando da posição desejada para o Sistema DP das duas embarcações, a fim de posicioná-las no plano horizontal, em uma configuração em que a fase entre os movimentos dos pontos de conexão esteja a $180^{\circ}$. 


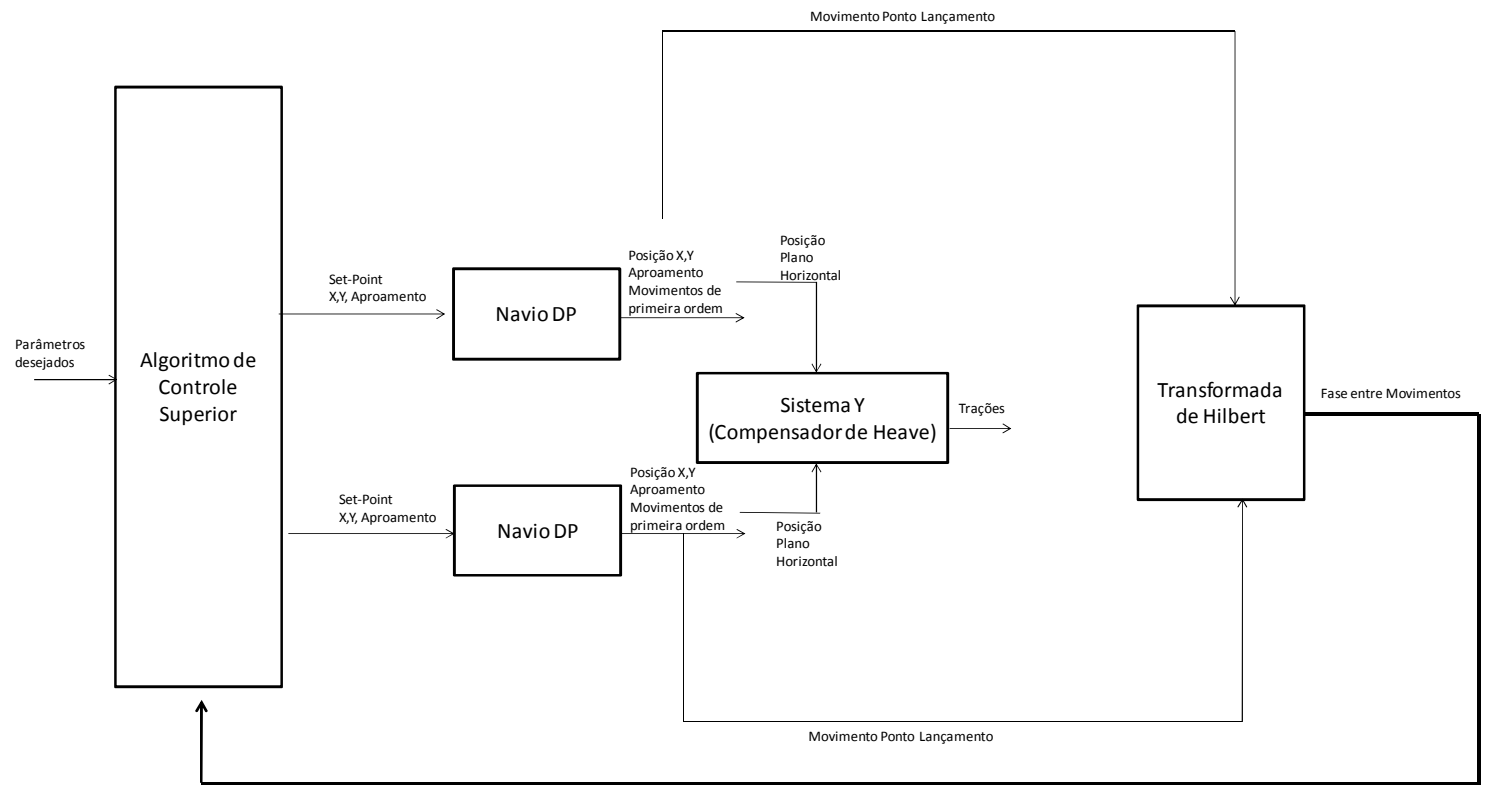

Figura 55: Controle proposto

\subsection{Transformada de Hilbert}

Em contraste às transformadas de Fourier ou Laplace, a transformada de Hilbert não é uma transformada entre domínios. Ela define um complemento imaginário para uma dada parte real, ou vice versa, deslocando cada componente do sinal por um quarto de período. Assim, a Transformada de Hilbert fornece um método para determinar a amplitude instantânea e a freqüência instantânea do sinal (Feldman, 2011).

\subsubsection{Definição da Transformada de Hilbert}

A Transformada de Hilbert de uma função $x h(t)$ é definida pela integral de convolução:

$H[x h(t)]=\tilde{x} h(t)=\pi^{-1} \int_{-\infty}^{\infty} \frac{x h(\tau)}{t-\tau} d \tau$

Que pela possível singularidade em $t=\tau$, esta integral pode ser considerada como um valor principal de Cauchy. É difícil avaliar qual o significado desta transformada ou sua aplicação pela sua definição matemática. Mas fisicamente ela é equivalente a um tipo especial de filtro linear, onde todas as amplitudes das componentes espectrais são mantidas, mas suas fases são deslocadas por $\pi / 2$. 


\subsubsection{Representação da Transformada de Hilbert na forma de sinal analítico e notação polar}

Um sinal analítico é um sinal bidimensional cujo valor em um instante de tempo é especificado por duas partes, a parte real e a parte imaginária. A parte imaginária é dada pela transformada de Hilbert da parte real.

$X(t)=x(t)+i \tilde{x}(t)$

Onde $\tilde{x}(t)$ é relacionado à $x(t)$ pela transformada de Hilbert. Um exemplo da construção do sinal analítico é mostrado na Figura 56.

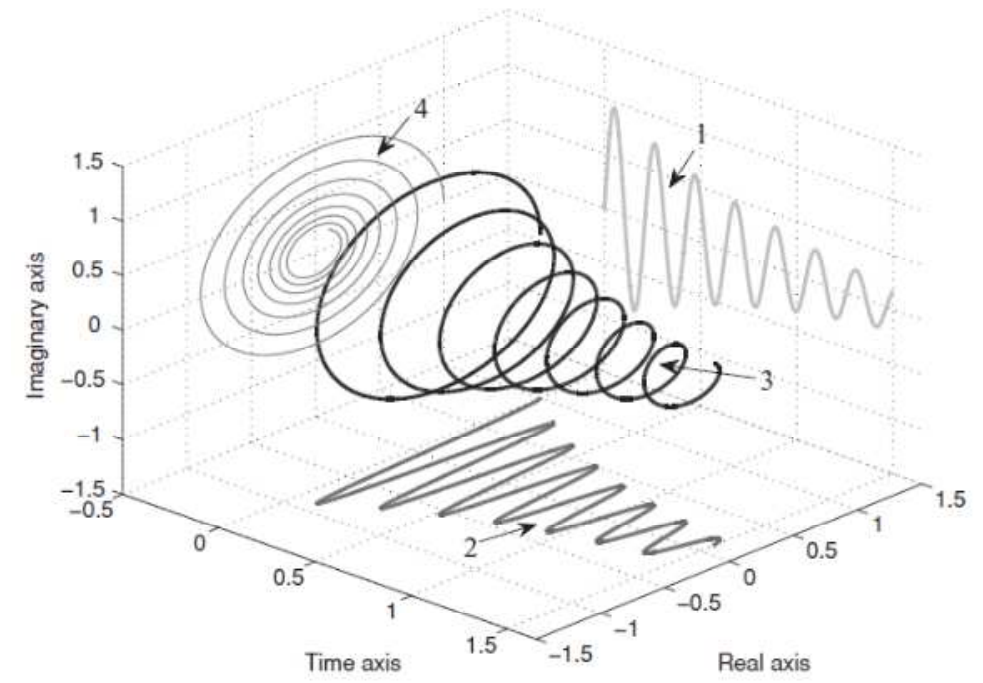

Figura 56: Representação em sinal analítico da transformada de Hilbert: Projeção (1), sinal real (2), sinal analítico (3) e o fasor no plano complexo (4), (Feldman, 2011)

Outra forma de representar o sinal analítico é em sua representação geométrica na forma de fasor no plano complexo (Figura 57)

No qual pode ser determinado o parâmetro da amplitude instantânea:

$A(t)= \pm|X(t)|= \pm \sqrt{x^{2}(t)+\tilde{x}^{2}(t)}= \pm e^{\operatorname{Re}[\ln X(t)]}$

A fase instantânea é dada por:

$\psi(t)=\arctan \left(\frac{\tilde{x}(t)}{x(t)}\right)=\operatorname{Im}[\ln X(t)]$ 


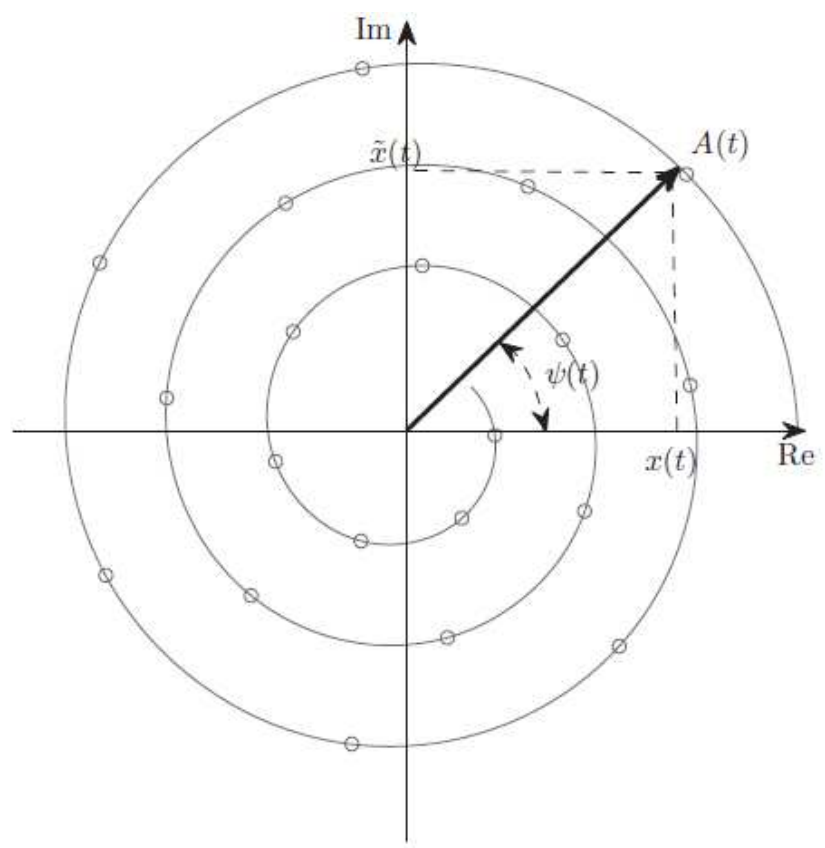

Figura 57: Sinal Analítico no plano complexo (Feldman, 2011)

\subsubsection{Diferença de fase relativa instantânea}

A diferença de fase relativa instantânea de dois sinais diferentes $x(t)$ e $y(t)$ pode ser estimada como uma fase instantânea relativa, de acordo com a fórmula:

$\Delta \psi=\psi_{y}(t)-\psi_{x}(t)=\arctan \left(\frac{x(t) \tilde{y}(t)-\tilde{x}(t) y(t)}{x(t) y(t)+\tilde{x}(t) \tilde{y}(t)}\right)$

O tamanho da janela amostral é dado por um período completo de onda. A janela armazena os útlimos dados do sinal e se atualiza a cada novo valor de amplitude de onda aquisitado. A cada valor aquisitado é calculada a fase instantanea relativa dos dois sinais e é calculada uma média da diferença de fase dos dois sinais.

Como exemplo de aplicação são simuladas na Figura 58 duas senóídes com diferença de fase $0^{\circ}$. O período da onda senoidal simulada é de $8 \mathrm{~s}$, o mesmo tamanho da janela amostral. No instante $t=50 \mathrm{~s}$ é dado um degrau na defasagem de uma das senóides para mostrar como o algoritmo reage para estimar a defasagem dos dois sinais. 

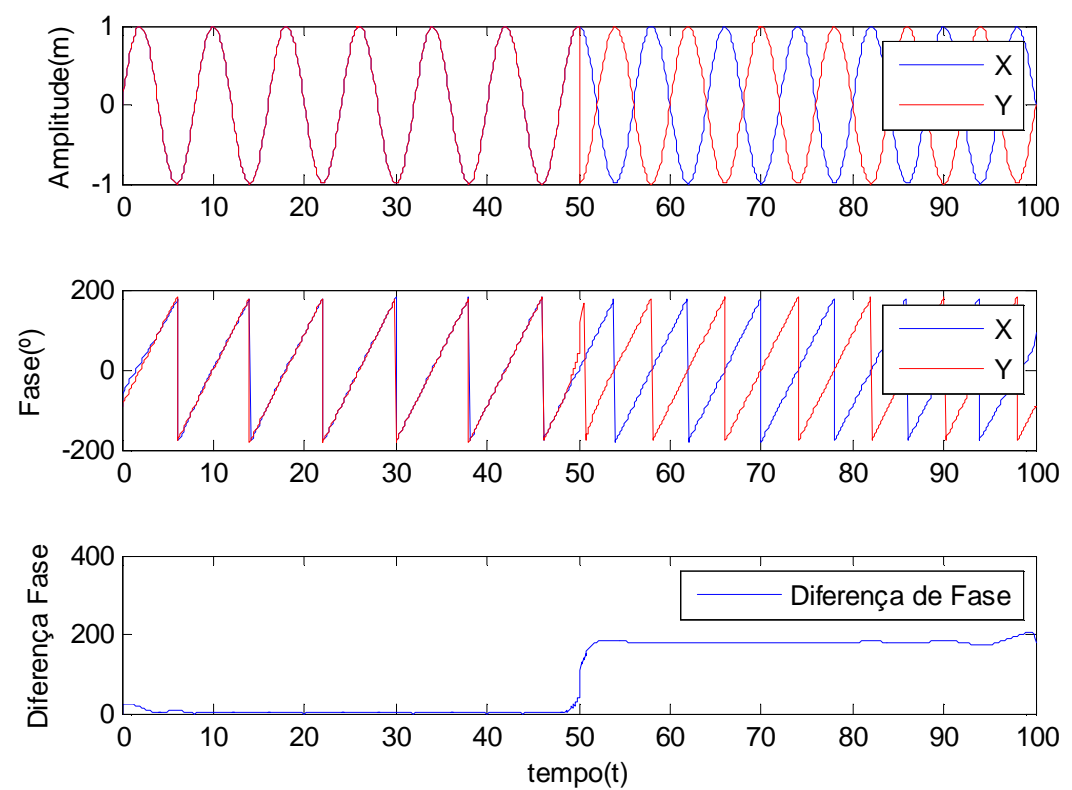

Figura 58: Estimação da diferença de fase utilizando a transformada de Hilbert

\subsection{Controle de Posição}

O controle será desenvolvido em dois níveis. No primeiro nível, um controle superior que define as posições desejadas (set-points) das embarcações de modo a manter o movimento do ponto de conexão em oposição de fase, baseado no mapeamento dinâmico apresentado no Capítulo 5. No segundo, o sistema DP da embarcação segue a posição desejada definida pelo controle superior.

\subsubsection{Controle superior - definição da posição desejada (set-point)}

A abordagem de controle utilizada para manter a fase em $180^{\circ}$ (oposição de fase) foi o controle PD da velocidade com saturação. A escolha deste controle se deve ao fato de sua simplicidade e por ter demonstrado bom desempenho nas simulações.

A estratégia proposta (Figura 59) será manter a posição da embarcação A fixa, controlada através de seu Sistema DP com set-point constante. O controle superior tem como variável a ser manipulada a variação da posição desejada longitudinal (surge) da embarcação B. Os set-points dos outros graus de liberdade da embarcação B (sway e yaw) também foram mantidos constantes. 


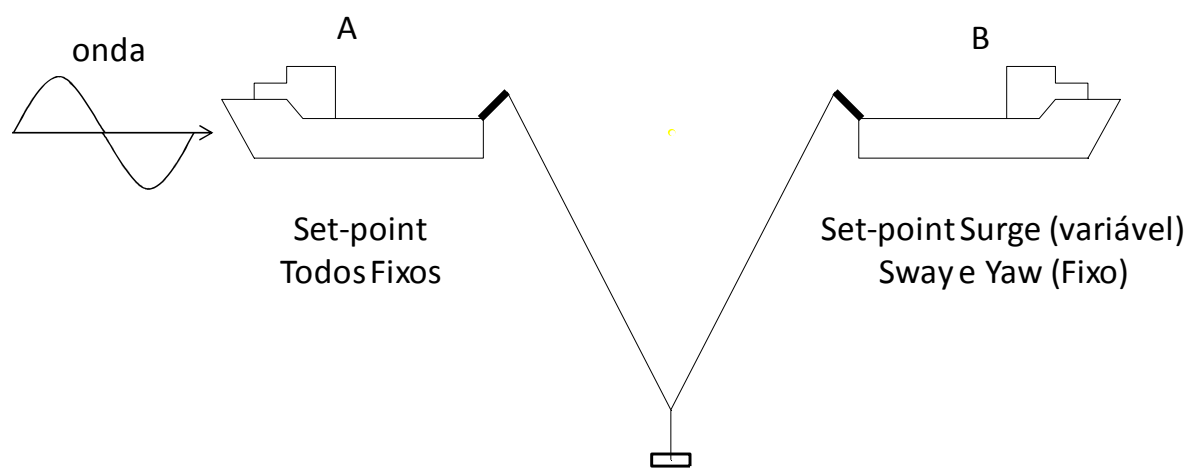

Figura 59: Estratégia controle superior

Um diagrama detalhado do controle superior é apresentado na Figura 60:

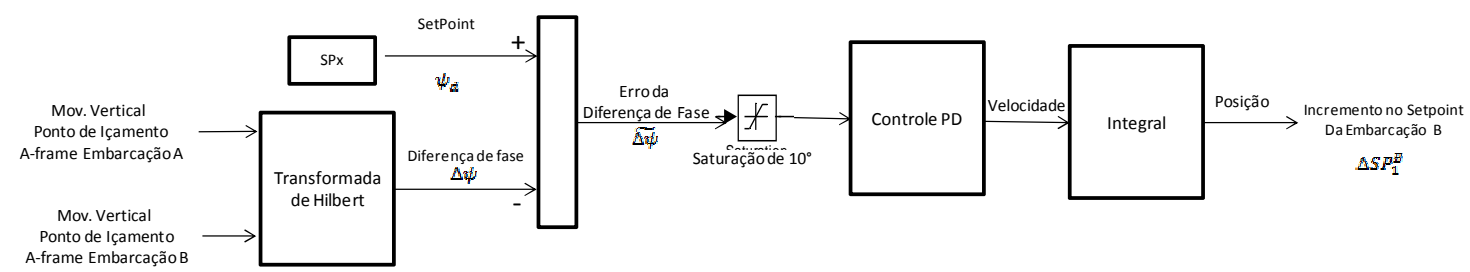

Figura 60: Diagrama de blocos do Controle Superior

Define-se o erro da diferença de fase do movimento vertical do ponto de conexão $\Delta \psi$ como:

$\widetilde{\Delta \psi}=\Delta \psi-\psi_{d}$

$\mathrm{Na}$ qual $\psi_{d}$ é a diferença de fase desejada $\left(180^{\circ}\right)$.

Logo, o incremento no set-point para a posição longitudinal da embarcação 2 será dado por:

$\Delta S P_{1}^{2}=\int\left[K_{P} * \operatorname{sat}\left(\frac{\widetilde{\Delta \psi}}{10^{\circ}}\right)+K_{D} * \frac{d}{d t}\left(\operatorname{sat}\left(\frac{\widetilde{\Delta \psi}}{10^{\circ}}\right)\right)\right] d t$

A função $\operatorname{sat}(x)$ é dada pela Figura 61: 


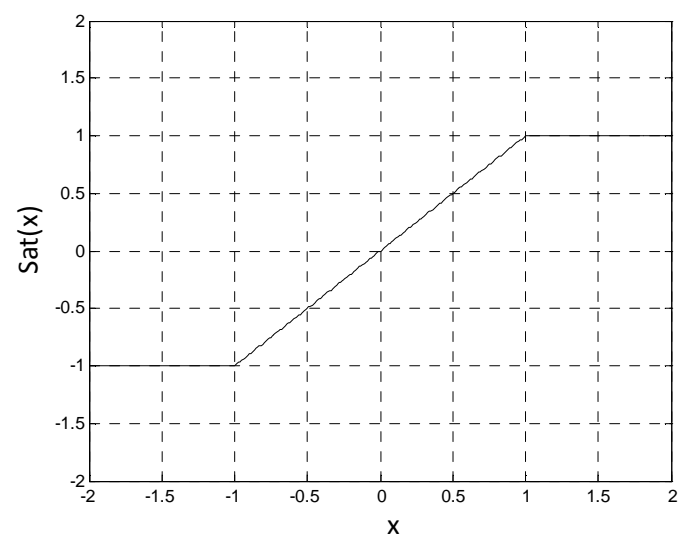

Figura 61: Função sat(x)

Utilizou-se o valor de saturação de $10^{\circ}$ para evitar variações elevadas de setpoint em surge da embarcação B. O ganho $K_{P}$ foi ajustado como $0,02 \mathrm{~m} / \mathrm{s}$ e o ganho $K_{D}$ como $0,2 \mathrm{~m}$.

\subsubsection{Controle da embarcação - Sistema DP}

O controle no nível superior fornece as posições e aproamento desejados (setpoint) ao sistema DP. Este por sua vez tem o objetivo de fazer a embarcação manter-se próxima a este set-point, através de uma malha de realimentação utilizando-se seus propulsores. O diagrama do sistema DP é apresentado na Figura 62. A descrição do sistema DP pode ser encontrada em (Fossen, 1994) e (Tannuri, 2002)

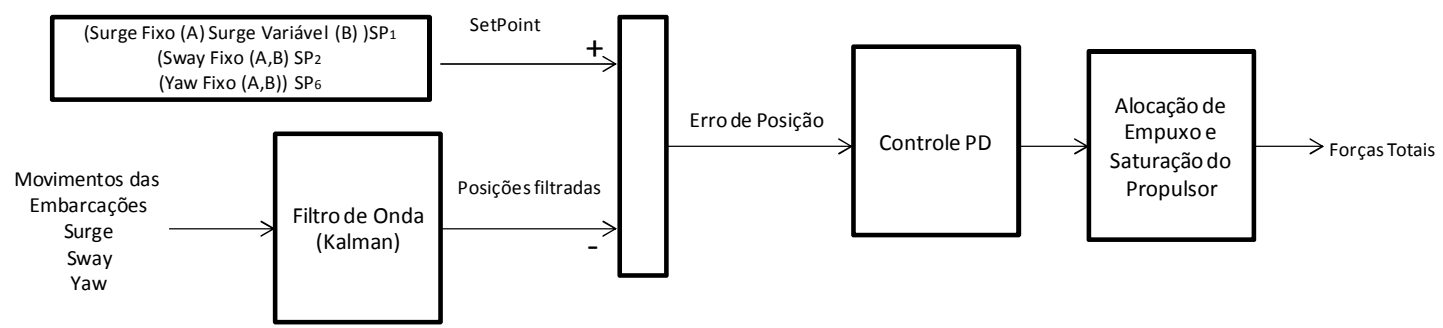

Figura 62: Diagrama Sistema DP

\subsubsection{Filtro de Kalman}

Nos métodos clássicos de filtragem, como por exemplo, no filtro Notch, ocorre um atraso o que motivou o desenvolvimento de sistemas de posicionamento dinâmico com filtros de Kalman. Neste trabalho o filtro foi utilizado para remover os movimentos na freqüência da onda (considerados como alta 
frequência para a malha de posicionamento dinâmico). Este sinal é indesejado, pois provoca o acionamento em alta freqüência dos propulsores, provocando desgaste e reduzindo-se a vida útil. Além disso, a atenuação destes movimentos na frequência da onda requereria uma potência muito grande de controle.

O observador proposto por Kalman (1960) consiste em um estimador do tipo predição-correção, e é ótimo no sentido da minimização da variância do erro, i.e., da diferença entre as estimativas e o comportamento real do sistema observado. Assim, um modelo representativo desse sistema deve ser equacionado e, a partir dele, obtém-se uma estimativa a priori do sinal a ser filtrado. Em seguida, uma medição (ruidosa) desse sinal é feita, e dela se subtrai o sinal estimado anteriormente. Essa diferença é finalmente multiplicada por ganhos, e o resultado é somado àquela estimativa feita a priori, resultando na estimativa ótima a posteriori.

Assim, ao contrário de um filtro clássico que, dado um sinal ruidoso, atenua as componentes de determinada banda de frequências, o filtro de Kalman faz uma estimativa de como deve ser o sinal na ausência dos ruídos. No caso de aplicação em Sistemas DP, utiliza-se um modelo para movimentos de baixa frequência, o que permite a obtenção do sinal de lenta variação já pronto para ser realimentado ao controlador.

A descrição detalhada do modelo matemático do desenvolvimento do filtro de Kalman pode ser encontrada em Tannuri, (2002). Na Figura 63 mostra-se a comparação do sinal original com o sinal filtrado. Os ganhos utilizados para as matrizes $Q$ (covariância do ruído do processo) e $R$ (covariância do ruído da medida) são dados por:

$$
R=\left[\begin{array}{ccc}
0,01 & 0 & 0 \\
0 & 0,01 & 0 \\
0 & 0 & 0
\end{array}\right] Q=\left[\begin{array}{ccc}
2 \times 10^{6} & 0 & 0 \\
0 & 1,33 \times 10^{4} & 0 \\
0 & 0 & 6,67 \times 10^{7}
\end{array}\right]
$$

\subsubsection{Controlador PID}

O sistema DP considera apenas os movimentos no plano horizontal. Para simular o Sistema DP, foi adicionando mais um termo de força $\left(\boldsymbol{\tau}_{\boldsymbol{C}}\right)$ no modelo simplificado da dinâmica acoplada: 


$$
\left(M+M_{A}(\omega)\right) \ddot{\eta}+\left(D_{E X T}+D_{P}(\omega)\right) \dot{\eta}+K \boldsymbol{\eta}=\tau_{W}+\tau_{T}+\tau_{C}
$$
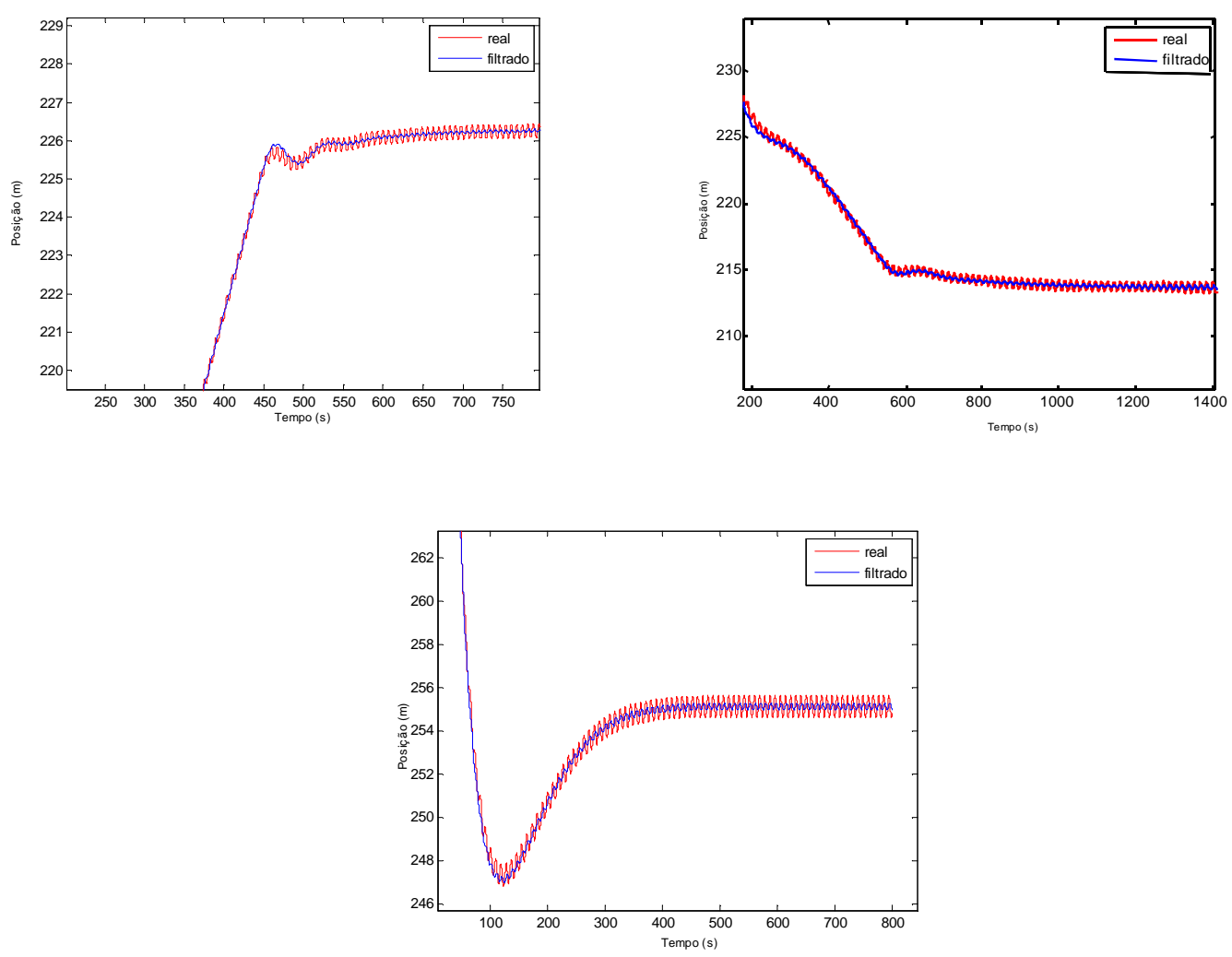

Figura 63: Filtro de Kalman: Período de onda 7s (acima, esq.), 8s (acima, dir.) e 9s(abaixo) No qual $\boldsymbol{\tau}_{\boldsymbol{C}}$ representa $\mathrm{o}$ vetor de forças dos propulsores instalados na embarcação dado por:

$$
\boldsymbol{\tau}_{C}=\left[\begin{array}{c}
F_{c 1} \\
F_{c 2} \\
0 \\
0 \\
0 \\
F_{c 6}
\end{array}\right]
$$

Desconsideraram-se as componentes de momento de pitch e roll oriundas do acionamento dos propulsores, por serem pequenas e atuarem numa faixa de baixa frequência. A dinâmica dos propulsores foi simulada como um sistema de primeira ordem com 5 s de constante de tempo como é utilizado em Tannuri et al. (2010). O valor máximo de empuxo longitudinal de 500kN.

Foi adotado o controle PID, e suas forças de controle são definidas como: 


$$
F_{c i}=K_{P i} * \operatorname{Erro}_{i}+K_{D i} * \frac{d}{d t}\left(\text { Erro }_{i}\right)+K_{I i} * \int\left(\text { Erro }_{i}\right) d t i=1,2 \text { e } 6
$$

Na qual:

$\operatorname{Erro}_{i}=S P_{i}-\eta_{i}, i=1,2$ e 6

Os seus ganhos calculados em Tannuri et al. (2009) utilizados nas simulações são obtidos por alocação de pólos descrito em Ogata, (2010) e são dados pela Tabela 9:

Tabela 9: Ganhos do Sistema DP

\begin{tabular}{|c|c|c|c|}
\hline & $K_{P i}(\mathrm{kN} /(\mathrm{m}$ ou rad $))$ & $K_{D i}(\mathrm{kN} . \mathrm{s} /(\mathrm{m}$ ou rad $))$ & $K_{I i}(\mathrm{kN} .(\mathrm{m}$ ou rad $) . \mathrm{s})$ \\
\hline $\mathrm{X}\left(\eta_{1}\right)$ & 8,5 & 662 & 0,1 \\
\hline $\mathrm{Y}\left(\eta_{2}\right)$ & 14,7 & 1146,1 & 0,09 \\
\hline$\psi\left(\eta_{6}\right)$ & 4656.4 & 36217 & 0,3 \\
\hline
\end{tabular}

Adicionalmente na força de controle em surge $\left(F_{c 1}\right)$ foi incluída uma parcela constante de força para compensar o peso do manifold equivalente de $500 \mathrm{kN}$.

\subsection{Controle de Pagamento da linha de içamento}

A diminuição da tração dinâmica dos cabos de içamento utilizando apenas o controle de posição das duas embarcações se mostrou inviável ao longo de todo o lançamento, conforme discutido em 5.2. Desta forma foi modelado um controle de pagamento de linha que compensa o movimento vertical dos pontos de conexão. Assim nem todo o movimento do ponto de conexão é transmitido ao manifold.

O pagamento de linha é termo usual em operações marítimas, e corresponde ao controle da rotação de tambores que possuem o cabo de içamento enrolado ao seu eixo. Estes tambores podem rotacionar para enrolar ou desenrolar o cabo, aumentando ou diminuindo o comprimento de cabo em içamento.

O controle de pagamento de linha é ilustrado na Figura 64 e é dado por:

$\overline{L_{l}}=L_{i}-y_{i} \frac{v}{L_{i}}, i=1$ e 2 
Sendo que $L_{i}$ é o comprimento inicial da linha que é compensado pelo movimento do ponto de conexão $y_{i}$ multiplicado pela relação da profundidade do manifold pelo comprimento inicial linha.

Para simular o sistema de controle de pagamento de linhas, foram introduzidos erros de medição de movimento (10\%) e atrasos devido ao acionamento do controle de 0 s, $0,5 \mathrm{~s}, 1,0$ s e $1,5 \mathrm{~s}$.

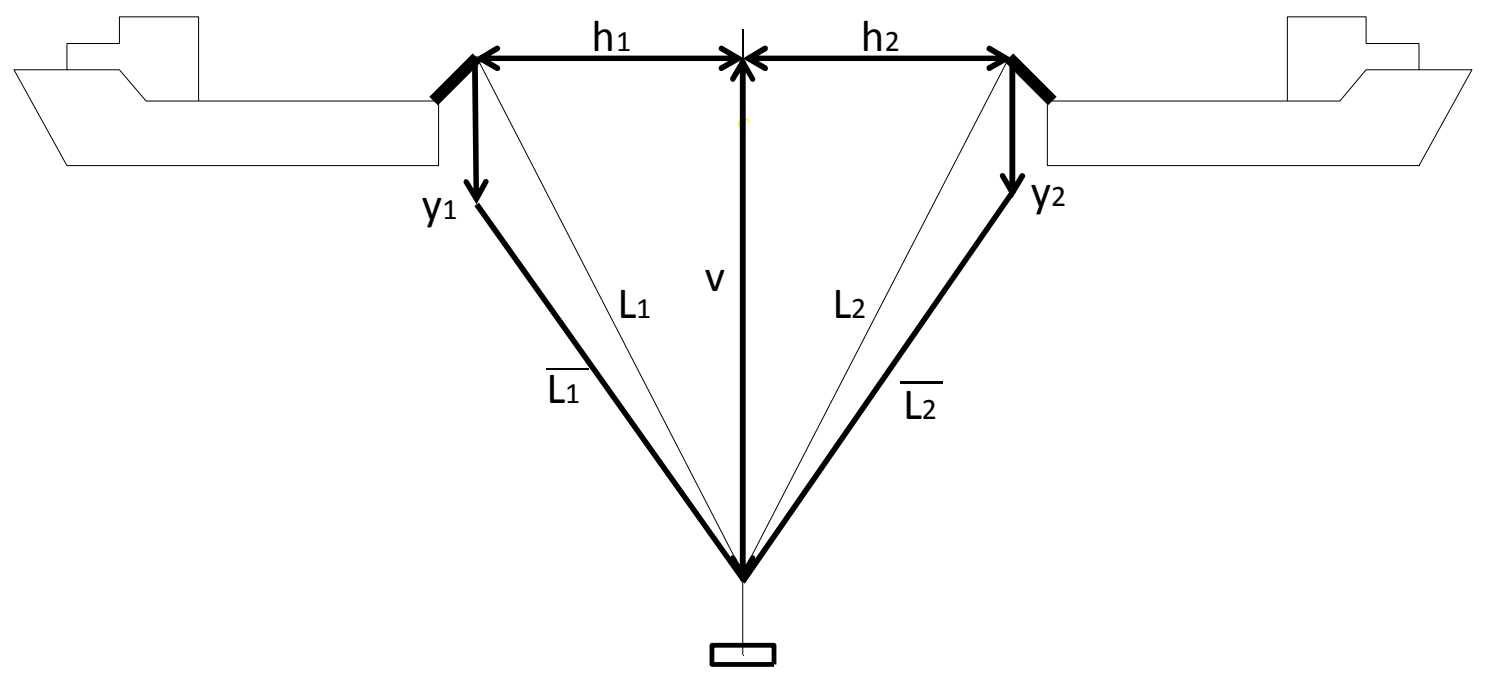

Figura 64: Controle de Pagamento de Linha

\subsection{Resultados}

Nesta seção são apresentados os resultados do controle proposto na seção 6.2, compreendendo o controle de posição e o controle de pagamento de linha.

\subsubsection{Controle de Posição}

O controlador proposto na seção 6.2 foi implementado e foram realizadas simulações que mostraram sua efetividade.

Consideraram-se ondas regulares de $2 \mathrm{~m}$ de altura com a incidência de proa para a embarcação A e popa para a embarcação B (Figura 59) e as incidências equivalentes de $15^{\circ}$ e $30^{\circ}$ com períodos de 7,8 e 9 s.

O mapa dinâmico da Figura 65 foi reproduzido novamente a partir da seção 5.1. A condição inicial de cada simulação é indicada no mapa pela palavra "início", sempre na zona vermelha (que representa a ocorrência de afrouxamento). O sistema de controle leva a embarcação B para uma nova 
posição, em que nos três casos simulados não ocorre mais afrouxamento. Estas posições são indicadas pela palavra "fim".

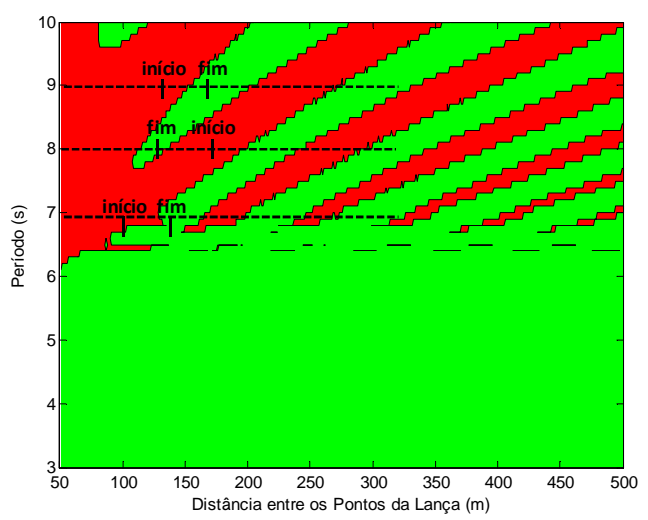

Figura 65: Mapa dinâmico: Simulações do Controle

Entre os instantes de tempo entre 0 e 500s o controle DP da embarcação B é mantido com setpoint fixo para o controle compensar a parcela de força do peso do manifold. A partir dos 500s o controle superior é acionado assim o setpoint da embarcação caminha até que o movimento entre os pontos de conexão se mantenham em oposição de fase.

Na Tabela 10 são apresentadas as simulações realizadas.

Tabela 10: Simulações controle de posição

\begin{tabular}{|c|c|c|c|c|c|}
\hline Simulação & $T(\mathrm{~s})$ & $\begin{array}{c}\text { Incidência } \\
\text { Embarcação } \\
\mathrm{A}-\operatorname{Proa}\left({ }^{\circ}\right)\end{array}$ & $\begin{array}{c}\text { Incidência } \\
\text { Embarcação } \\
\text { B - Popa }\left(^{\circ}\right)\end{array}$ & $\begin{array}{c}\text { Início - Distância } \\
\text { entre as } \\
\text { embarcações }\end{array}$ & $\begin{array}{c}\text { Final - Distância } \\
\text { entre as } \\
\text { embarcações }\end{array}$ \\
\hline 1 & 7 & 180 & 0 & 100 & 130 \\
\hline 2 & 7 & 165 & -15 & 100 & 130 \\
\hline 3 & 7 & 150 & -30 & 100 & 130 \\
\hline 4 & 8 & 180 & 0 & 165 & 120 \\
\hline 5 & 8 & 165 & -15 & 165 & 120 \\
\hline 6 & 8 & 150 & -30 & 165 & 120 \\
\hline 7 & 9 & 180 & 0 & 130 & 190 \\
\hline 8 & 9 & 165 & -15 & 130 & 190 \\
\hline 9 & 9 & 150 & -30 & 130 & 190 \\
\hline
\end{tabular}

As simulações considerando o período de onda de 7s: Figura 66, Figura 67 e Figura 68 representam respectivamente as incidências de $0^{\circ}, 15^{\circ}$ e $30^{\circ} \mathrm{em}$ relação à proa da embarcação $A$. As simulações começaram com uma distância entre em embarcações de 100m e terminam com a distância de 
130m. Observam-se as embarcações saíram de uma região onde os movimentos do ponto de conexão estavam em fase, para uma região em que estão em oposição de fase. Foram necessários 900s para que o controle reposicionasse as embarcações na distância desejada.
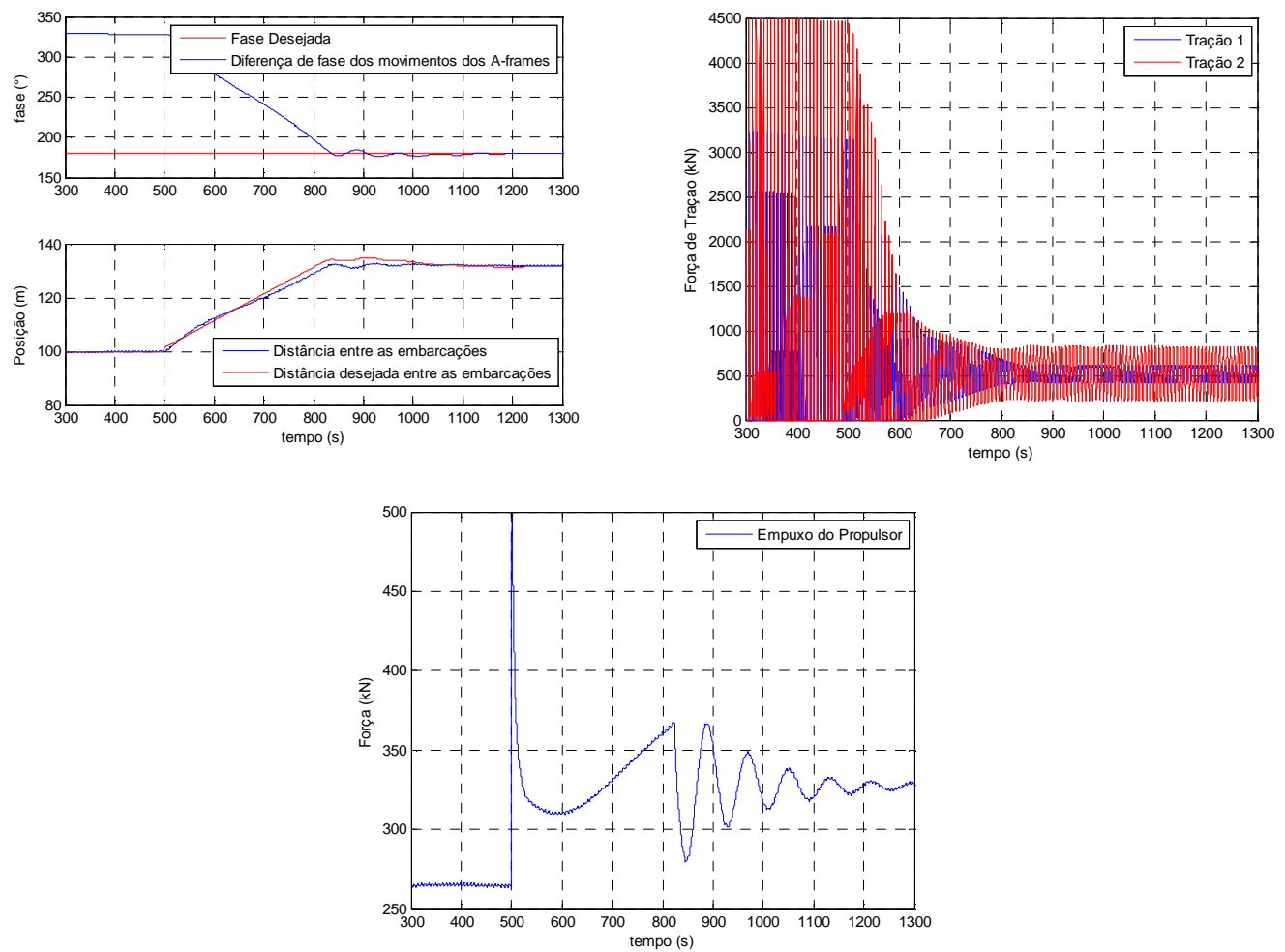

Figura 66: Simulação 1: Caso período de onda de 7s - $0^{\circ}$ Incidência 

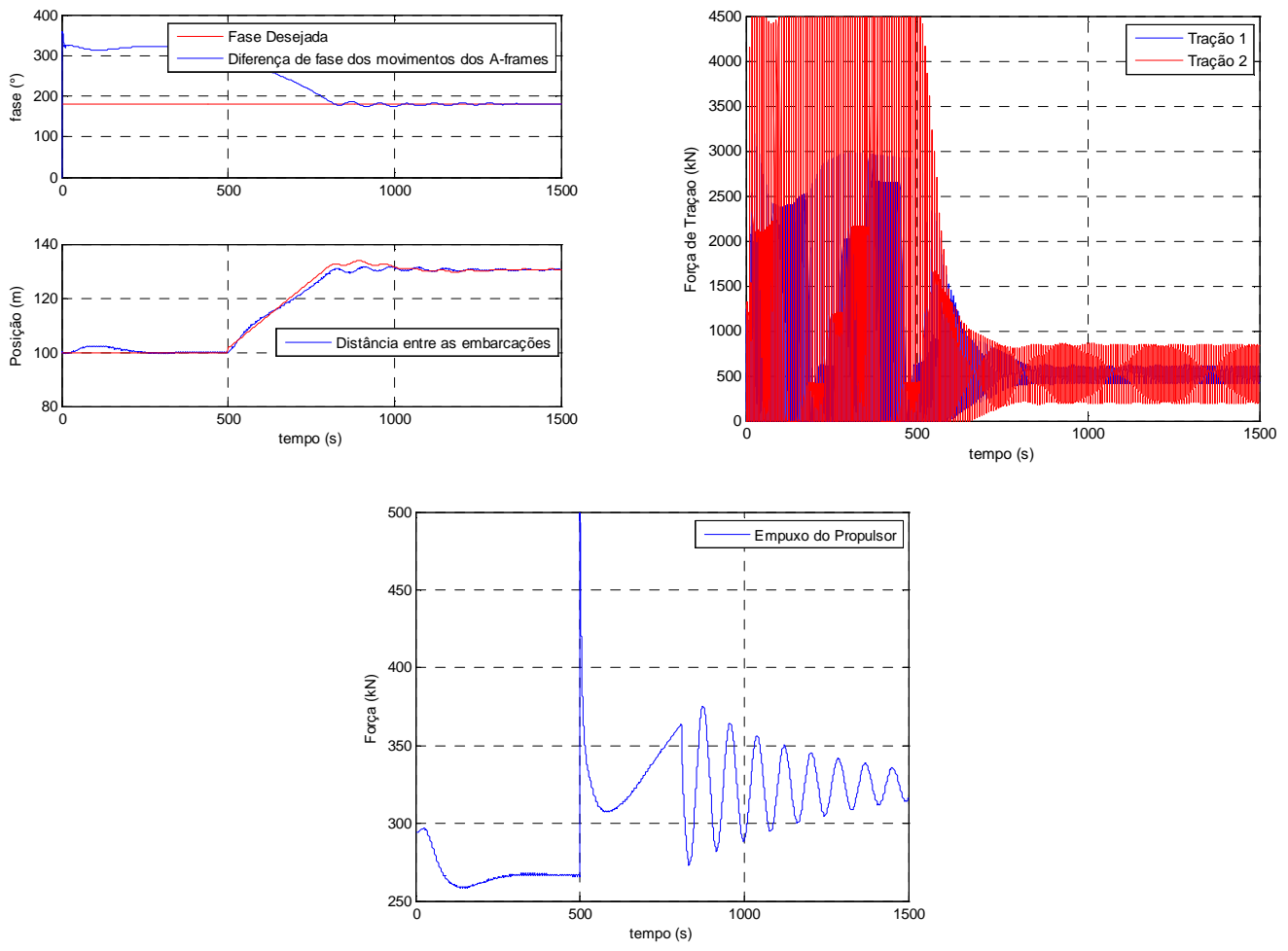

Figura 67: Simulação 2: Caso período de onda de 7s - 15 Incidência
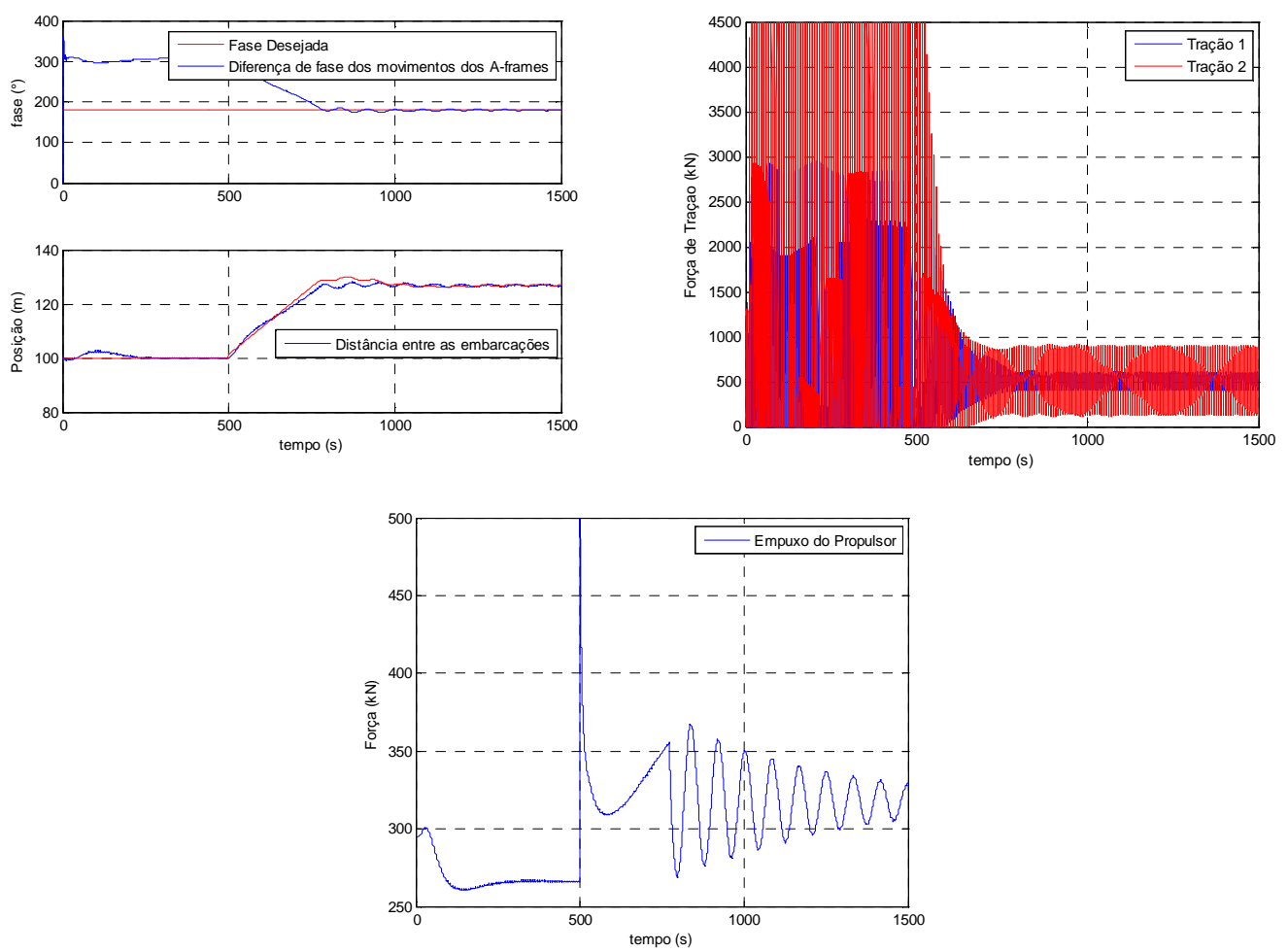

Figura 68: Simulação 3: Caso período de onda de 7s - 30 Incidência 
As simulações considerando o período de onda de 8s: Figura 69, Figura 70 e Figura 71 representam respectivamente as incidências de $0^{\circ}, 15^{\circ}$ e $30^{\circ} \mathrm{em}$ relação à proa da embarcação $A$. As simulações começaram com uma distância entre em embarcações de $165 \mathrm{~m}$ e terminam com a distância de $120 \mathrm{~m}$. Novamente, as embarcações alcançaram automaticamente uma posição em que os pontos de conexão estão em oposição de fase. Foram necessários 1000s para que o controle reposicionasse as embarcações na distância desejada.
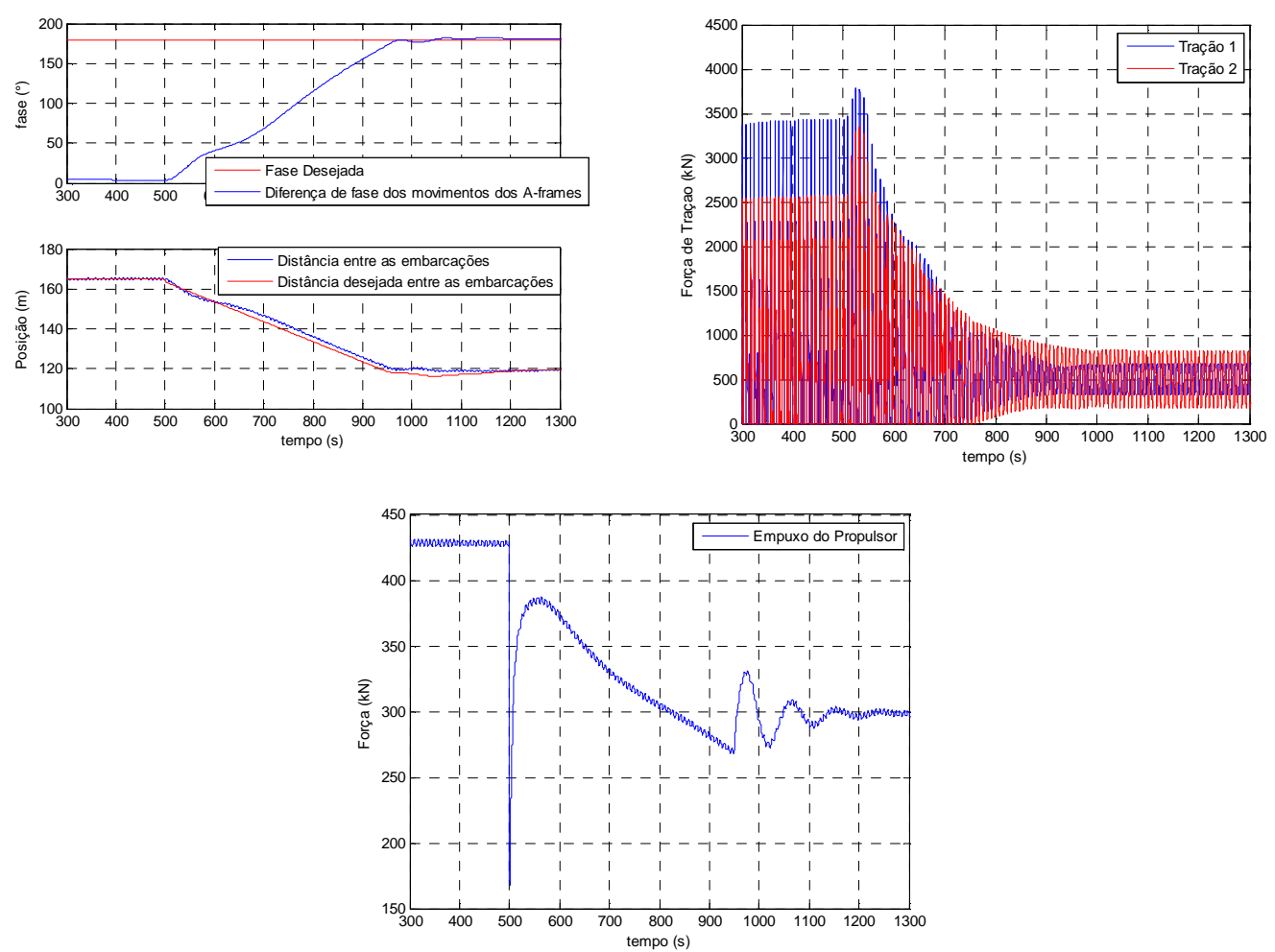

Figura 69: Simulação 4: Caso período de onda de $8 s-0^{\circ}$ Incidência 

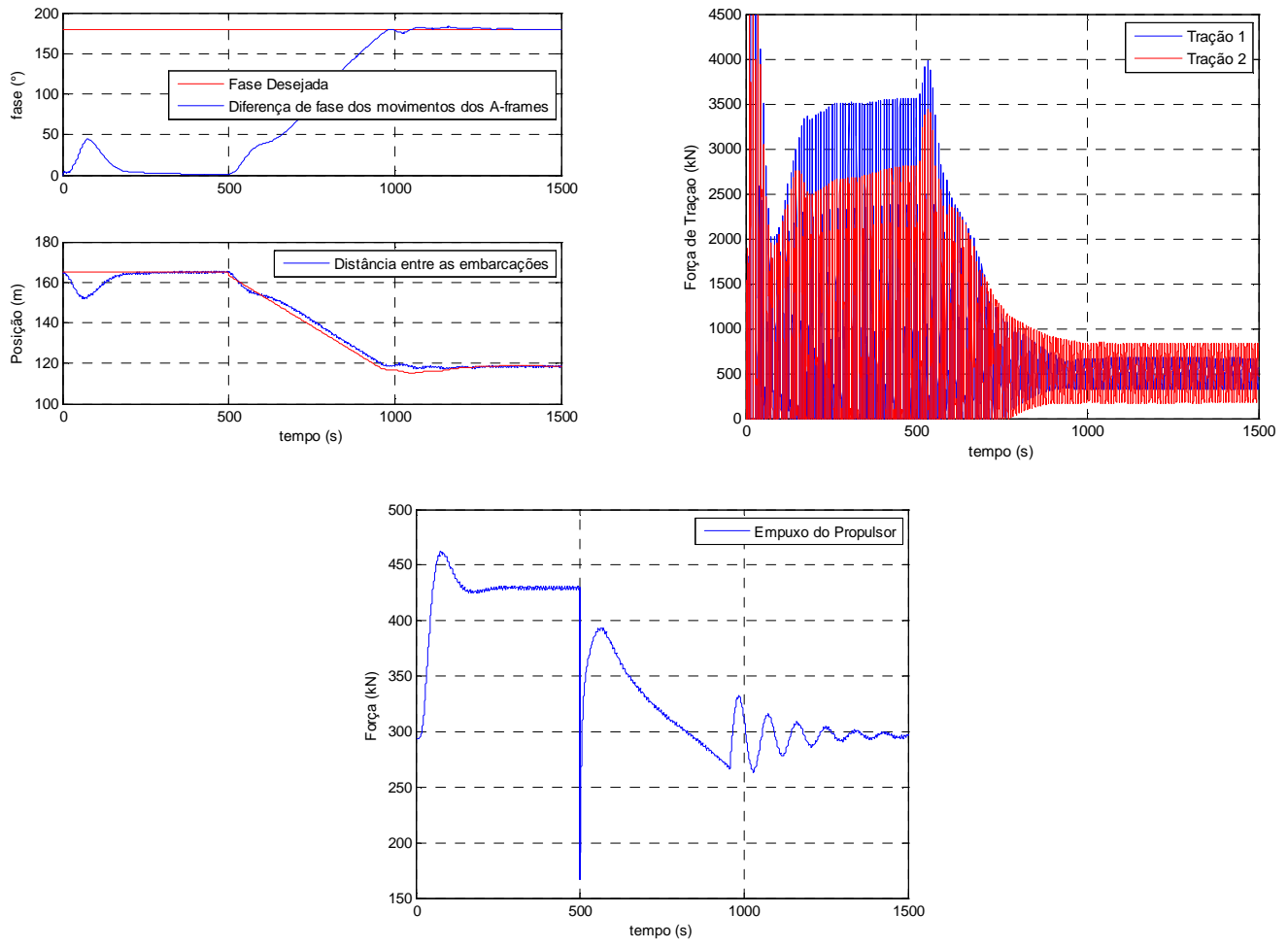

Figura 70: Simulação 5: Caso período de onda de 8s - 15 Incidência
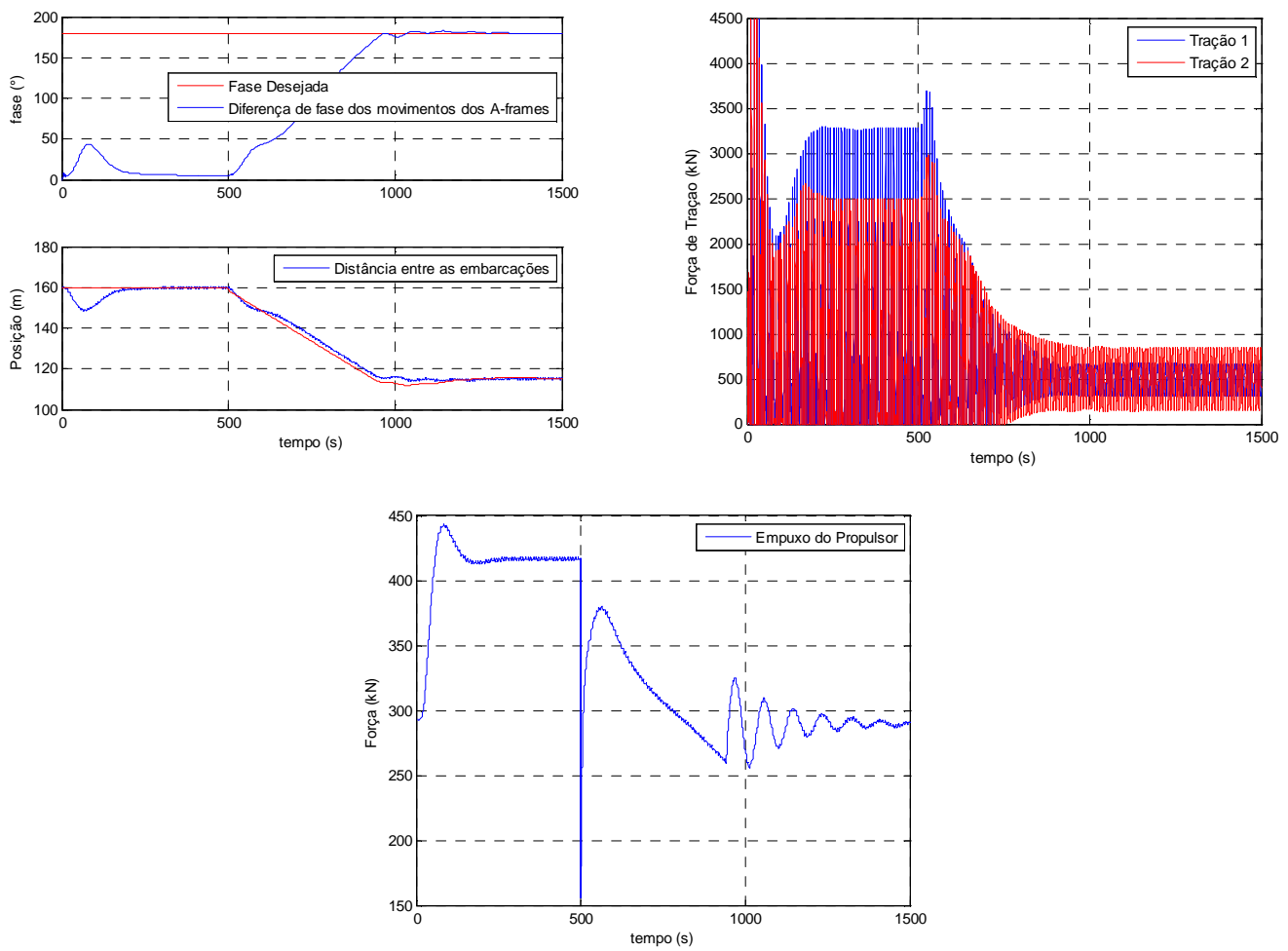

Figura 71: Simulação 6: Caso período de onda de 8s - 30 Incidência

As simulações considerando o período de onda de 9s (Figura 72, Figura 73 e Figura 74) representam respectivamente as incidências de $0^{\circ}, 15^{\circ}$ e $30^{\circ} \mathrm{em}$ relação à proa da embarcação $A$. As simulações começaram com uma distância entre em embarcações de 130m. O sistema de controle as 
reposicionou durante 1200s para a distância de $190 \mathrm{~m}$, na qual os pontos de conexão movimentam-se em oposição de fase e não ocorre afrouxamento das linhas.
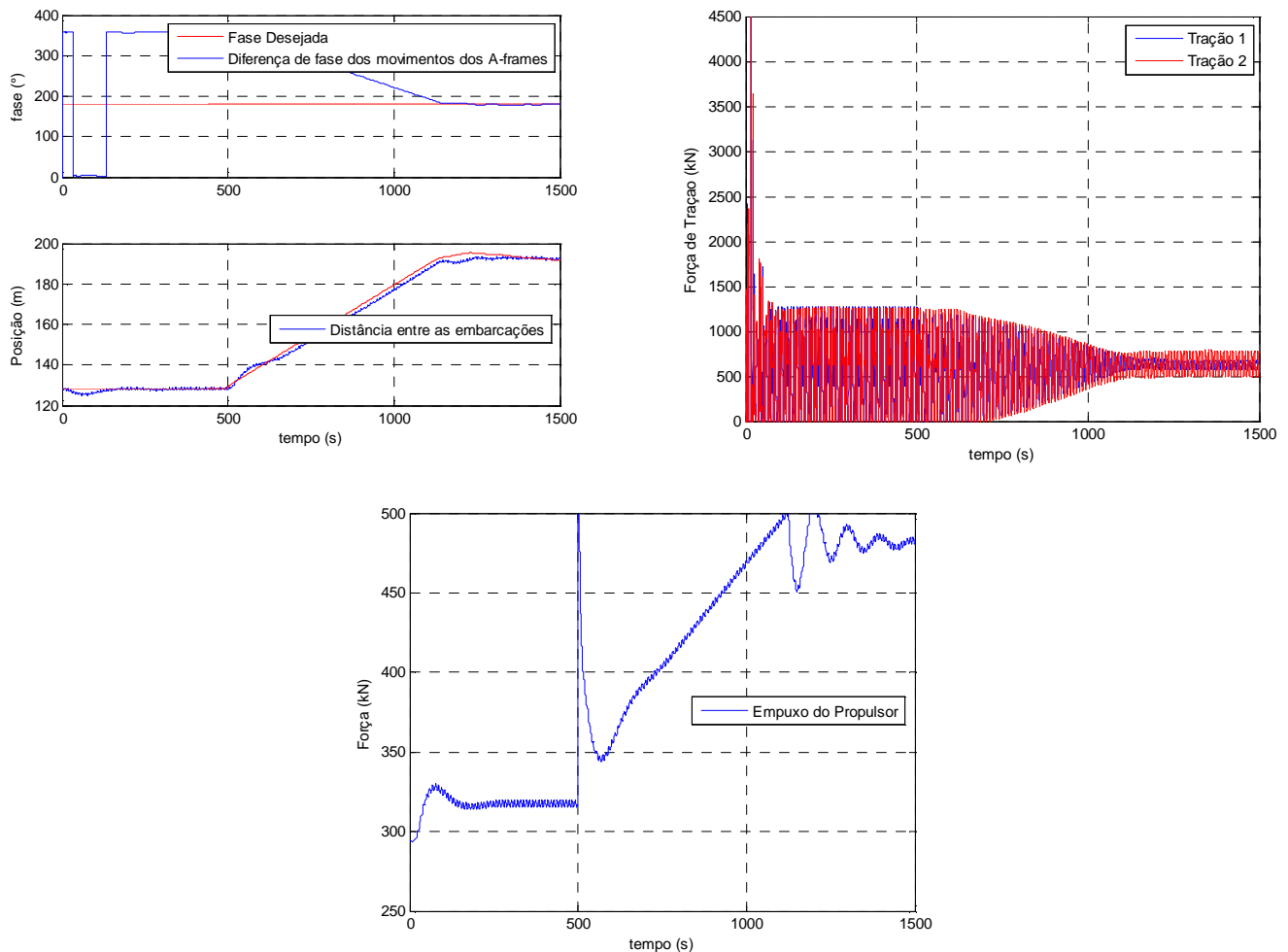

Figura 72: Simulação 7: Caso período de onda de 9s - $0^{\circ}$ Incidência
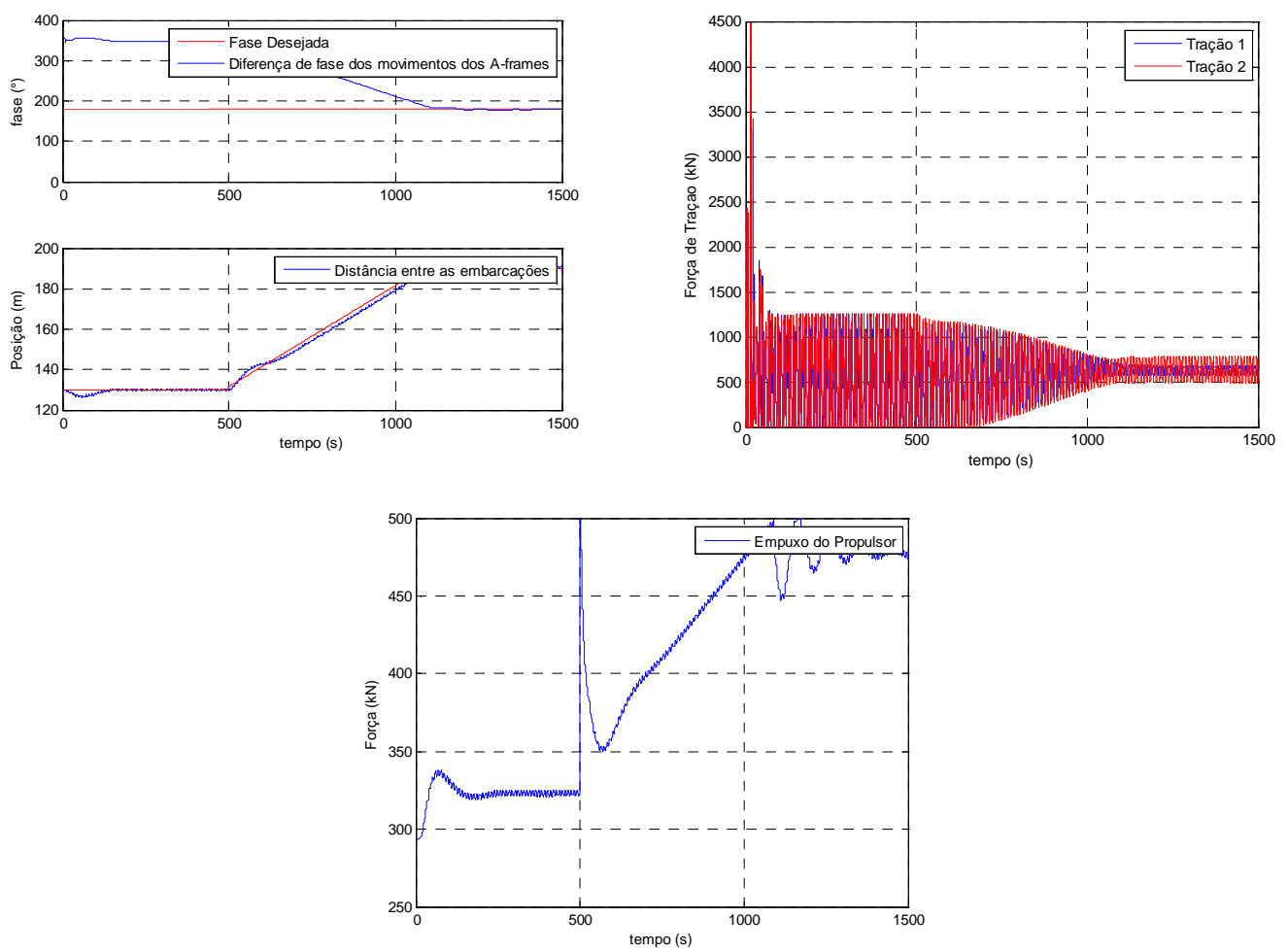

Figura 73: Simulação 8: Caso período de onda de 9s - 15º Incidência 

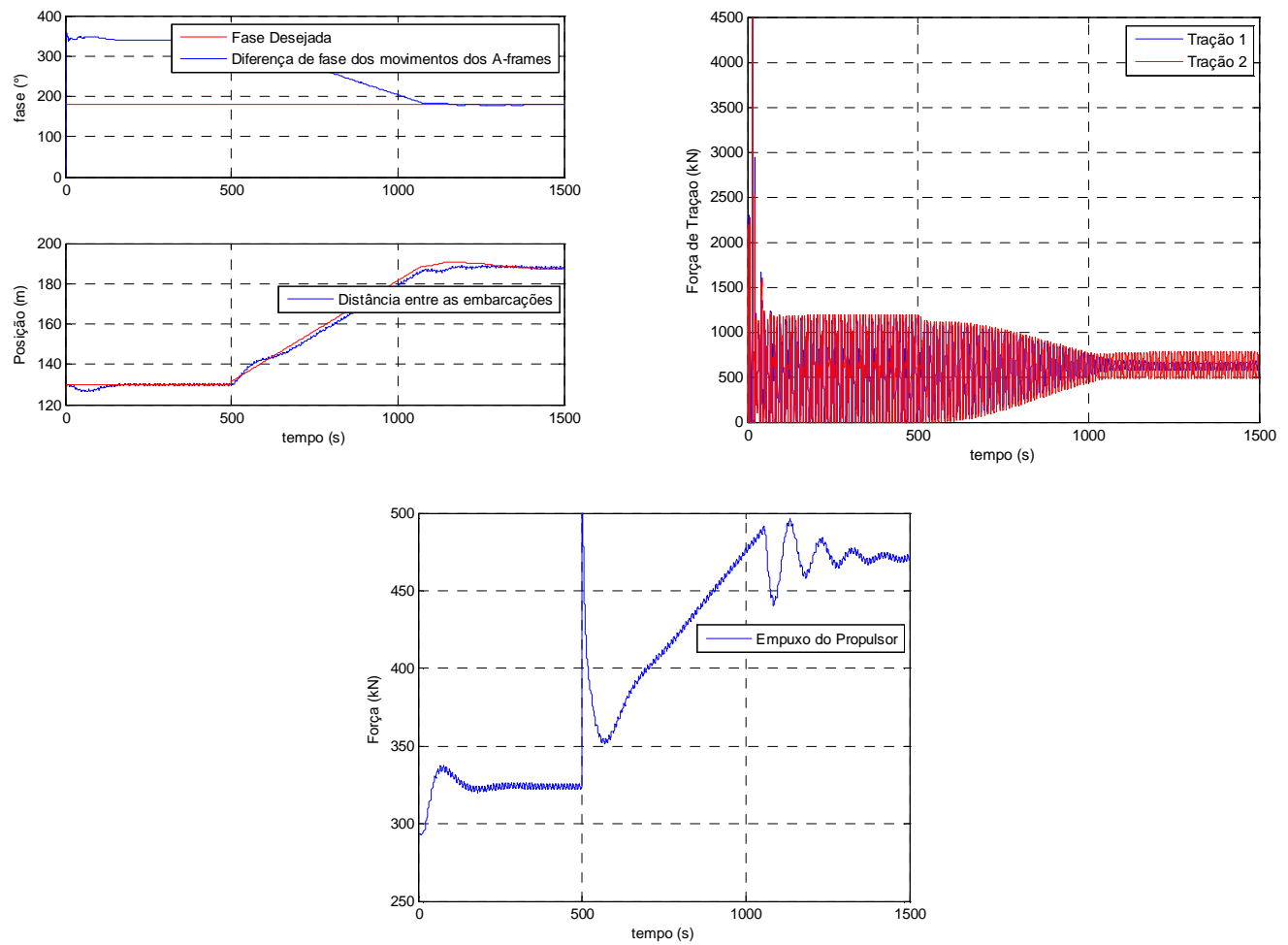

Figura 74: Simulação 9: Caso período de onda de 9s $-30^{\circ}$ Incidência

De um modo geral os resultados mostram que o controle é efetivo, pois corrige automaticamente a posição das embarcações, procurando pela posição onde os pontos de conexão se movimentem em oposição de fase. A mudança da incidência da onda não interfere no comportamento do controle.

\subsubsection{Controle de pagamento de linha}

Foram realizadas simulações das embarcações com as seguintes configurações:

- Distância entre as embarcações de 165m (movimento dos pontos de conexão do em fase) e 120m (movimento dos pontos de conexão em oposição de fase).

- Período de ondas de $8 \mathrm{~s}$, altura de onda de $2 \mathrm{~m}$.

- Diversos cenários de controle foram considerados:

- Sem controle.

- Com controle perfeito. Sem erros nem atrasos.

- Controle com erro na medição da posição do ponto de conexão de $10 \%$, sem atraso. 
- Controle com erro na medição da posição do ponto de conexão de $10 \%$, com atraso de 0,5s.

- Controle com erro na medição da posição do ponto de conexão de $10 \%$, com atraso de 1,0s.

- Controle com erro na medição da posição do ponto de conexão de $10 \%$, com atraso de $1,5 \mathrm{~s}$.

A Figura 75 apresenta as simulações na qual a distância entre as embarcações é de $165 \mathrm{~m}$ com os pontos de conexão se movimentando em fase. Nota-se que ao se acionar o controle de pagamento de linha, há uma grande diminuição nas trações dos cabos de içamento. No entanto percebe-se que o aumento no atraso de acionamento do controle de pagamento de linha acarreta um aumento da força de tração e a partir de $1,5 \mathrm{~s}$ de atraso volta a ocorrer afrouxamento no cabo.

A Figura 76 apresenta as simulações na qual a distância entre as embarcações é de $120 \mathrm{~m}$ com os pontos de conexão se movimentando em oposição de fase. Essa simulação teve como objetivo avaliar o efeito de controle de pagamento de linha quando os pontos de conexão se movimentam em oposição de fase. Observou-se que o acionamento do controle de pagamento de linha leva a uma diminuição das trações medidas. Verifica-se também que mesmo utilizando o controle com erros de $10 \%$ na medida e 1,5 s de atraso é possível eliminar 0 afrouxamento na linha.

Os resultados mostram que um simples sistema de controle permite 0 lançamento de um manifold sem os picos de tração nos cabos de lançamento. A dificuldade estaria no fato de se construir um sistema de controle com tais especificações. Para os pontos de conexão se movimentando em fase seria necessário um controle bem mais acurado enquanto quando se movimenta em oposição de fase seriam tolerados erros de $10 \%$ na medida e atrasos de $1,5 \mathrm{~s}$ no seu acionamento. 
Sem controle

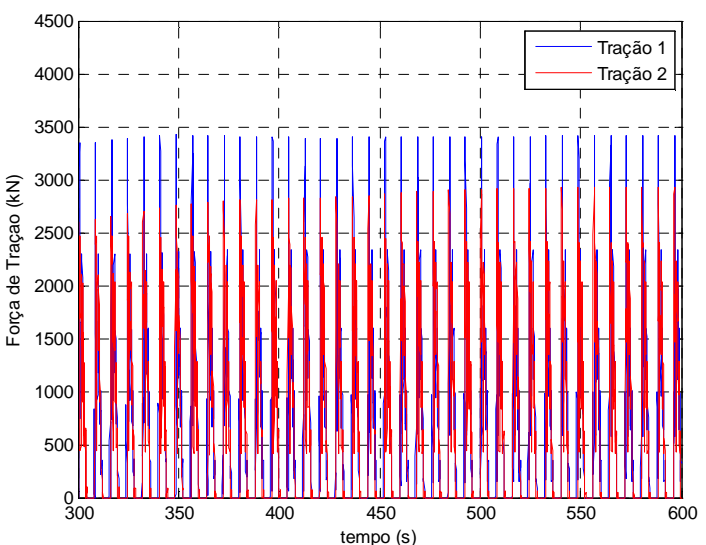

Erro $10 \%$ na medida, sem atrasos

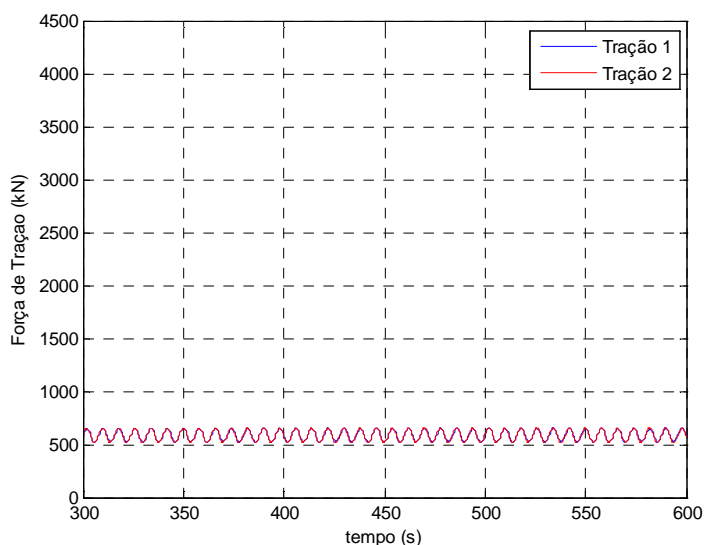

Erro $10 \%$ na medida, atraso de 1,0 s

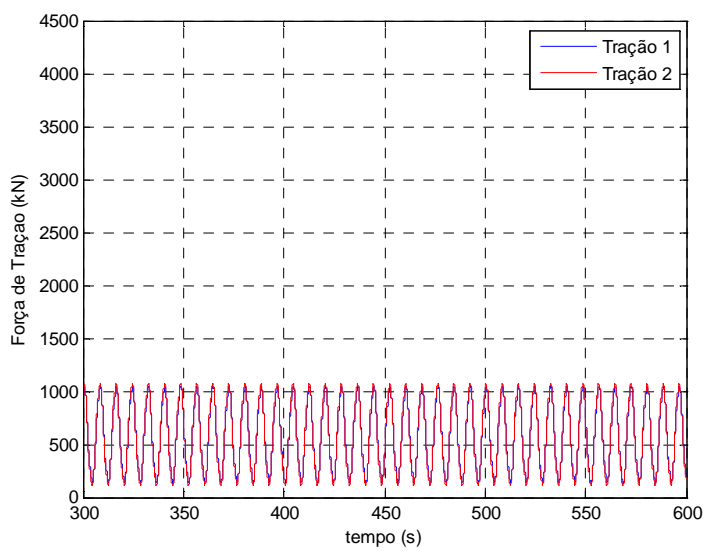

Com controle perfeito, sem erros nem atrasos

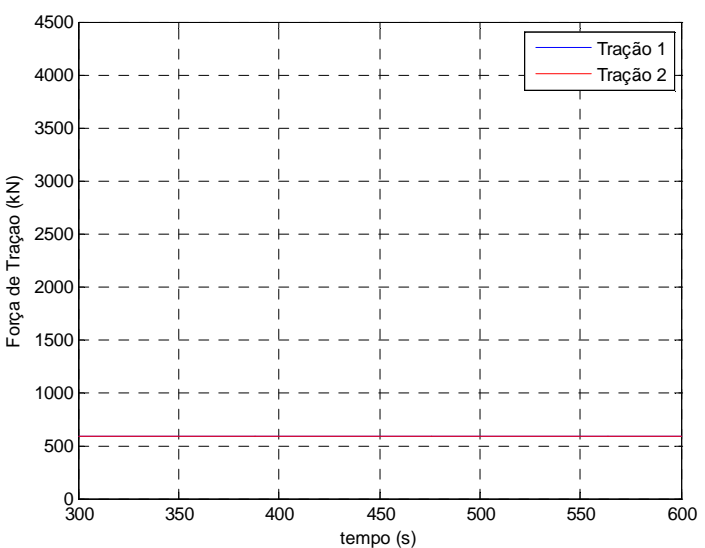

Erro $10 \%$ na medida, atraso de $0,5 \mathrm{~s}$

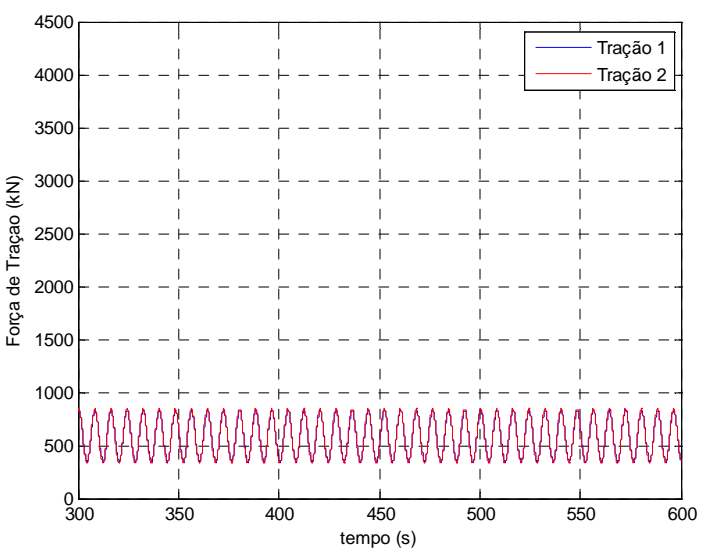

Erro $10 \%$ na medida, atraso de $1,5 \mathrm{~s}$

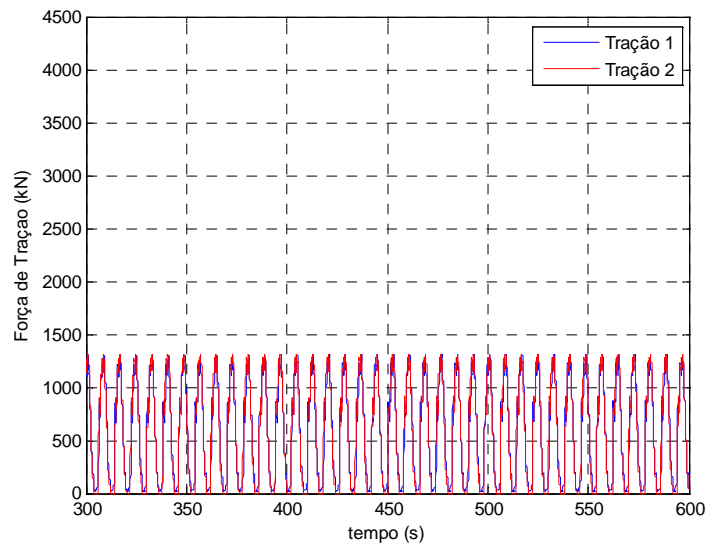

Figura 75: Pagamento de linha - Onda $(\mathrm{T}=8 \mathrm{~s}, \mathrm{H}=2 \mathrm{~m})$ - Ponto de Conexão em fase 
Sem controle

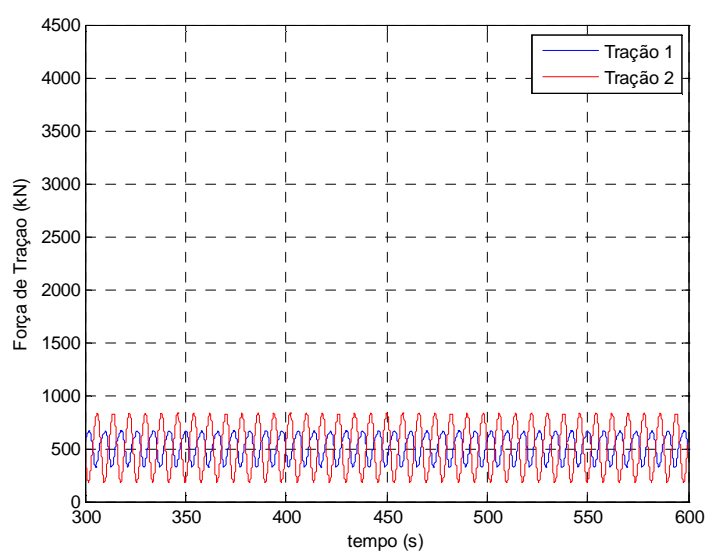

Erro $10 \%$ na medida, sem atrasos

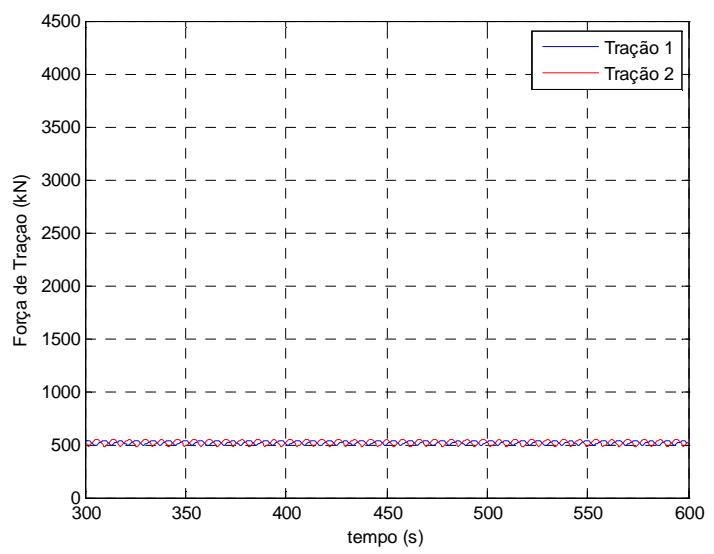

Erro $10 \%$ na medida, atraso de 1,0 s

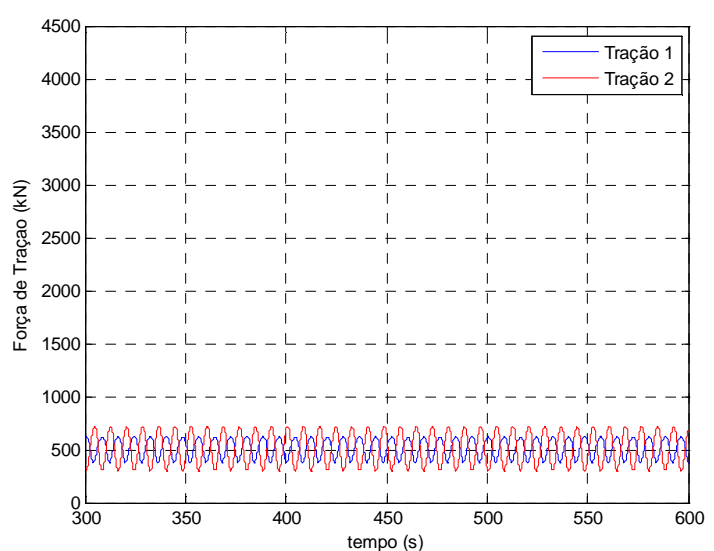

Com controle perfeito, sem erros nem atrasos

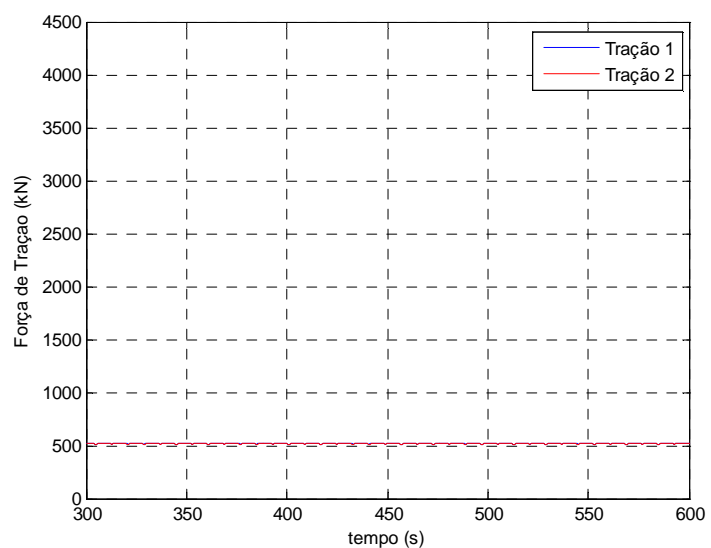

Erro $10 \%$ na medida, atraso de 0,5 s

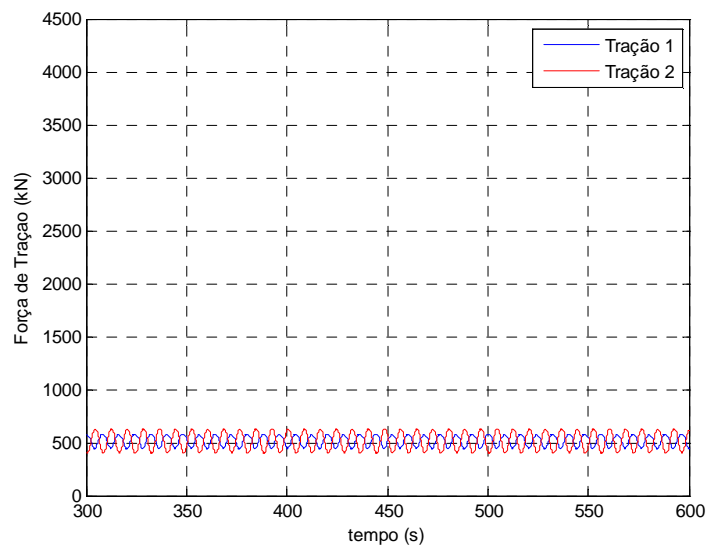

Erro $10 \%$ na medida, atraso de $1,5 \mathrm{~s}$

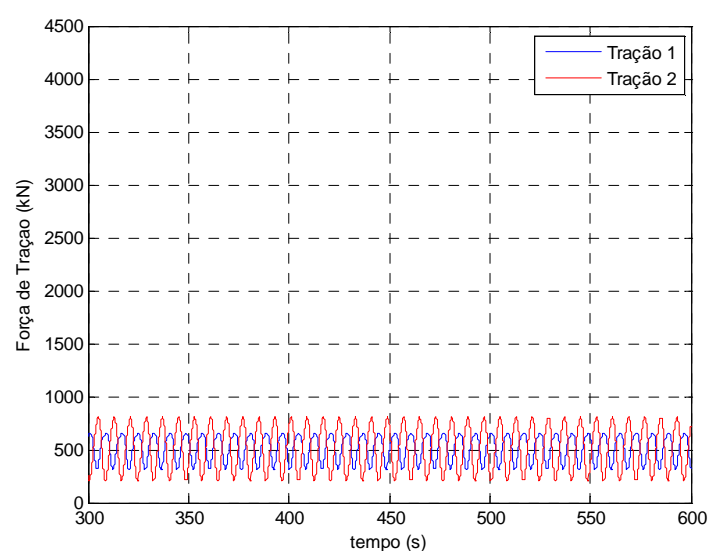

Figura 76: Pagamento de Linha - Onda ( $T=8 \mathrm{~s}, \mathrm{H}=2 \mathrm{~m})$ - Ponto de Conexão em oposição de fase 


\subsubsection{Controle de Posição com swell}

Com o objetivo de simular uma análise de um caso representativo será realizada incluindo-se o efeito de swell (ondas longas, períodos maiores que 12s). Simulou-se o caso da Figura 77. Um caso com duas ondas. Uma onda vindo de proa em relação à embarcação $A$ e outra onda de swell vindo $30^{\circ} \mathrm{em}$ relação a proa da embarcação $A$.
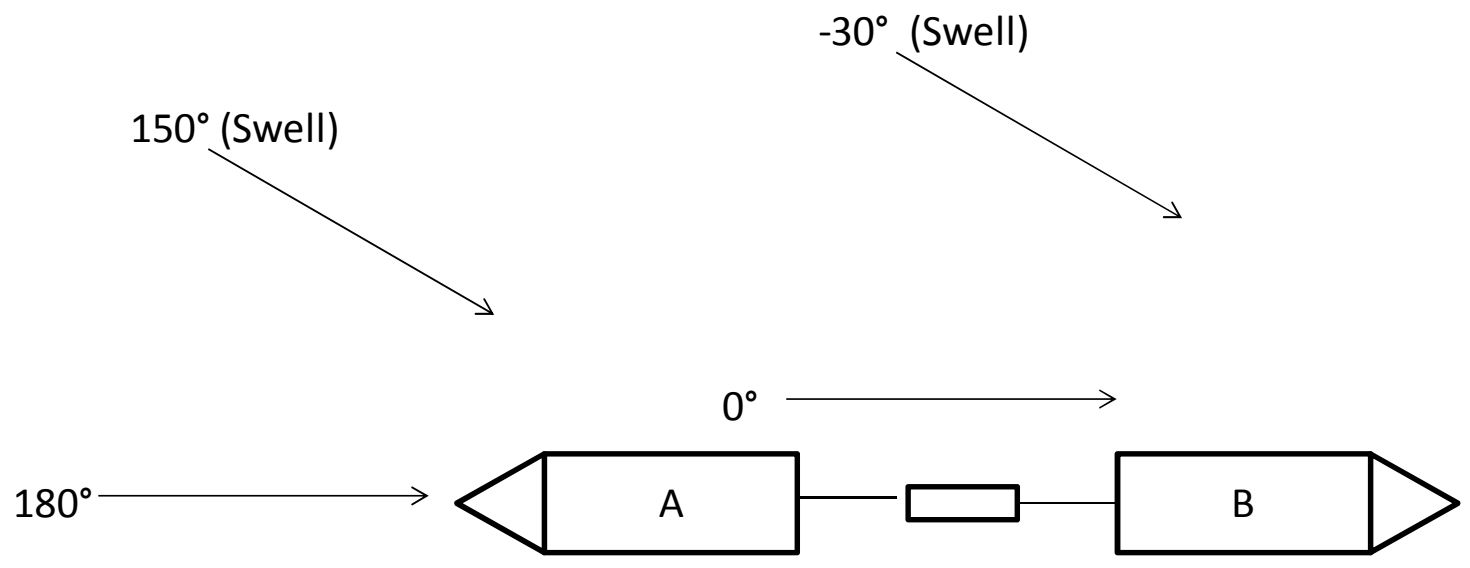

Figura 77: Incidência das ondas da simulação com swell

O ponto inicial escolhido para se realizar a simulação foi o mesmo $165 \mathrm{~m}$ de distância para a simulação com o período de onda de 8s (Figura 78). A simulação começou com o movimento dos pontos de conexão em fase e o controle movimentou as embarcações para uma posição em oposição de fase dos movimentos (Figura 79).

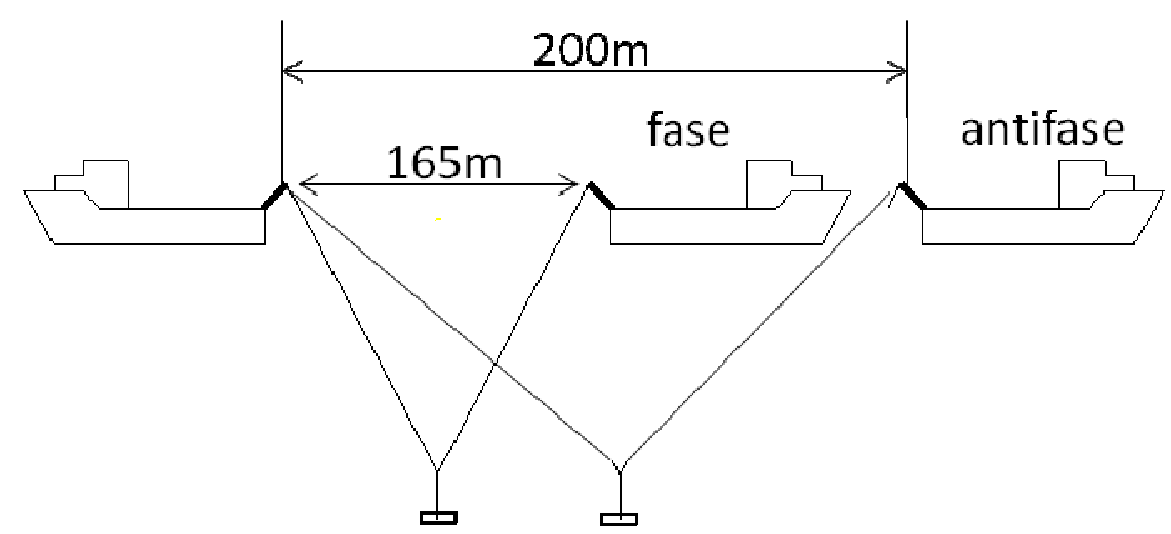

Figura 78: Distância percorrida simulação com swell 
Movimentos em Fase

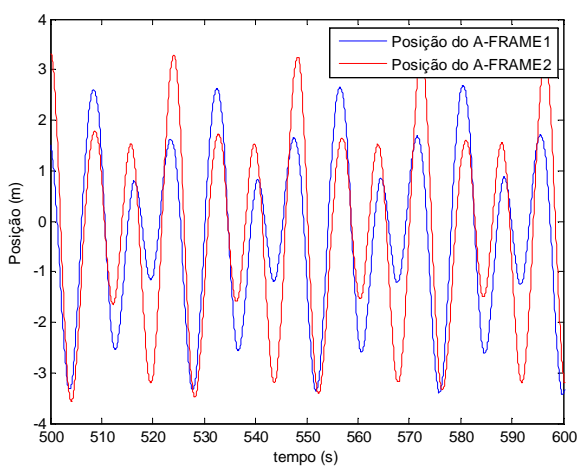

Movimentos em Oposição de fase

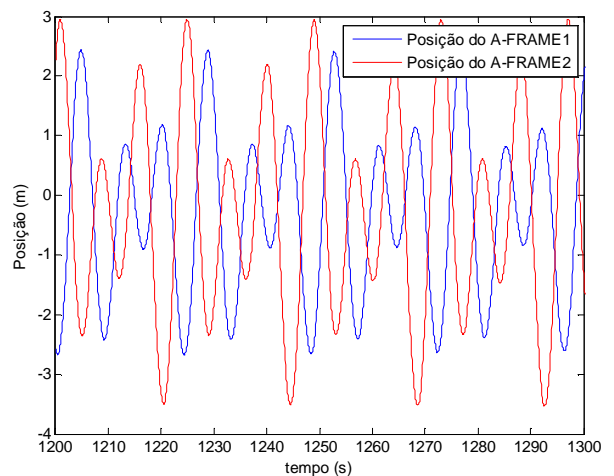

Figura 79: Movimentos do ponto de conexão para simulação com swell

A simulação mostra que a transformada de Hilbert consegue estimar a diferença de fase entre o movimento dos dois pontos com um erro de estimação devido à superposição das duas ondas. Isto se reflete na força do propulsor que apresenta um caráter mais oscilatório. No entanto, o algoritmo consegue estimar a diferença de fase dos movimentos e levar as embarcações de uma região onde ocorre afrouxamento na linha para uma região que não ocorre afrouxamentos na linha (Figura 80).
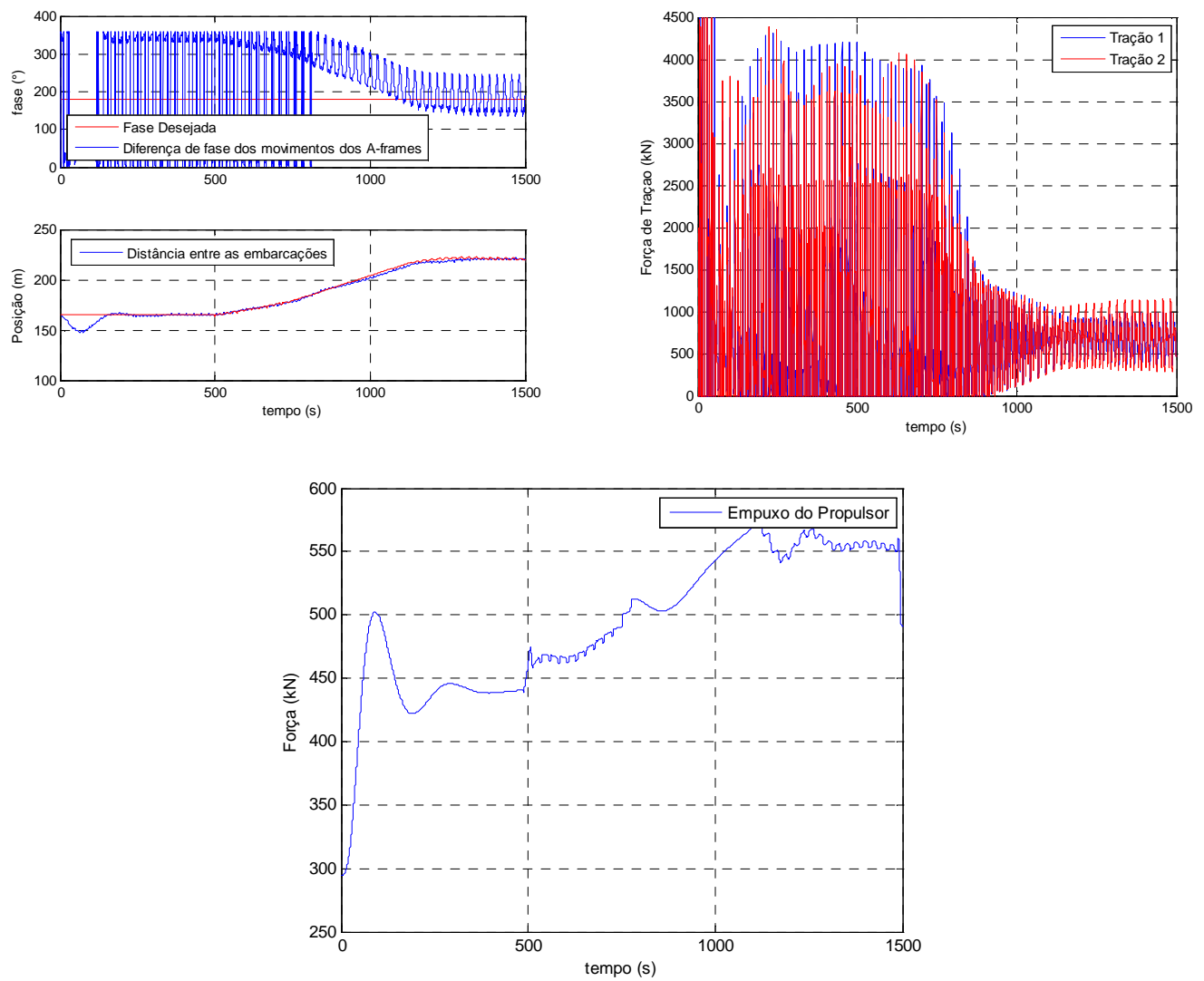

Figura 80: Simulação com swell 


\section{Considerações Finais}

Este trabalho apresentou o desenvolvimento da técnica de controle cooperativo aplicado a embarcações dotadas de sistemas de posicionamento dinâmico. Um caso ilustrativo foi estudado, o lançamento de um manifold utilizando dois rebocadores DP. Neste exemplo, o controle cooperativo atuou sobre a distância relativa das embarcações.

O projeto deste controlador foi baseado inicialmente na modelagem da dinâmica do sistema. Esta contempla a dinâmica de embarcações excitadas por ondas em seis graus de liberdade, associada à dinâmica do movimento do manifold suspenso por cabos. Estes modelos matemáticos foram validados através de ensaios experimentais e através de comparações com outro simulador numérico (TPN).

Através deste modelo foram construídos mapeamentos dinâmicos. Estes mapeamentos definiram as regiões nas quais o controle cooperativo das embarcações deve posicioná-las para evitar a ocorrência de afrouxamento nas linhas de lançamento. Este mapeamento foi avaliado variando-se a distância entre as embarcações, parâmetros da onda como sua altura e período e profundidade do manifold. Deste mapeamento foi concluído que apenas um controle de posição das embarcações não é suficiente e um controle adicional de pagamento de linha é necessário.

As regiões do mapeamento dinâmico que evitam a ocorrência de afrouxamentos nos cabos são aquelas em que os pontos de conexão das linhas de içamento nos navios estão se movimentando em oposição de fase. Assim o controle de posição procura manter a distância entre as embarcações de tal forma que estes pontos se movimentem em oposição de fase. Para isso foi necessário utilizar um estimador da diferença de fase do movimento destes pontos, através da aplicação da transformada de Hilbert.

Adicionalmente foi incorporado o controle de pagamento das linhas para compensar o movimento do ponto de conexão e não transmiti-los diretamente ao equipamento suspenso. Este controle foi modelado e foram considerados erros na medida da posição do ponto e um atraso no acionamento do controle. 
Os resultados mostram que o controle é capaz de eliminar os picos de tensão e a ocorrência de afrouxamentos.

Portanto a estratégia de controle adequada, considerando ondas regulares, é combinar tanto o controle de posição e o controle de pagamento das linhas. Assim o controle de posição através do mapeamento dinâmico define um caminho ótimo que aliado ao controle de pagamento de linha possibilita realizar a operação de lançamento evitando-se as regiões de afrouxamento.

Este trabalho teve o enfoque na análise de ondas regulares. Consideraram-se ondas de proa $\left( \pm 30^{\circ}\right)$ em relação à embarcação $A$ (que equivale à incidência de popa para embarcação B). O desempenho do controlador foi avaliado nestas condições verificando-se robustez em seu desempenho.

Uma análise de um caso representativo foi realizada incluindo-se o efeito de swell (ondas longas, períodos maiores que 12s). Nesta simulação impôs-se uma onda incidente de proa associada a um swell vindo numa direção de $30^{\circ}$ em relação à proa. O resultado mostra que mesmo com a superposição das ondas, o algoritmo mostrou-se efetivo em levar as embarcações para uma distância que não ocorre afrouxamentos na linha.

Para a continuação deste trabalho será importante considerar a incidência de ondas irregulares. É de se esperar que haja problemas envolvendo a transformada de Hilbert na estimação da diferença de fase, pois haverá diversas componentes de onda superpostas. Além de problemas na estimação de fase, a introdução de ondas irregulares necessitará rever a modelagem da dinâmica das embarcações em ondas, com a inclusão de efeitos, como o efeito de memória. $O$ controle de pagamento de linha também necessitará ser revisto e aprimorado para ondas irregulares. 


\section{REFERÊNCIAS}

Bai, Y., \& Bai, Q. (2010). Subsea Structural Engineering Handbook. Elsevier.

Balchen, J. G., Jenssen, N. A., Mathisen, E., \& Sælid, S. (1980). A dynamic positioning system based on Kalman filtering and optimal control. Modeling, Identification and Control , 1 (3), pp. 135-163.

Bunnik, T., Buchner, B., \& Veldman, A. (2006). The Use of a Volume of Fluid (VOF) method coupled to a time domain motion simulation to calculate the Motions of a Subsea Structure Lifted Through the splash zone. Proceedings of the 25th International Conference on Offshore Mechanics and Arctic Engineering - OMAE. Hamburg.

Cerqueira M. B., F. A. (2000). Parametric Study of Intervention System in UltraDeepwater up to $3000 \mathrm{~m}$. Proceedings of the Tenth (2000) International Offshore and Polar Engineering Conference. Seatle: The International Society of Offshore and Polar Engineers.

den Hartog, J. B. (1947). Mechanical Vibrations. New York, USA: McGraw-Hill.

Faltinsen, O. M. (1990). Sea loads on ships and offshore structures. Cambridge, UK: Cambridge University Press.

Feldman, M. (2011). Hilbert Transform Application in Mechanical Vibration. John Wiley \& Sons.

Fossen, T. I. (1994). Guidance and control of ocean vehicles. Chichester, England: John Wiley \& Sons.

Fossen, T. I. (2002). Marine Control Systems: Guidance, Navigation and Control of Ships, Rigs and Underwater Vehicles. Trondheim, Norway: Marine Cybernetics AS.

Fujarra, A., Tannuri, E., Masetti, I., \& Igreja, H. (2008). Experimental and Numerical Evaluation of the Installation of Sub-Sea Equipments for Risers Support. 27th International Conference on Offshore Mechanics and Arctic Engineering (OMAE2008). Estoril. 
Grimble, M. J., Patton, R. J., \& Wise, D. A. (1980). Use of Kalman filtering techniques in dynamic ship positioning systems. IEE Proceedings , 27 (3), pp. 93-102.

Holden, O. M. (2006). Ormen Lange Pipelines Seabed Intervention Design in Deep Water. Sixteenth International Society of Offshore and Polar Engineers. California: International Society of Offshore and Polar Engineers.

Mello, P. C., Rateiro, F., Fujarra, A., Oshiro, A., Neves, C. R., Santos, M. F., et al. (2011). Experimental set-up for analysis of subsea equipment installation. ASME 30th International Conference on Ocean, Offshore and Arctic Engineering .

Newman, J. N. (1977). Marine Hydrodynamics. Cambridge, USA: The MIT Press.

Nishimoto, K., Ferreira, M., Martins, M. R., Masetti, I. Q., Martins Filho, P. D., Russo, A. A., et al. (2003). Numerical Offshore Tank: Development of Numerical Offshore Tank for Ultra Deep Water Oil Production Systems. International Conference on Offshore Mechanics and Arctic Engineering. Cancun: OMAE.

Ogata, K. (2010). Engenharia de Controle Moderno. Prentice Hall.

Oshiro, A., Tannuri, E. A., Fucatu, C. N., \& Santos, M. F. (2012). DP Cooperative Control For Subsea Installation with Multiple Vessels: An Illustrative Case Study Based On Numerical Simulations. ASME 31th International Conference on Ocean, Offshore and Arctic Engineering, OMAE2012. Rio de Janeiro: ASME 31th International Conference on Ocean, Offshore and Arctic Engineering, OMAE2012.

R., G., Aguiar, A., Pascoal, A., Silvestre, C., Kaminer, I., \& Hespanha, J. (2009). Coordinated Path Following in the Presence of Communication Losses and Time Delays. J. Control Optim.

Rateiro, F. F. (2011). Numerical Analysis of a Novel Method for Subsea Equipment Installation. Proceedings of the 30th International Conference on 
Offshore Mechanics and Arctic Engineering - OMAE. Rotterdam: International Conference on Offshore Mechanics and Arctic Engineering - OMAE.

Ribeiro, M. L. (2008). Concepção de Manifolds Submarinos para Lançamento Pendular em Águas Ultra Profundas. São Paulo: UFRJ, tese de doutorado.

Roveri F. E., V. E. (2006). Numerical Analyses and Sensitivity Studies for Development of the Pendulous Method. 25th International Conference on Offshore Mechanics and Arctic Engineering . Hamburg: Conference on Offshore Mechanics and Arctic Engineering .

Rowe, J. M. (2001). Deepwater Installation of Subsea Hardware. Proceedings of the 10th Offshore Symposium, SNAME. Houston, TX.

Santos, M., Neves, C., \& Sanches, C. (2009). Y-Method for Subsea Equipment Installation. 22nd Deep Offshore Technology Exhibitions and Conference (DOT2009). Estados Unidos.

Simos, A. N. (2011). Hidrodinâmica I. Notas de aula. In A. N. Simos, Hidrodinâmica I. Notas de aula (p. 164). São Paulo: Departamento de Engenharia Naval e Oceânica - EPUSP.

SNAME. (1950). Nomenclature for treating the motion of a submerged body through a fluid. Technical Report Bulletin 1-5, Society of Naval Architecs and Ocean Engineers .

Solutions, A. (2012, julho 24). Aker Solutions. Retrieved julho 24, 2012, from Site da Aker Solutions: www.akersolutions.com

Souza Jr., J. A., Tannuri, E. A., \& Oshiro, A. T. (2009). Development and Application of a Ship Manoeuvring Digital Simulator for Restricted Waters. onference on Manoeuvring and Control of Marine Craft (MCMC'2009). Guarujá: Proceedings of 8th Conference on Manoeuvring and Control of Marine Craft (MCMC'2009).

Souza, C. E., Oshiro, A. T., \& Morishita, H. M. (2010). Cooperative control applied to coordinated operations of ships with dynamic positioning system. 
SOBENA 2010 - 23ํ Congresso Nacional de Transporte Aquaviário, Construção Naval e Offshore. Rio de Janeiro, Brazil.

Tannuri, E. A. (2002). Desenvolvimento de metodologia de projeto de sistema de posicionamento dinâmico aplicado a operações em alto-mar. São Paulo, Brazil: University of São Paulo, tese de doutorado.

Tannuri, E. A., Silva, J. L., Oshiro, A. T., \& Azevedo Jr., P. C. (2009). Design and Analysis of Dynamic Positioning Systems: Comparison Between Static and Dynamic Approaches. 10th International Marine Design Conference. Trondheim: Proceedings of 10th International Marine Design Conference, 2009.

Tannuri, E. A., Silva, J. L., Oshiro, A. T., \& Saad, A. C. (2009). DP Pipe-Laying and Crane Barge: Procedure for Defining Operational Window and Capability Plots Using Dynamic Simulations. ASME 28th International Conference on Ocean, Offshore and Arctic Engineering OMAE 2009. Honolulu: Proceedings of the ASME 28th International Conference on Ocean, Offshore and Arctic Engineering, 2009.

WAMIT. (2006). WAMIT user manual. Chestnut Hill, USA: WAMIT, Inc.

Y., H., \& R., A. (2008). Behaviour-based Circle Formation Control Simulation for Cooperative UUVs. Second IFAC Workshop Navigation, Guidance and Control of Underwater Vehicles (NGCUV'08). Irlanda. 